\title{
العوامل المؤثرة على فاعلية جمعية تنمية المجتمع المحلى بمحافظة المنوفية
}

\author{
خالا عبد الفتاح على قتيبر(') ، رضا محى الدين على شاهين(ץ) \\ (') قسم الارشاد الزراعى والمجتمع الريفى -كلية الزراعة - جامعة المنوفية

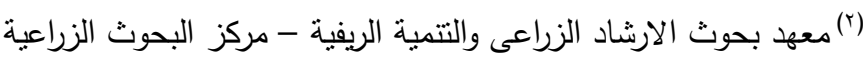

Received: Aug. 30, 2016

Accepted : Sep. 24,2016

الملخص

استهوفت الدراستة الحالية التعرف على طبيعة العلاقات الإرتباطية ببين الدتغيرات الدستقلة الددروسة وأبعاد فعالية

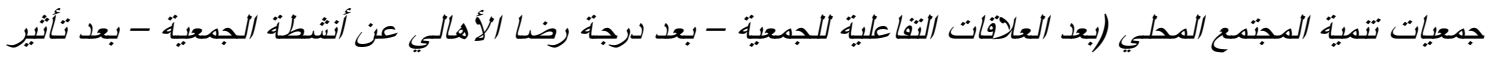

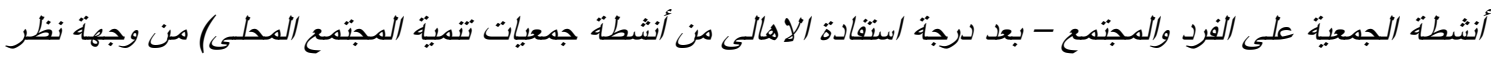

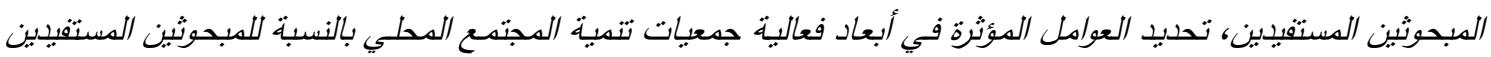

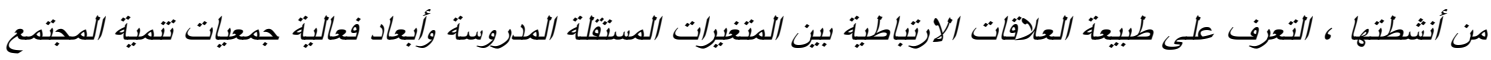
المحلي (بعد تحقيق الأهداف - بعد التنسيق المنظمى - بعد الرضا الوظيفي - بعد التنظبيم الداخلي) و تحديد العوامل المؤثرة

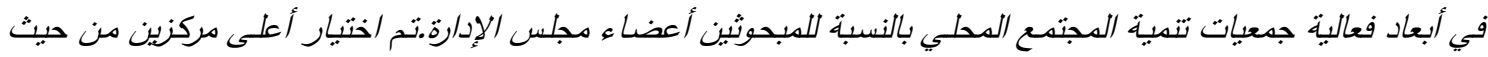

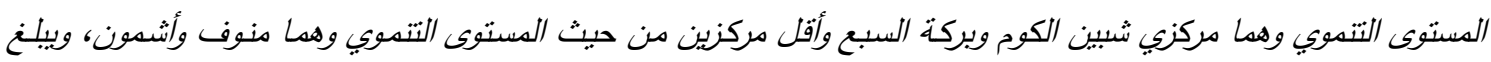

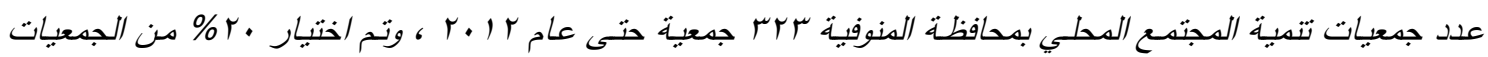

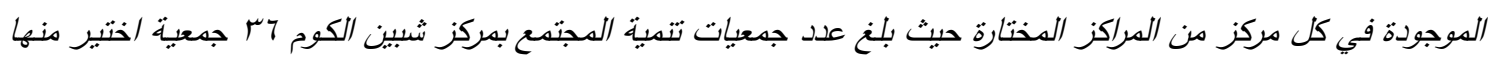

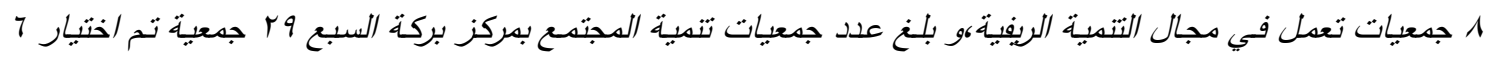

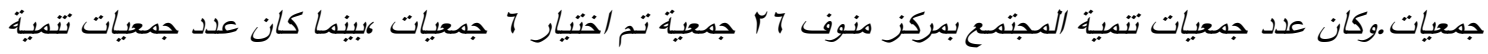

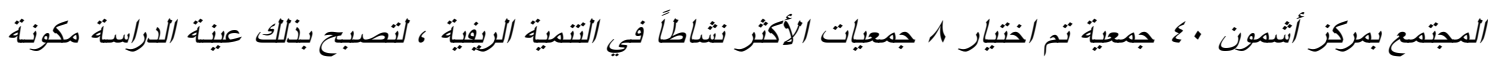

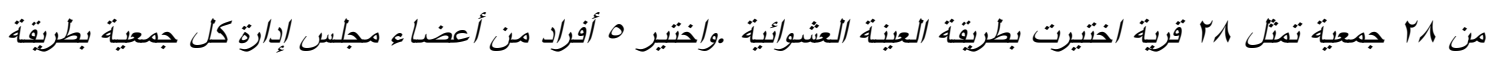

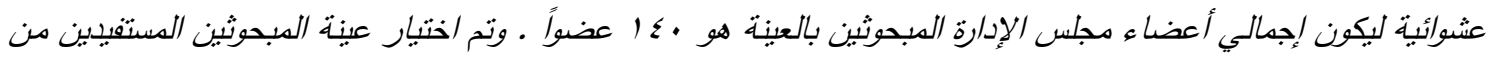

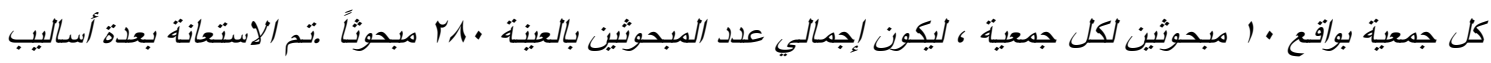

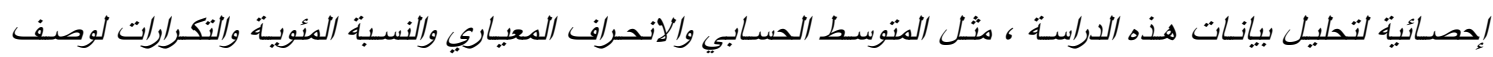

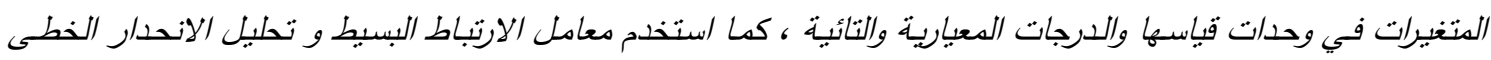

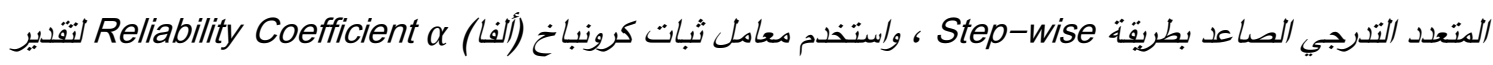

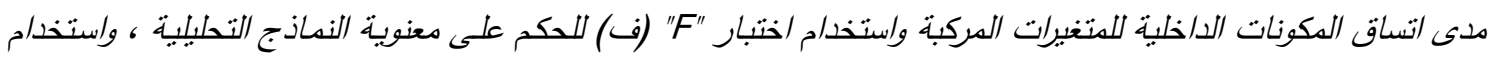

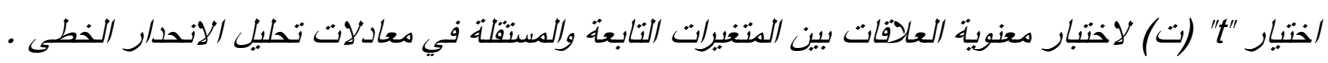

أوضحت نتائج تحليل الارتباط وجود علاقة ارتباطبة معنوية موجبة عند مستوى ا . . ، بين درجة فعالية جمعية تتهية

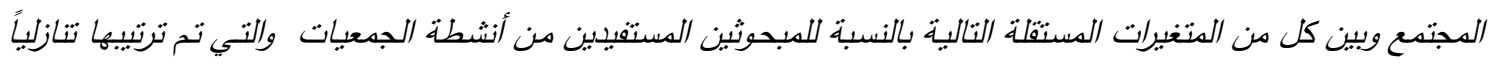

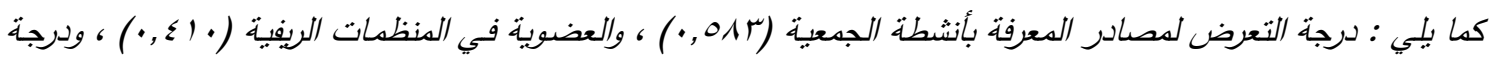

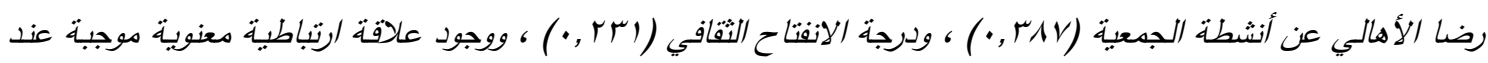

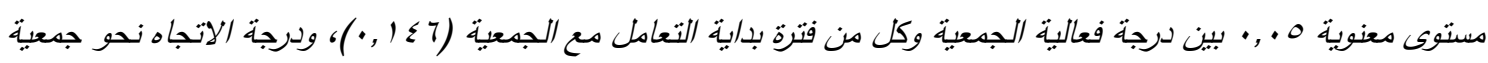

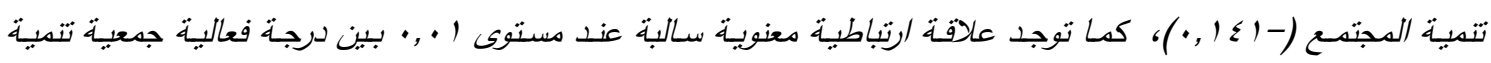


المجتمع وكل من درجة الانفتاح الجغرافي حيث بلغت قيهة معامل الارتباط البسيط ومجموع المشكلات حيث بلغت قبيم

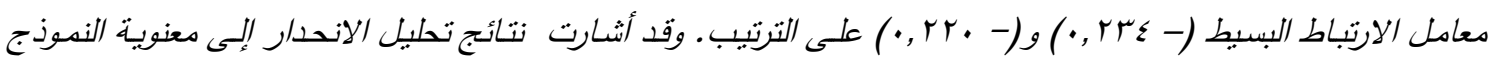

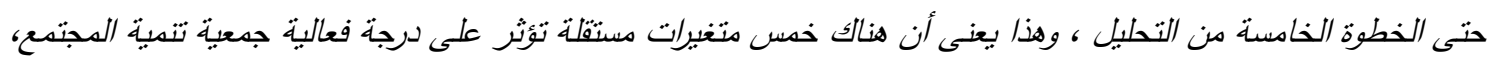

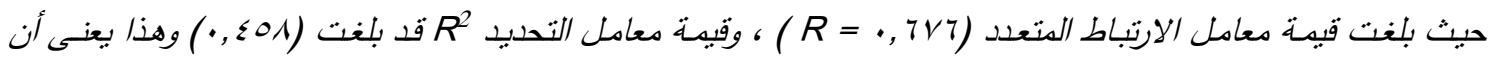

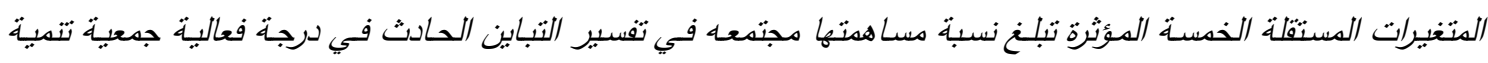

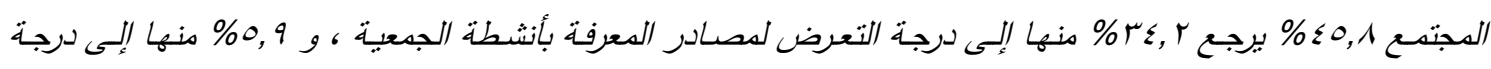

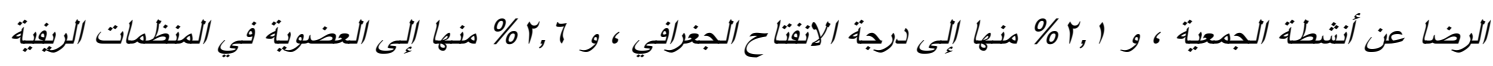

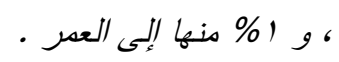

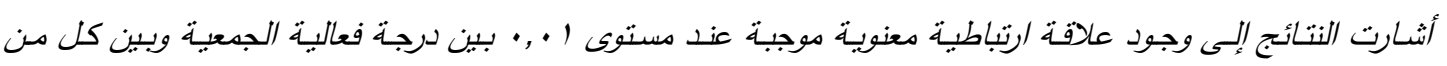

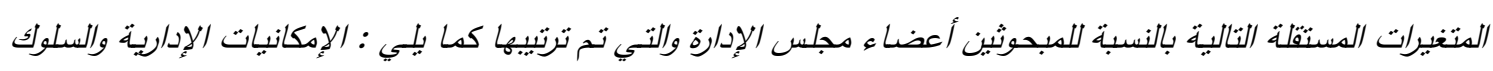

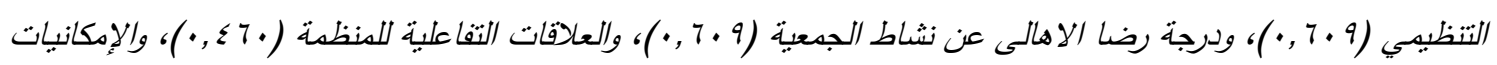

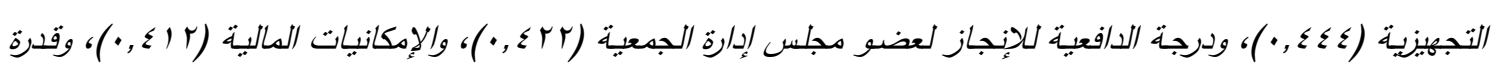

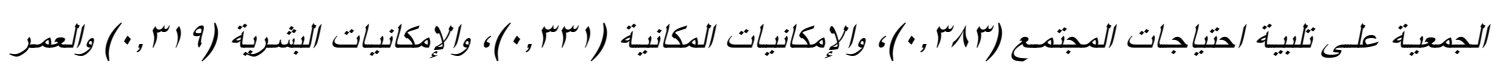

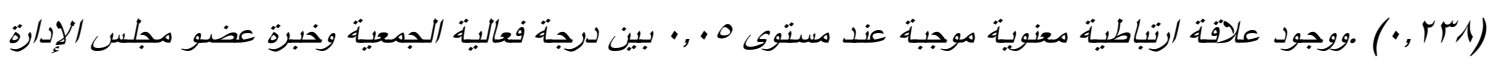

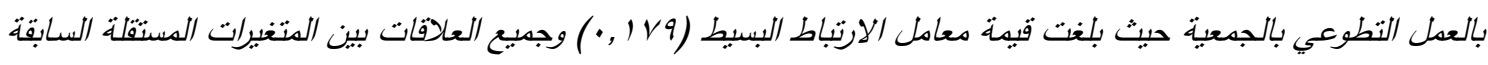

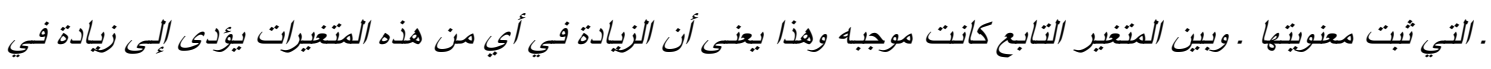

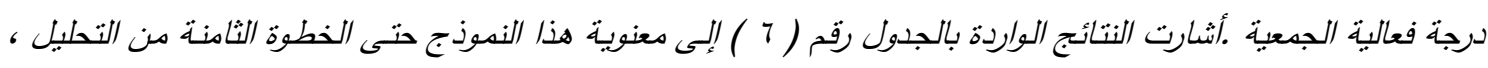

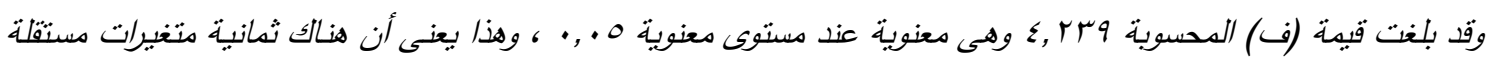

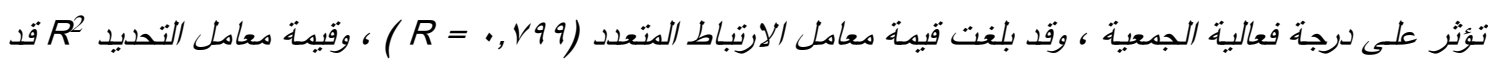

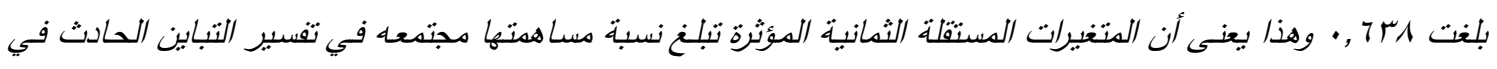

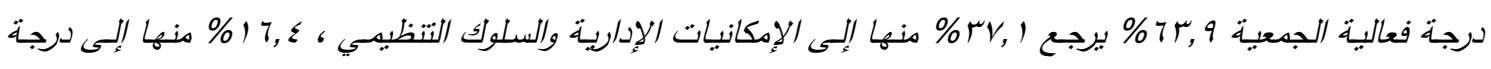

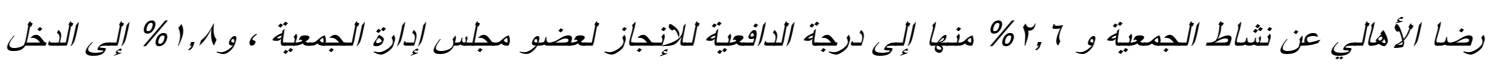

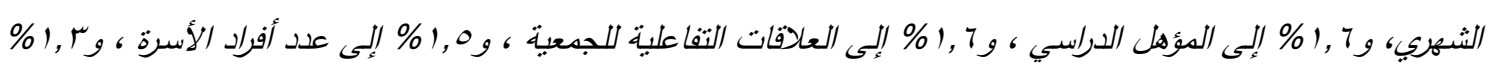

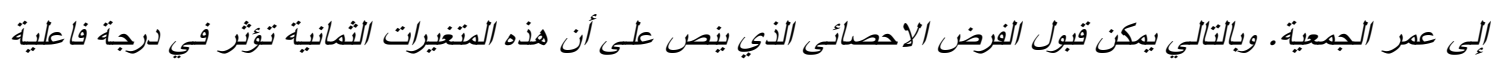

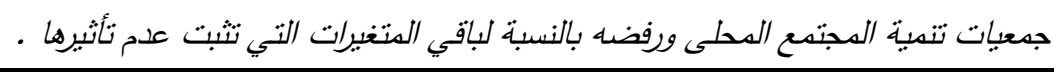

المنظمات الاجتماعية الريفية - الحكومية وغير الحكومية مقدمة

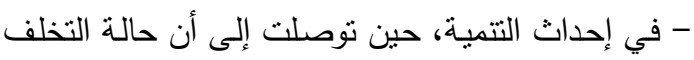

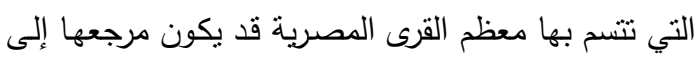

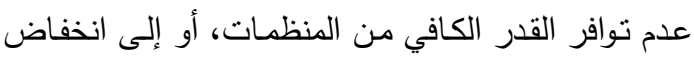

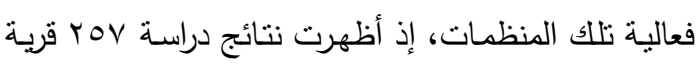

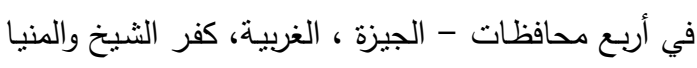

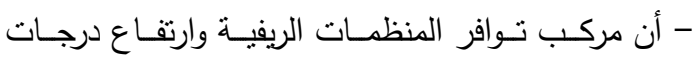

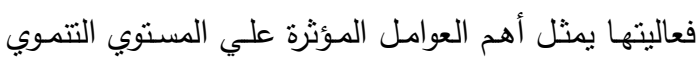
للقرية (جامع وآخرون، $919 v$ (19). تحتل قضية التتمية الريفية مكاناً بارزاً ضمن أولويات

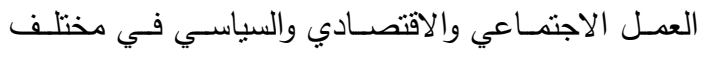

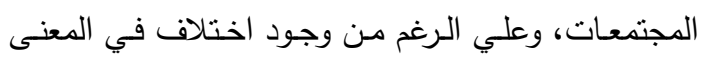

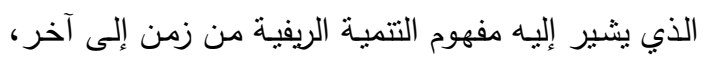

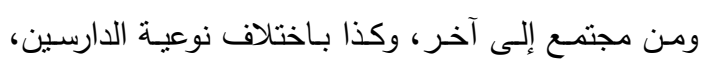
فـن المتفق عليه أن الهدف الرئيسي من التتميـة الريفيـة يتجسد في تحسين نوعية حياة السكان الريفيين • وأبرزت دراسـة أسباب تخلف القريـة المصـرية أهميـة 
فإن هناك بعض الجوانب التي لم تنل الاهتمام الكافي من

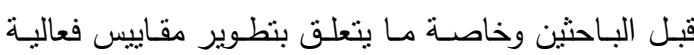
المنظمات غير الحكومية وما يترتب عليها من آثار بحثية

وتطبيقية.

وقد أكدت معظم الدراسات وجود العديد من المعوقات

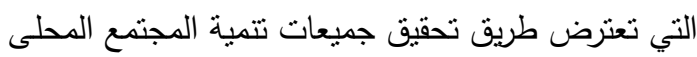

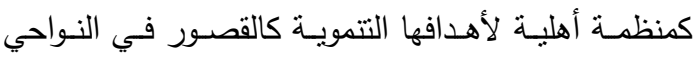
المادية ، أو في القائمين على هذه الجمعيات لعدم إيمانهم

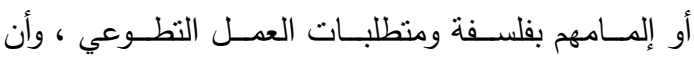
الغرض من قيامها في هذه الحالة لا يتعدى كونه مظهراً

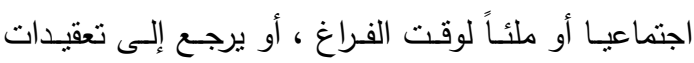

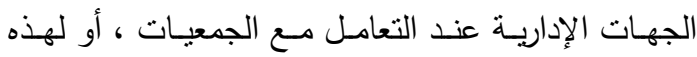

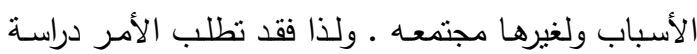

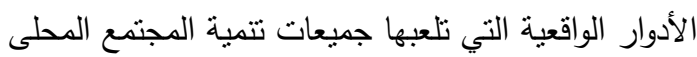

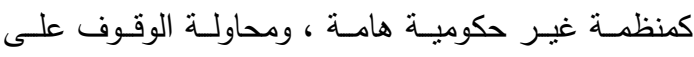
الأسباب الحقيقية التي تقف حائلاً دون تحقيقها لأهدافها بصورة مرضية ـ وكذا الخروج بمجموعـة من المقترحات التي تفعل من أداء هذه الجمعيات للدور التتوي المرجو

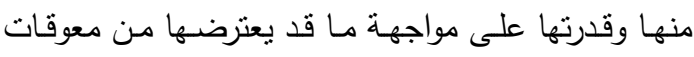

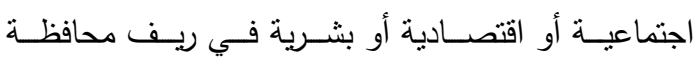

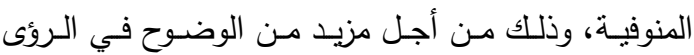
العلمية ، ومزيد من التكامل والتتاغم في العمل التتموي كي تدخل القريـة عصرها الجديد كقوة حضـارية فاعلة وبذلك فلكي تتحدد المشكلة البحثية في الإجابة على عدة تساؤلات كيفية

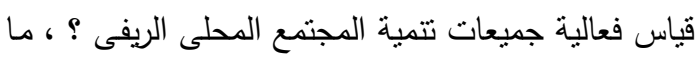

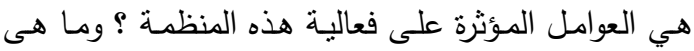
درجة فعالية جمعية تتمية المجتمع من وجهة نظر كل من لهن

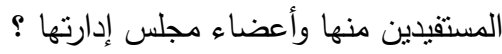

\section{الأهد|ف البحثية}

1- التعـرف علـى طبيعـة العلاقــات الإرتباطيــة بـين المتغيرات المستقلة المدروسـة وأبعـاد فعاليـة جمعيـات تتمية المجتمع المحلي (بعد العلاقات التفاعلية للجمعية

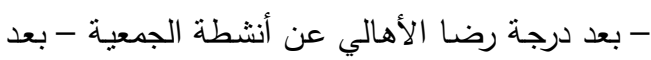
تأثير أنثطة الجمعية على الفرد والمجتمع - بعد درجة التها
وتعد جمعيات تتمية المجتمع المحلي العاملة بالمناطق الريفية منظمات اجتماعية غير حكومية، تتشأ وتمول وتدار

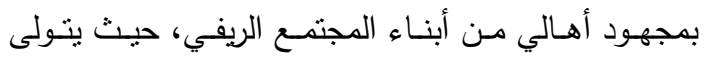
الأمر فيها مجلس إدارة منتخب، والعمل بها طوعي، وتعان

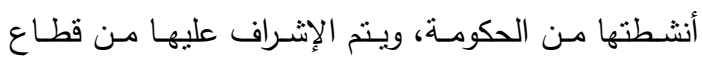
الثئون الاجتماعية بوزارة التضامن الاجتماعي، وهي بذلك التك

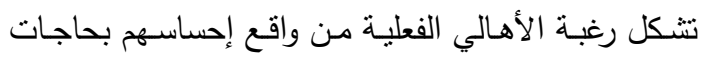
بيئتهم من خدمات مختلفة، وهي تسعى في سبيل ذلك إلى الى تقديم خدمات على درجة كبيرة من الأهمية والتتوع يمكن

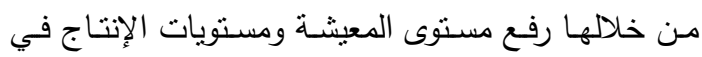
النواحي الاجتماعية والاقتصادية والصحية، وتتظيم الجهود

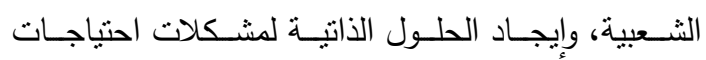

$$
\text { المجتمع الريفي (عبد الرحمن، V. . †). }
$$

وأكدت دراسات عديدة على أن هناك عوامل يمكن أن

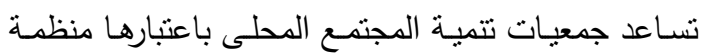
حيوية على القيام بدورها وزيادة فعاليتها في مجال التتمية الريفيـة ، والبحث الحسالي بدور حول هذا المحور مؤكدا أهمية دراسة تلك العوامل والكثف عنها ـ الكال

\section{المشكلة البحثية}

أبرزت العديد من الدراسات أهية الدور الذي تقوم به

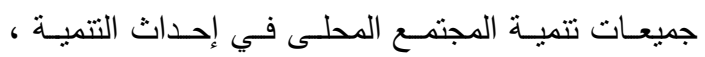
وأكدت على أن حالة التخلف التي نتسم بها معظم القرى التح التها الهصرية قد يكون مرجعها إلى انخفاض فاعليتها ـ كما

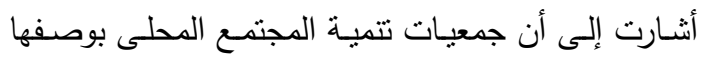

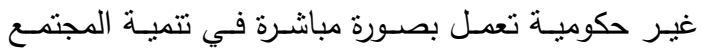
الريفى إلا أنه في ظل الأوضاع الراهنة التي يمر بها العالم

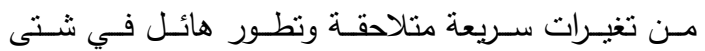
المجالات فإن هذه الجمعيات بوضعها الحالي لا تستطيع مواكبة هذه التغيرات ، ومن ثم قصورها عن أداء أدوارها

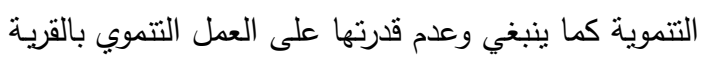
المصرية . وبالرغم من تعدد الدراسات والبحوث التي أجريت في . البراء

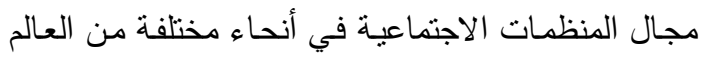

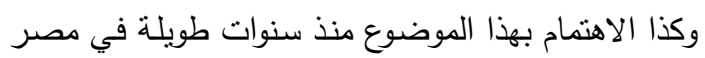


مقاييس اللغة ان الفاء والعين واللام أصل صحيح بدل

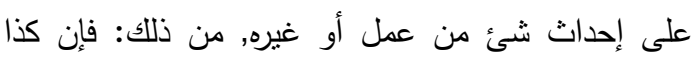
أفعله فعلاً.ويذكر بدوي (غير مبين ناريخ النشر) بأنها "الظاهرة التي نقوم على إنتاج أثر حاسم في زمن محدد",

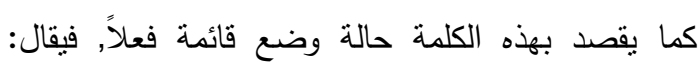

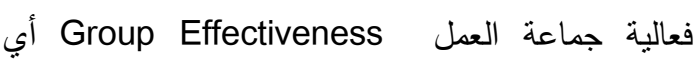
Organ قيامها بالجهد المطلوب, وفعالية التنظيم أو النظام التعام Effect

\section{r - مفهوم الفعالية اجتماعياً وإدارياً}

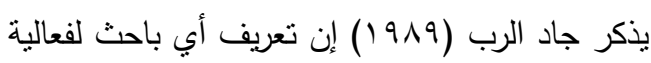

المنظمات يتوقف على المدخل الذي يستخدمه لدراستها,

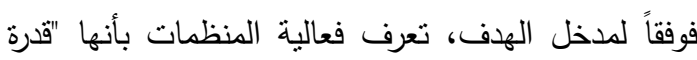

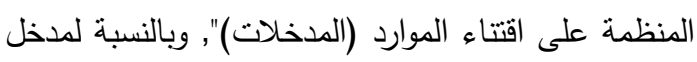

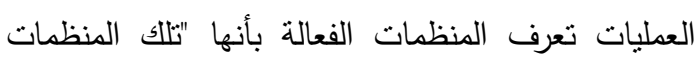
التي تتصف عملياتها الداخلية بخصائص تتظيمية معينة"، أما مدخل جمهور المتعاملين منل : العاملين بالمنظمة،

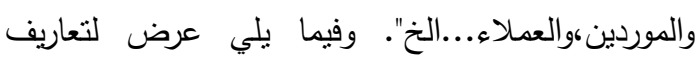
فعالية المنظمات غير الحكومية وفقاً لتلك الدداخل،فقي إطار المدخل الأول اتفق كل من عايدة خطاب (1997) ) ،

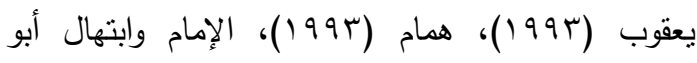

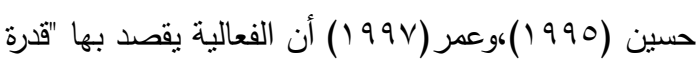
المنظمة على تحقيق أهدافها التي قامت من أجلها".أما

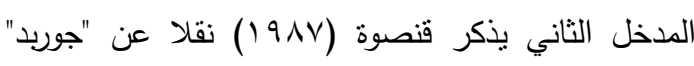
"Ghorpade"

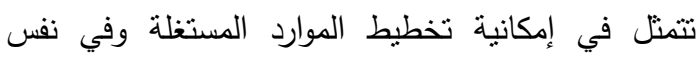

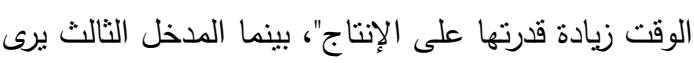

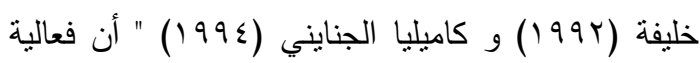
الهنظمات هي "النتيجة النهائية للأعمال من خلال النوازن النيان

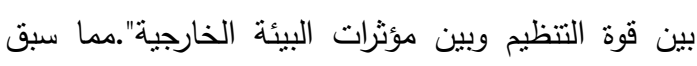

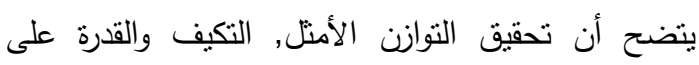

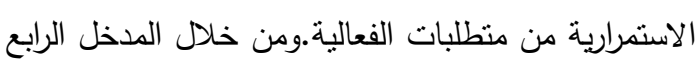

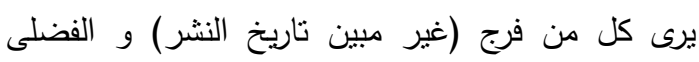

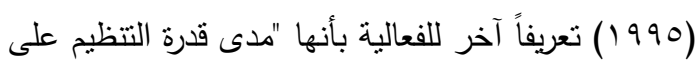

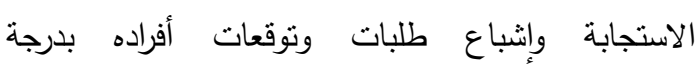

استفادة الاهـالى مـن أنتشطة جمعيات تتميـة المجتمـع المحلى) من وجهة نظر المبحوثين المستقيدين. ץ- تحديد العوامل المؤثرة فى أبعاد فعالية جمعيات تتمية المئن

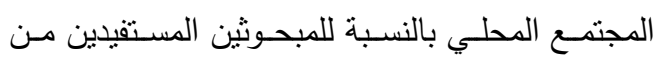

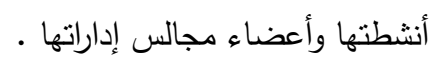

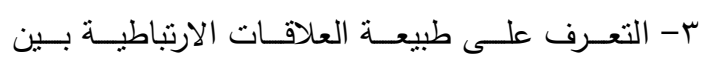

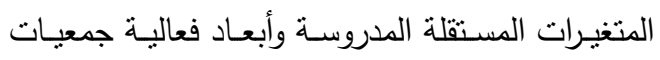
تتميـة المجتمع المحلـي (بعد تحقيـق الأهداف - بعد فيد التتسيق المنظمى - بعد الرضا الوظيفي - بعد النتظيم الداخلي) من وجهة نظر أعضاء مجالس الإدارة

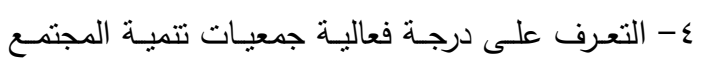
المحلي من وجهة نظر المبحوثين المستقبدين منهـا وأعضاء مجالس الادارة.

\section{الإطار النظري والدراسات السابقة} مفهوم فعالية المنظمات غير الحكومية تعددت التعاريف التي تتاولت الفعالية والتي أوردها المتخصصون في هذا المجال, واختلفت وجهات نظرهم حسب رؤية كل منهم لتصور هذا المفهوم من منظور

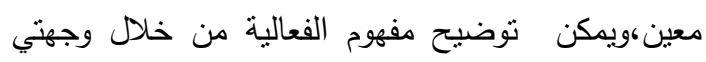
النظر اللغوية والاجتماعية كما يلي:

\section{1 - مفهوم الفعالية لغوياً}

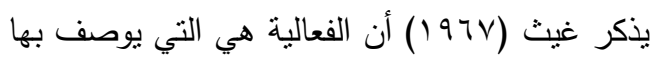

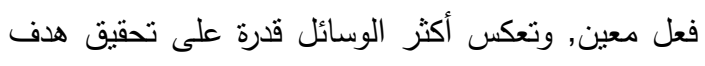
محدد, وتتحدد عن طريق العلاقة بين الوسائل المتعددة,

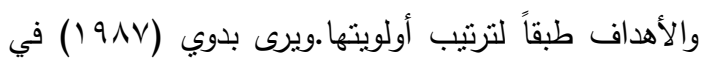
المعجم أن الفعالية تعني "تحقيق النتيجة المقصودة تحقيقاً

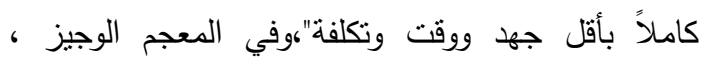

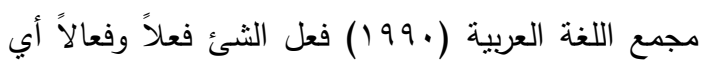

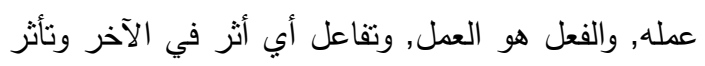

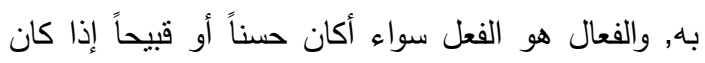

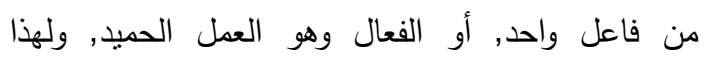
فالفاعلية في اللغة هنا تعني "القدرة على التأثير والأثر الحيد الفعلي".وأورد بن زكريا (غير مبين تاريخ النشر) في معجم لفي لفئ 
حيث أن تحقيق هذا التكامل يؤدي إلى تحقيق الأهداف

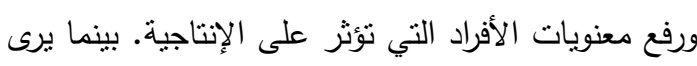
Deen, Champion

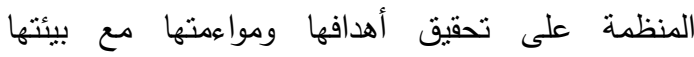

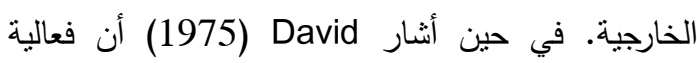
المنظمة يقصد بها درجة النجاح في تحقيق الأهداف التي

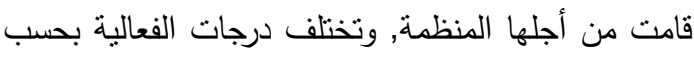

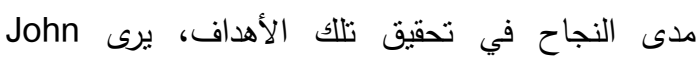
(1980) أن الفعالية تعني الأثر المرغوب أو المتوقع الذي لئي

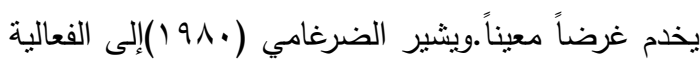

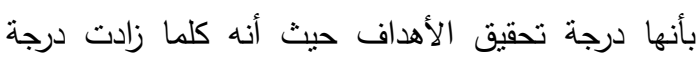

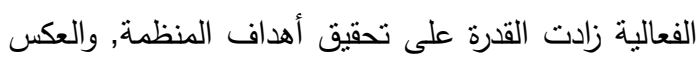

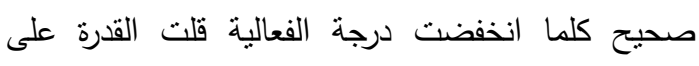

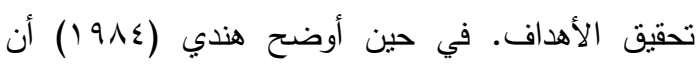

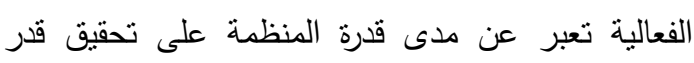

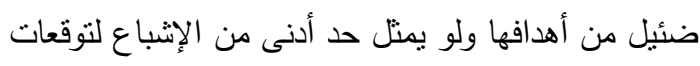

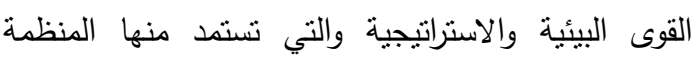
استمرارية وجودها وبقائها. وقد ذكر الحنفي (9Av ( I) نقلاً عن "James" أن الفعالية المنظمية هي: مدى قدافئ لكرة

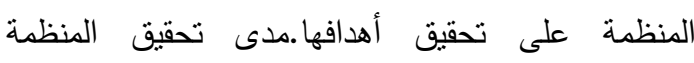
للأهداف المخطط لها.مدى قدرة المنظمة على اختئل الهنيار

$$
\text { الغايات المناسبة. }
$$

ويرى (Warren, 1996) أنه يجب قياس الفعالية

على أساس مقياس أعم وأثثمل بحيث ينتاول النظام بأكمله

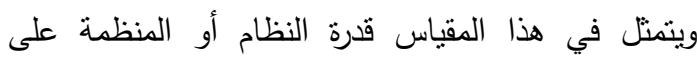
التغيير وتحقيق أهدافه استجابة للمنطلبات الموضوعية,

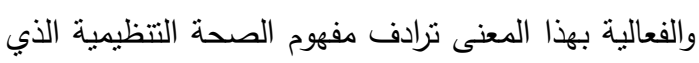
يفضل "Bennis" استخدامه في وصف المنظمة.

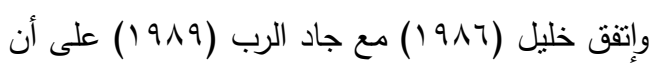
تعريف أي باحث لفعالية المنظمات ينوقف على الري المدخل

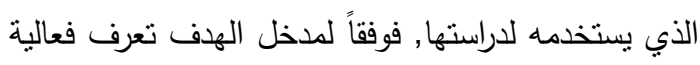

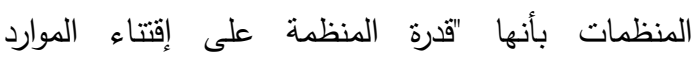
(المدخلات)", وبالنسبة لدذخل العمليات نعرف المنظمات الفعالة بأنها "تلك المنظمات التي تتصف عملياتياتها الداخلية بخصائص نتظيمية معينة"، أما مدخل جمهور المتعاملين
مرضية"،ويلاحظ أن هذا المدخل في تعريف الفعالية مدخل شامل يعبر عن إنجاز أهداف الهنظمة, وإنباع الحاجات

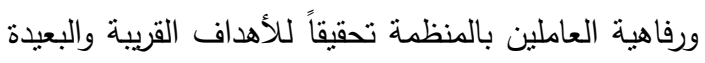
المدى على مستوى المجتمع المحلي, والمجتمع العام.

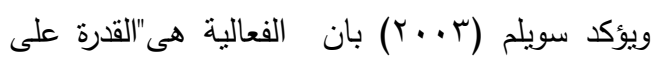

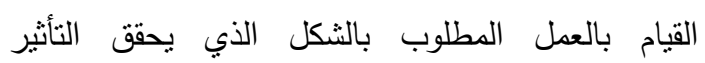

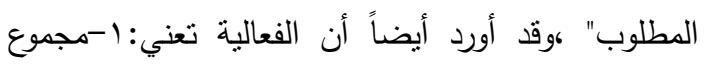

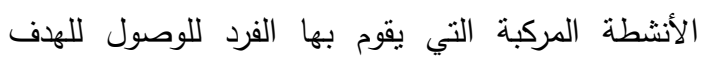

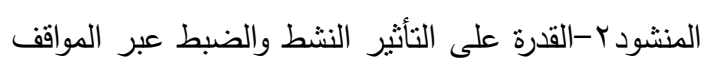

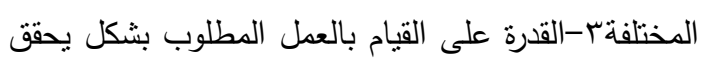

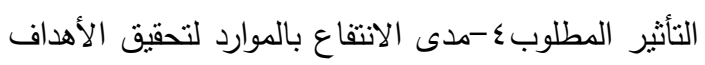

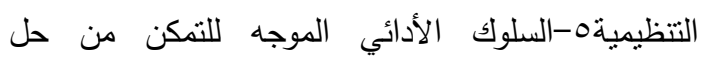

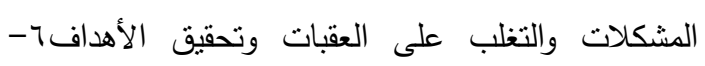
محصلة تفاعل مكونات الأداء الكلي للمنظمة بما تحتويه من أنشطة فنية ووظيفية وإدارية، وما يؤثر في هذا الأداء

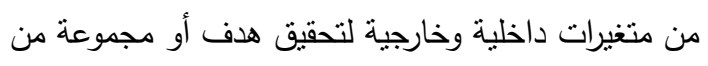

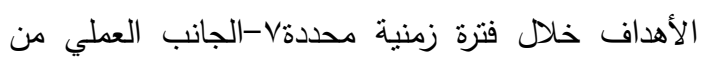
السلوك الذي يخرج لحيز التتفيذم-توقع القدرة على الأداء.

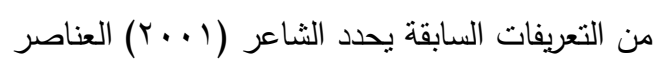
التي تعبر عن فعالية المنظمات وهي قدرة المنظمة على التئي

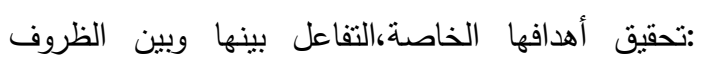

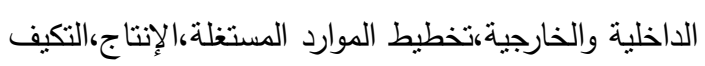

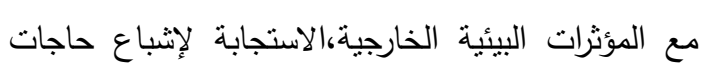

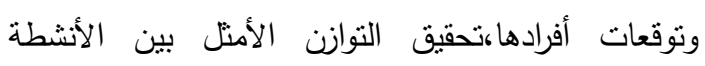

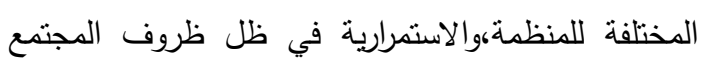
المحلي الذي تعمل فيه. ومن العرض السابق يتبين أن مفهوم الفعالية التتظيمية مفهوم شامل وغير محدد وفي هذا السياق يوضح الإمام (9V99) أنه يجب أن يوضع في الاعتبار أن فعالية

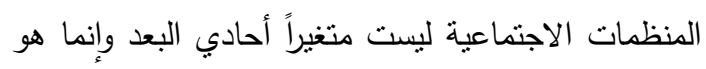
متغير متعدد الأبعاد، وأوضح James Price (1969) أن الفعالية تعني قدرة المنظمة على تحقيق أهدافها، ويرى الإئر Baulhersy التنظيم فإنه ينبغي نوافر التكامل بين أهداف الأنظمة لئه

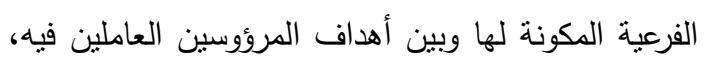


هذا المدخل ان الفعالية هي درجة تحقيق المنظمة

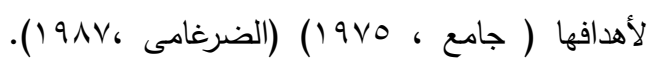

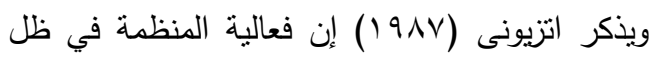
هذا المدخل تتوقف على تحقيق كامل أو جوهري للأهداف وتزداد فعالية المنظمات باستغلال موارد أكثر

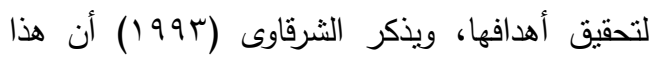

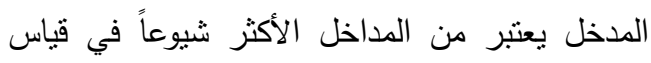
فعالية المنظمة ويرى أصحابه أن الوظيفة الحقيقية

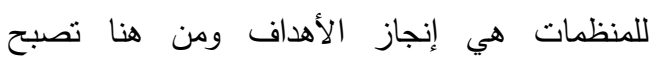
الأهداف التنظيمية هي المدخل الملائم لدراسة المنظمة

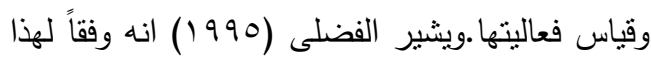
المدخل فان لكل منظمة مجموعة من الأهداف

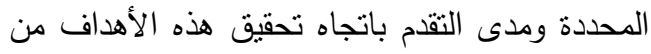

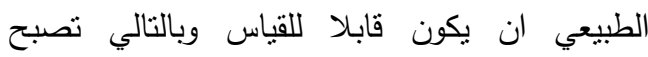
المخرجات هنا هي وسيلة القياس الأساسية للفعالية

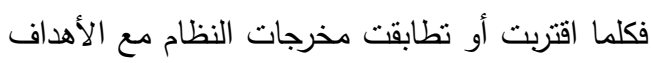

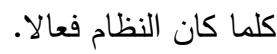

وتذكر سعاد نائف (910) أن هناك عدداً من المداخل النظرية لمعرفة كيف تحدد الأهداف ويمكن حصرها في مدخلين رئيسيين: الددخل الأول أن الفعالية يمكن قياسها على عدة أسس هي:مدى ما تحققه المنظمة للمجتمع الذي نقوم بخدمته، مدى استجابة المنظمة

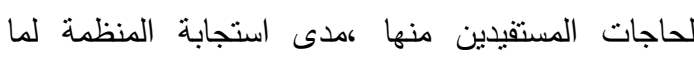

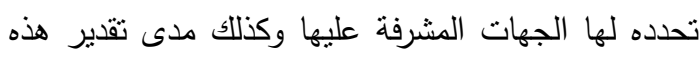

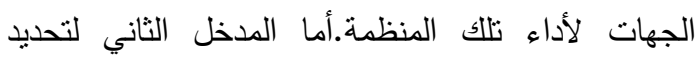

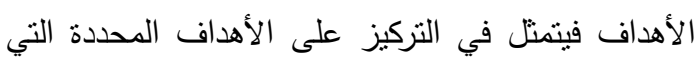

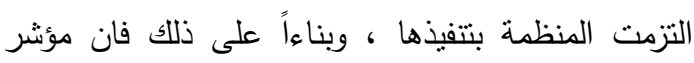

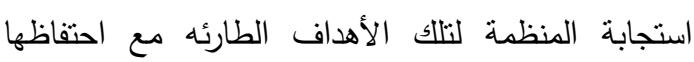
بهويتها ومتابعة تتفيذ أهدافها يعتبر من الدقاييس الأكثر حساسية لفعاليتها.

وبالرغم من سهولة تعريف الفعالية نظرياً وفقاً لهذا المدخل إلا إنه توجد بعض المشكلات المنهجية المنعلقة

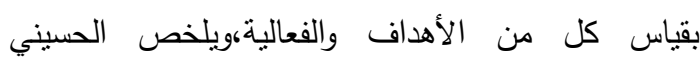

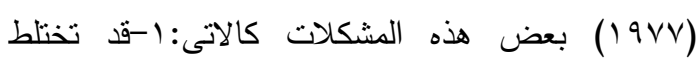

مثل: العاملين بالمنظمة، والموردين، والعملاء...إلخ". أثنار محمود (1991 1) نقلاً عن "Suchonr Uchtman"إلى أن الن النمان الفعالية تتحدد على أساس القدرة التفاوضية للمنظمة في

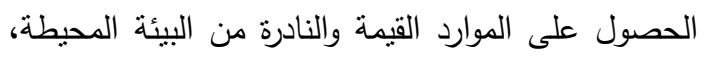
ويضيف جريم (997) إلى أنه قد تباينت الآراء حول

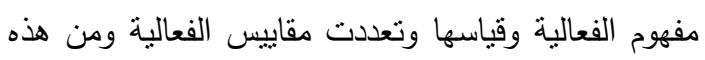
الآراء من بنظر إلى الفعالية بمقياس تحقيق أهداف

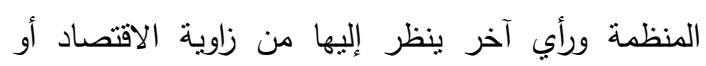

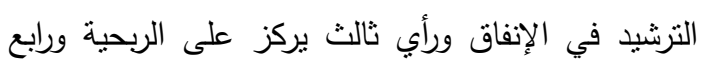
يركز على الجودة, وقد ركزت نظرية النظم على الوسائل

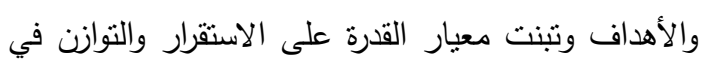

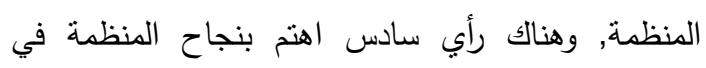

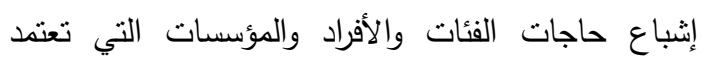
عليها المنظمة في عملها. ويستخلص من العرض السابق أن الفعالية تعني "قدرة

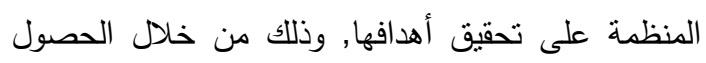

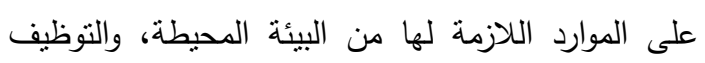

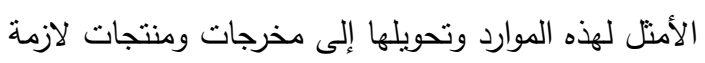

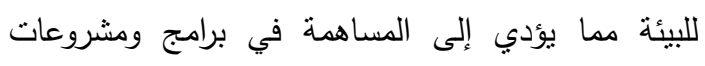
"التتمية"وهو المفهوم الذي سنتخذه الدراسة مفهوما إجرائيا

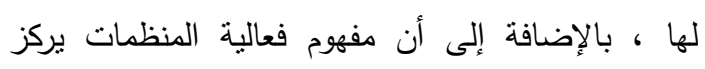

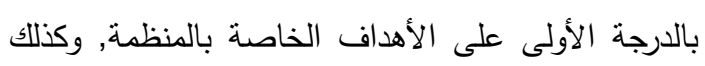

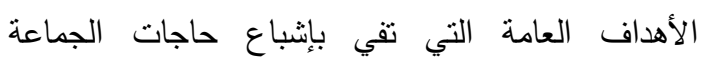

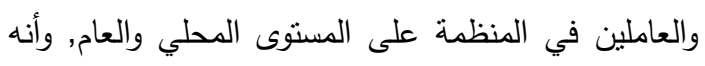

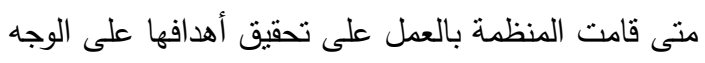
المطلوب فإنها تصبح فعالة وناجحة في أداء دورها, أما إذا الدا عجزت عن القيام بتحقيق تلك الأهداف فإنها تفقد فعاليتها

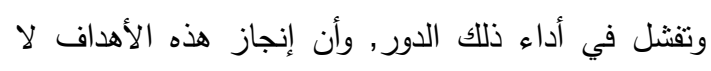
يأتي إلا بإمكانية تخطيط الموارد المستغلة تخطيطاً جيداً,

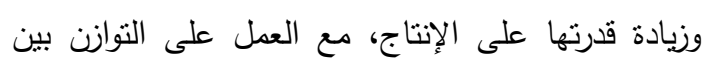

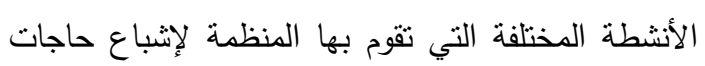
الأفراد. المداخل النظرية لاراسة فعالية المنظمات ا-مدخل الأهداف : Goals Approach : يرى أنصار 
عن طريق التقارير السنوية والوثائق المكتوبة وان الأهداف نظل محكا رئيسيا لمعظم نظريات المنظمات وفعالياتها.

\section{System Resource مدخل موارد النظام} يذكر Steers : Approach هذا المدخل يعتمد على نظرية النظام المفتوح والتي توضح أهمية التفاعل البيئي للمنظمة وتركز بشدة على لفئل العلاقات القائمة بين المكونات المختلفة داخل وخارج

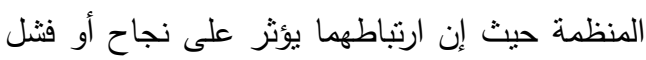
المنظمة، ويشير البيومى (9Nv) أنه إذبا كان مدخل

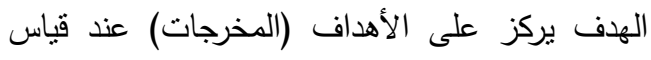
الفعالية المنظمية, فإن مدخل موارد (مصادر) النظام

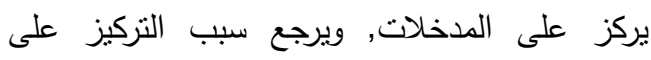
استخدام هذا الدذخل إلى أن كثيراً من الموارد التي لئي

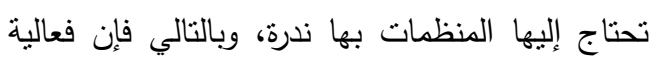
المنظمة في ظل هذا المدخل تتحدد بمدى قدرتها على لئل حسن استغلال البيئة المحيطة للحصول على الموارد القيمة والنادرة اللازمة لممارسة أنشطنها وضمان النمان استقرارها ونموها, وفي ضوء هذا المدخل بمكن النظر النظ إلى المنظمة على أنها في علاقة تفاوض مع البيئة

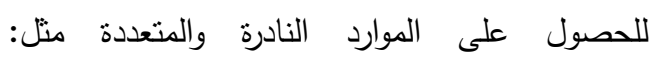

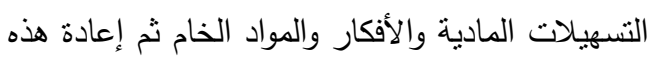
الموارد إلى البيئة في صورة سلع وخدمات.

ويذكر الجمل (1911) أن أصحاب هذا الدخل لاحظوا أن المتغيرات المتعلقة بقياس الفعالية المنظمية

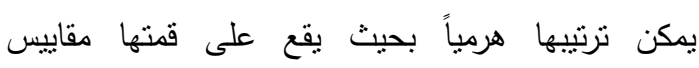

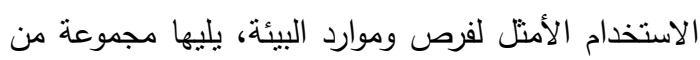
المقاييس الوسطي، وهي أكثر من الأولى في العدد وهي لإني لإني

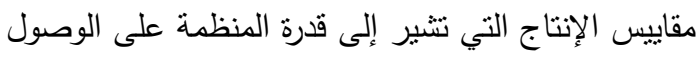

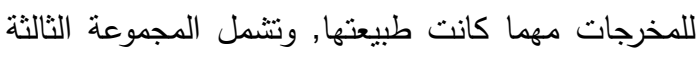

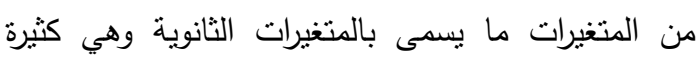

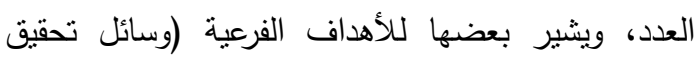

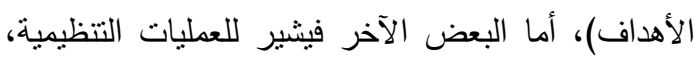

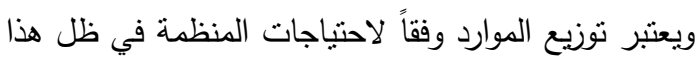

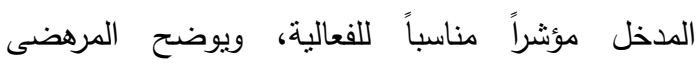

الأهداف التنظيمينبالأهداف الثخصية.r-وجود مشكلة في تحديد وتعريف الأهداف حيث يخضع لوجهات نظر مختلفة هي وجهات نظر المديرين وأعضاء مجلس الإدارة

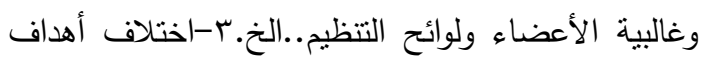

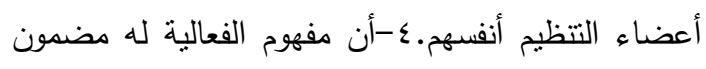

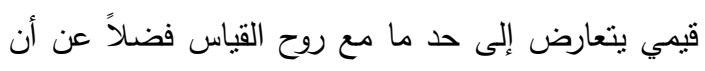

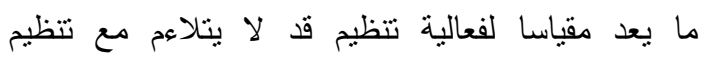

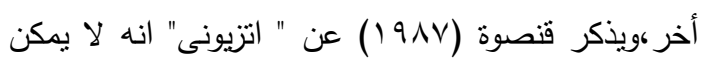

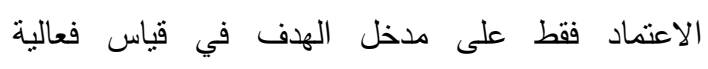
المنظمات وان المنظمات أنساق اجتماعية وأنشطتها تتميز

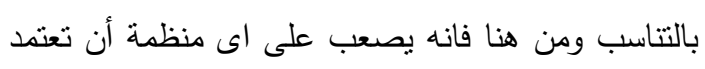
فقط على قياس تحقيق الهدف. ولقد تعرض هذا المدخل لعدة انتقادات أوردها حلوة (910) الأول: ما يتعلق بصعوبة نعريف الأهداف ذاتها

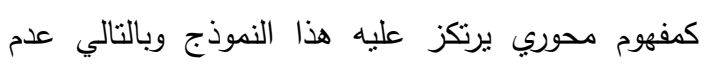
إمكانية نطبيق هذا المدخل والاستفادة منه علمياً.الثاني:

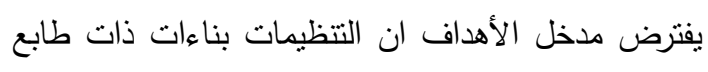

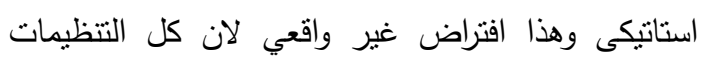
تتصف بالدينامية فهي تتغير من حيث الحجم والتعقيد

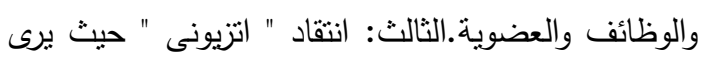

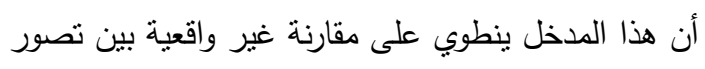
مثالي للأهداف وتصور أخر حقيقي ومنل هذه المقارنة في

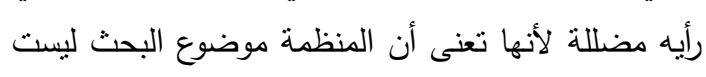
ذات فعالية كبيرة فى انجاز أهدافها. ويذكر Bedeian (ع ا9 1) أن احد العيوب الأخرى

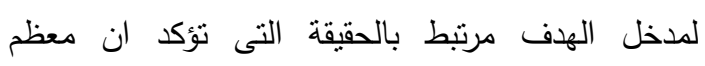

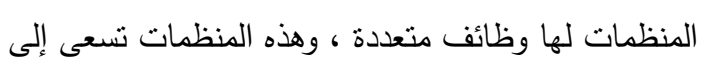

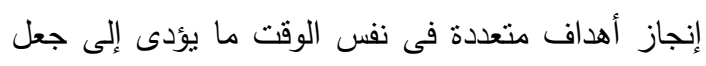

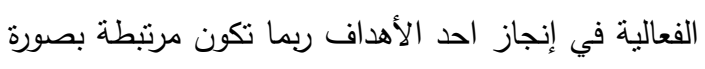

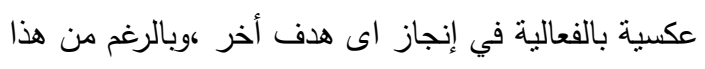

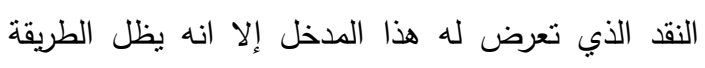

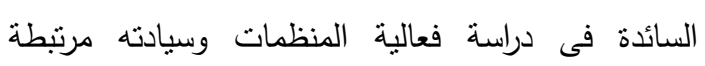

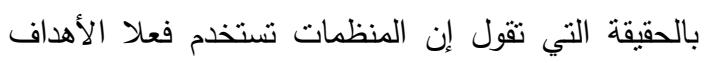


خصائص المنظمات الفعالة في ظل هذا المدخل فيما يلي: ا-تقليل الإجهاد والتوتز داخل المنظمة.ب-تحقيق التكامل بين أهداف الأفراد وأهداف المنظمة.ب-مدى

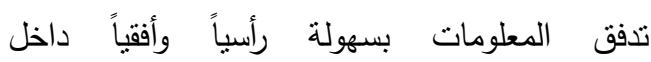
المنظمة.ع-مدى سهولة أداء الوظائف الداخلية.0درجة الاستفادة من طاقات الأفراد والجماعات داخل

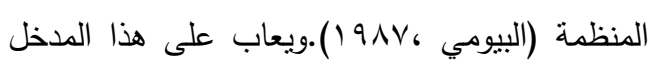
ما يلي:ا-أنه لم يضع في اعتباره الأهداف التي التي لهي تسعى المنظمة إلى تحقيقها.ب-أنه يركز على عنصر

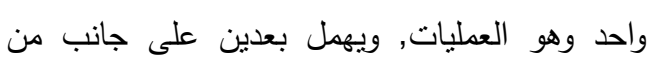
الأهمية وهما المدخلات والمخرجات،وبالرغم من تللك العيوب إلا أن هذا المدخل هو الأنسب لدراسة فعالية المنظمات بالنسبة للمنظمات التي تكون أكثر اعتمادا وارتباطا بالعمليات الداخلية للمنظمة, حيث تكون هذه العمليات على درجة عالية من التحديد وعدم التعقيد. ع - مدخل أصحاب المصلحة أو من المنتفعين Stakeholders Approach المصلحة أي مجموعة بداخل المنظمة (بيئتها الداخلية) أو في خارجها (البيئة الخارجية) تعتمد عليهم المنظمة في بقائها أو تطورها من خلال تلبيتها لمطالبهم،وتعد المنظمة فعالة عند إرضائها لكل أصحاب المصلحة وتزبد فعاليتها بزيادة إرضائهم ومنهم المساهمون، الموارد البشربة في المنظمة، المستقيدون،المنظمات الحكومية ذات العلاقة, وهيئات حماية البيئة والمستهلك (Daft, 1992) . مون مؤشرات الفعالية رضا المساهمين عن عوائدهم المالية, ورضا العاملين عن العمل, ورضا المستفيدين عن مونين نوعية السلع أو الخدمات, ورضا الدائنين عن سداد المنظمة لديونها وفوائدها, ورضا المنظمات ورضيات الحكومية عن امتنال المنظمة للقوانين ذات الصلة بعملها, ورضا هيئة حماية البيئة عن نشاطات المنظمة تجاه حماية البيئة, ورضا هيئة حماية المستهلك عن النزام المنظمة في تسويقها لمنتجاتها وخدماتها بمطالب هذا الهيئة وتقديم منتجات وخدمات غير ضارة بصحة المستهلك وتوفير معلومات صحيحة عن نوعيتها وكيفية (r...) إن فعالية المنظمة في ضوء مدخل النظم تكمن

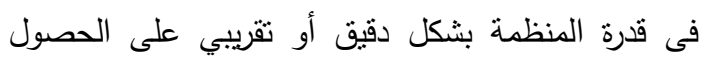

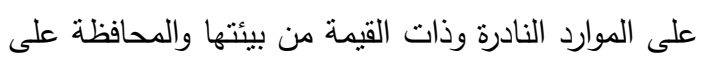

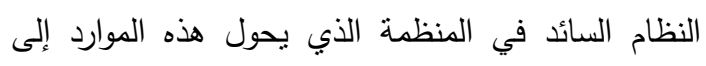

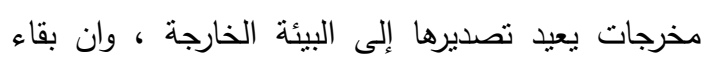

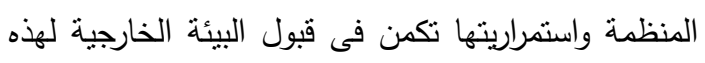

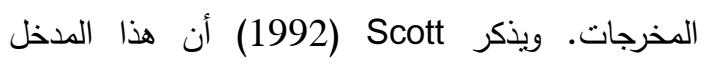
يصف الهنظمات بقدرنها على تحقيق أهداف خاصة الهنا

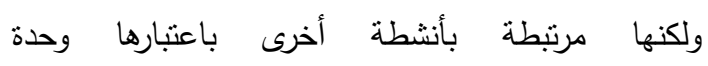

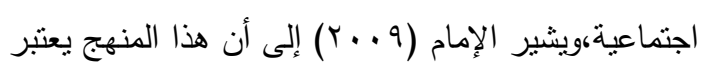

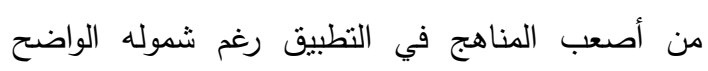

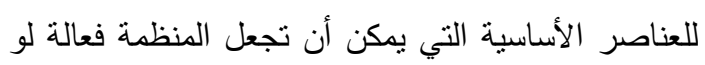

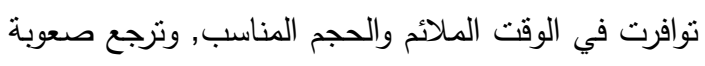

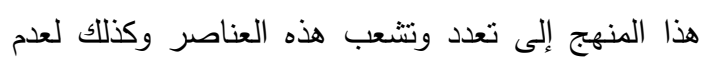

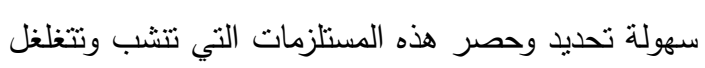
بين مكونات كلُ من البيئة الداخلية والخارجية, وكنلك تظهر الصعوبة حيث أن النكامل الذاني والتزابط بين ولتين

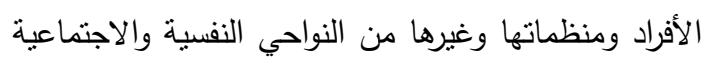
معقدة وتتطلب مقاييس ثابتة سليمة قد لا تكون متوافرة.

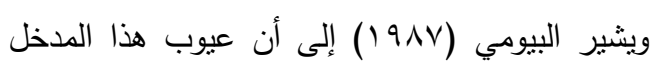

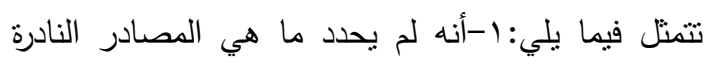

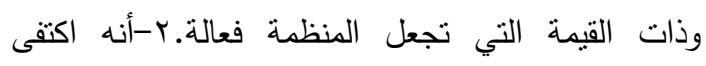
بالتركيز على القدر الذي تحصل عليه المنظمة من البيئة

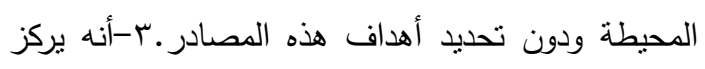
بدرجة اكبر على الدخخلات مما قد يؤدي إلى حدوث آثاد آثار

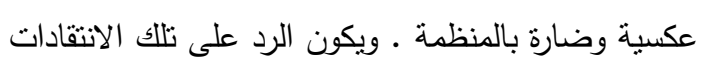

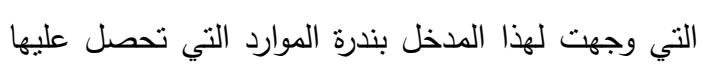

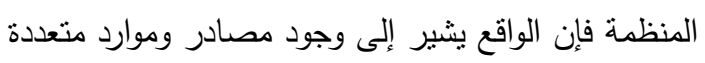

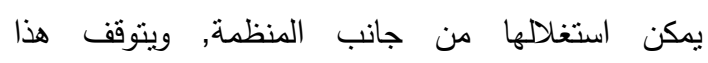
الاستغلال لنتلك الموارد على وجود إدارة جيدة تعمل على استغلال هذه الموارد وتثنظيها بكفاءة.

r- مدخل العمليات Processes Approach : يركز

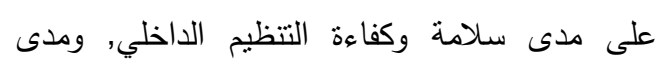
تكيف وتناسق عملياته مع بعضها البعض, وتتمثل أهم 
الإنجاز Achievement وهو محصلة العناصر الثثلاثة

السابقة.

ب- نموذج "وارن بنس" Warren Bennis : أوضح سليمان (غير مبين ناريخ النشر) أن نموذج "وارن بنارن

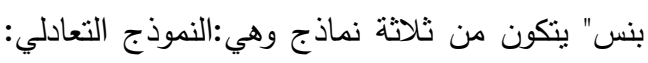

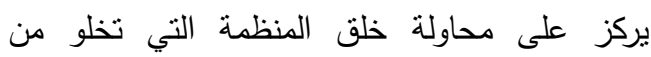
التضارب وذلك من خلال الإقلال من حالات القلق القئل

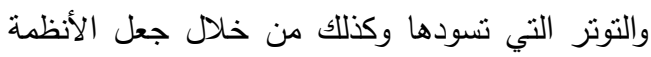

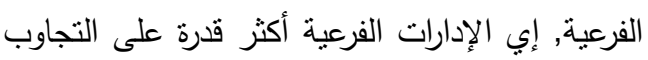

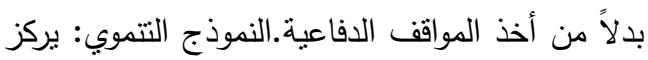
على محاولة خلق علاقات واضحة وصريحة بين أفراد المنظمة وذلك حتى يمكن تتمية العلاقات والقيم التي عاتي تساعد على بقائها ونموها, وعليه فإن الهدف في ظل بل فئل

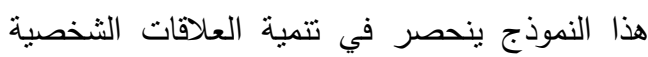
بين أفراد المنظمة الرسمية وغير الرسمية.النموذج

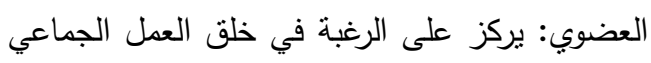

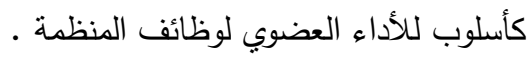

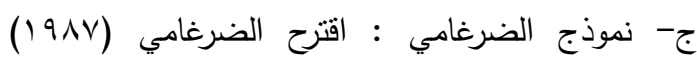

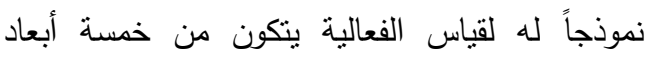

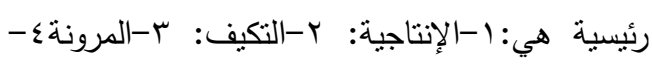
رضا العاملينه-الابتكار

: Mulford \& Others" دموذج "مالفورد وآخرون أنشار Mulford (1977) إلى أربعة متغيرات فرعية يتضمنها هذا النموذج لقياس الفعالية وهي: الفية الفيرات Organization الإنتاجية المنظية Productivity ودرجة تحقيق المنظمة لأهدافها, وكفاءة تشغيل

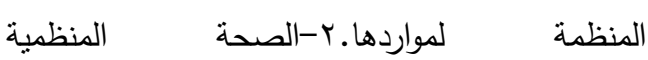
Organization Health للعاملين, وتعرفهر على الأهداف التتظيمية, وإدراكهم التحن

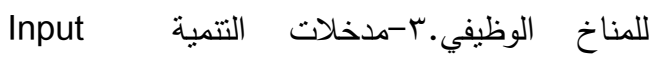
Program development الأهداف الرسمية, وتقدير الاحتياجات, وتثرتيب الأهداف, والكفاءة الاقتصادية.ع-الدعم الجماهيري Public Support
استعمالها (Oldcorn \& Parker, 1996).ومن أهم مميزات هذا المدخل النظرة الواسعة للفعالية من

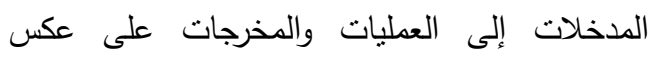
المداخل المذكورة سابقاً, ومن أهم محددات هذا المدخل

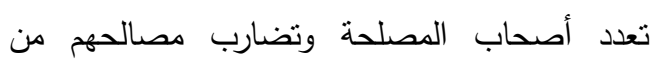
المنظمة ، وتغيرها باستمرار مما بستدعى موازنة

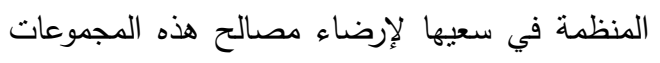
بحسب الموقف بمستوى الإرضاء الأكبر لمصالح

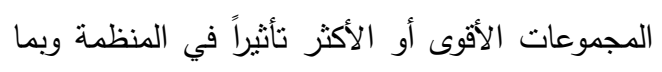

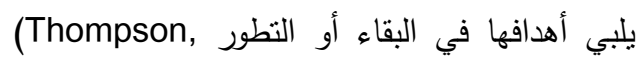
.1997) ه- مدخل الوظيفة الاجتماعية (المدخل الجهازي) : يشير

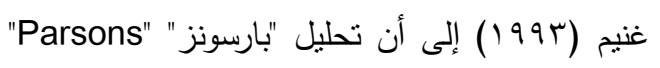

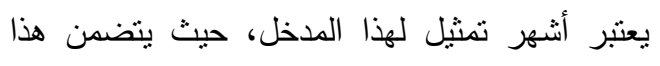

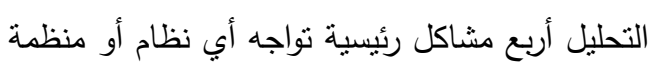

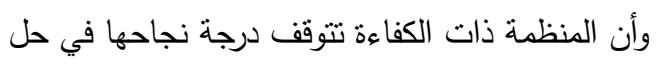

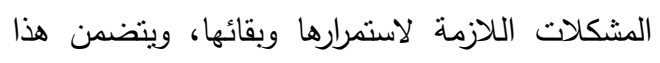

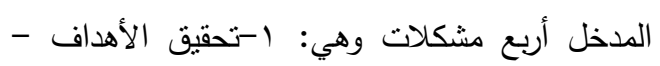

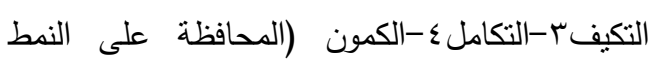

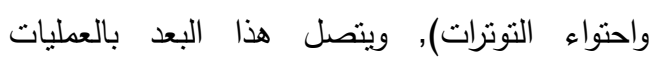
المتعلقة بالتتاغم بين أدوار العاملين ونتيجة التزام الفرد

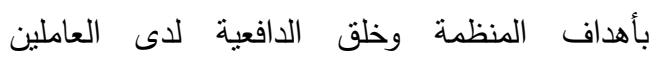
والمحافظة عليها.

\section{طرق ونماذج قياس فعالية المنظمات}

هناك عدة نماذج يمكن من خلالها قياس فعالية

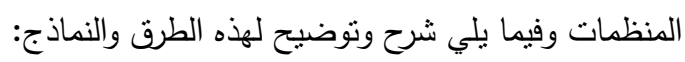
أ- نموذج سيفا Caplow J SIVA يذكر الحنفي (9AV (

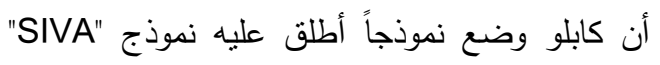

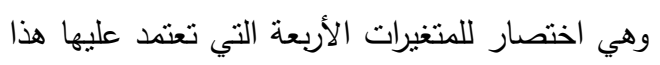

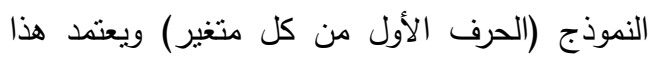
النموذج على أن المنظمة الفعالة هي التي تثميز بما لإنير

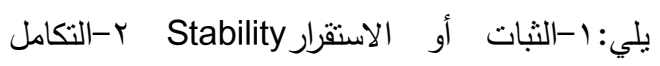
Integration 
ممارسة أعمالها وقبول المجتمع لها على الددى

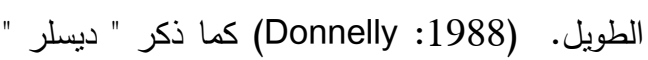
عessler

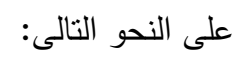

The Paters and نموذج باتريس وواترمان : Waterman Model

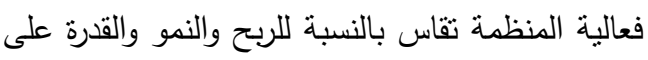

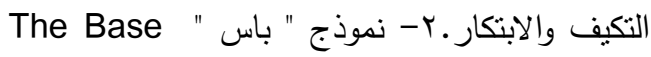
يذكر " باس " فى هذا النموذج أن تقييم : Model المنظمة يجب أن يتم وفقاً لما يلي :ا-درجة الإنتاجية والمرابحة وقوة المنظمة ب-درجة اعتزاز الأعضاء

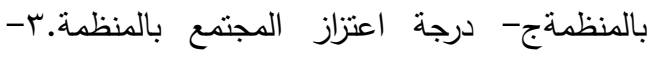

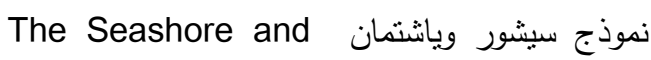
:يركز هذا النموذج على أن Yuchtman Model الفعالية هي استخدام المنظمة لكصادرها المختلفة

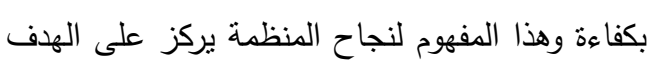
الأساسي المدد الذي تكافح من أجله المنظمة أكثر

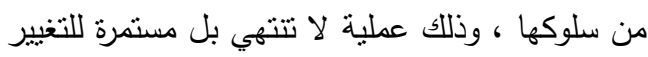
والمنافسة فيما يتعلق بمصادرها ذات القيمة المختلفة. ويذكر خاطر (1999) محكات أخرى لقياس فعالية المنظمة هي :ا-مدى رضا الجمهور منذ إنثاء المنظمة

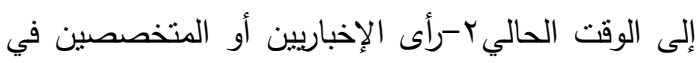
مجال الإدارة والذين لهم علاقة بالمنظمة.r-مقارنة الإنتاجية أو التكلفة في الوحدات المنتشابهة داخل المنظمة

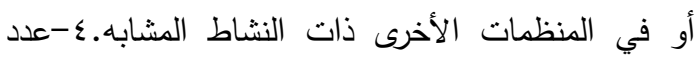
المنظوعين لصالح المنظمةه-مدى تفهم العاملين لمعايير

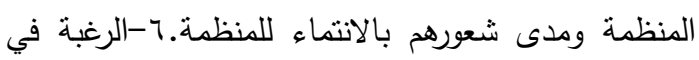

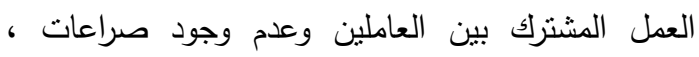

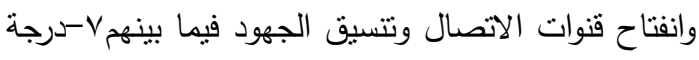
الاسنقرار الذي تتمتع به المنظمة حاليا، ومدى وضوح

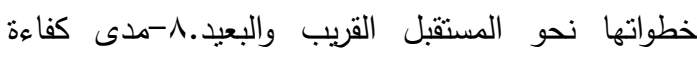
المديرين، ومدى قدرتهم على توفير تشهيلات للتفاعل

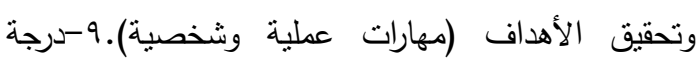
الكفاية والتكامل في الاتهات لهاتلات الرسمية داخل
المنظمات الأخرى, إجراء دراسات تصورية لتقدير أداء المنظمة بالاعتماد على الخبراء والمتخصصين.

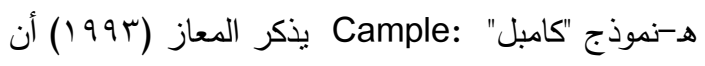
كامبل نوصل إلى قائمة لمعايير الفعالية التتظيمية عند

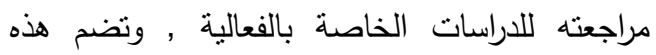
القائمة عدة معايير هي: الفعالية الإجمالية، الكفاءة، لإنة

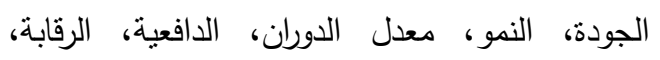

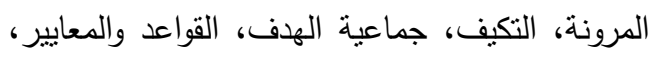
إدارة المعلومات، الاتصالات، التقييم بواسطة الخبراء

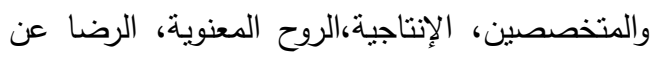

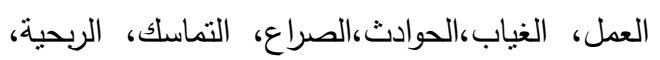

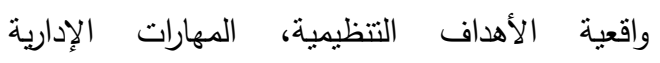

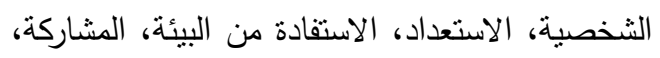

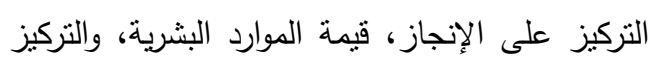
على التطوير والتدريب. و - نموذج "ليكرت" Likert : ويسمى نموذج التنظيم الإنساني, ويتضمن عدة عمليات يوضحها الهوا ري (1999) كالآتي:ا-عمليات القيادة-ب-طبيعة القوى التحفيزيةr- طبيعة عمليات الإتصال \&-طبيعة عملية

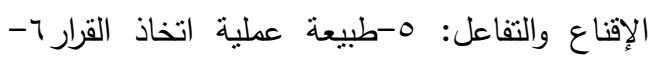
طبيعة وضوح الأهداف V-طبيعة عملية الرقابة. و - نموذج "ستنرس" Steers : قام Steers (1975) بمراجعة سبعة عشر دراسة للفعالية التتظيمية وتوصل إلى أربعة عشر معياراً لقياس الفعالية التتظيمية وهذه درالة للفية

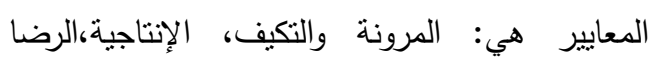

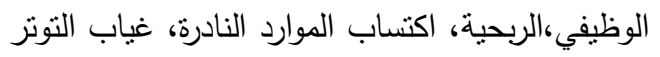

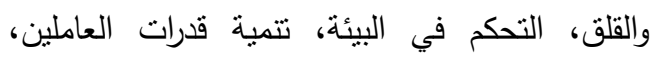

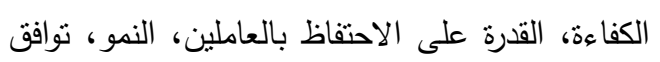

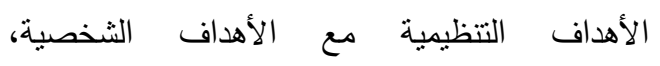
الاتصالات، وأخيراً البقاء والاستمرار • وبالنظر إلى هذا لأها

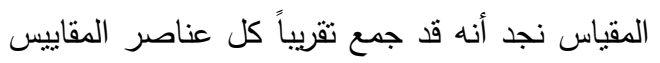
السابقة. ح- نموذج جييسون ودونللى Gibson \& Donnelly حيث تقاس الفعالية هنا على أساس عامل الوقتى

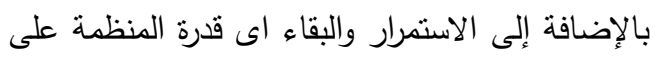


ع - اهتمت الدراسات في بداية القرن الحالي بالتعرف على الحي

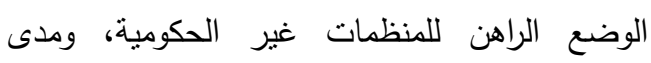

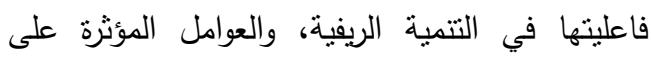

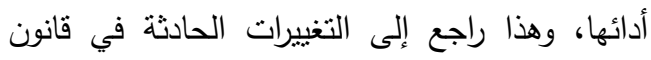

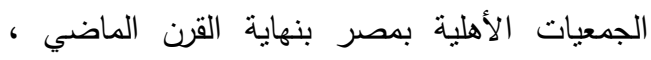

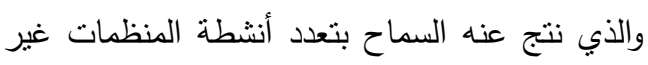

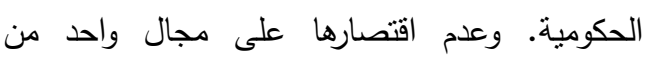
الأنشطة، مما تتطلب معه المحاولة في إعادة التصنيف والحصر للمنظمات التى تعمل بمجالات متعددة للتعرف على نوعية هذه المجالات وعددها. ه- تركزت أغلب الدراسات المتعلقة بدور المنظمات غير الحكومية العاملة في الريف على مدى إحساس أهل الهل

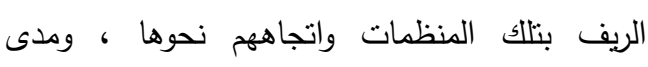

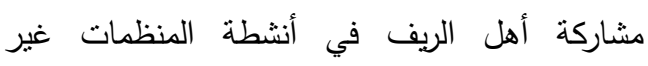

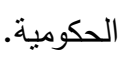

צ- ضآلة عدد البحوث والدراسات التىى أقرت نتاول

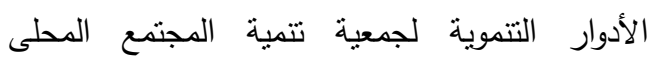
كمنظمة غير حكومية أهلية ريفية ، وإنما نم تتاولها لهية

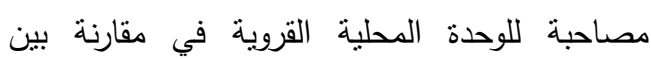
منظمنين حكومية وأهلية على درجة كبيرة من الأهمية التتموية ، كما تتاولها البعض كواحدة من المنظمات

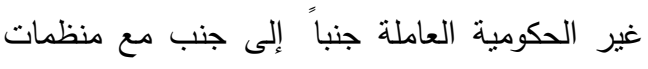
غير حكومية أخرى كمنظمات الرعاية الاجتماعية

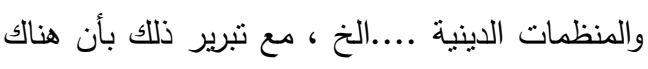

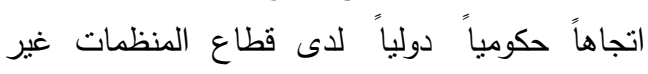

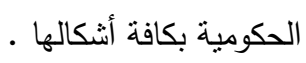

- دراسة جمعية تتمية المجتمع ليس أمراً سهلاً يسنطيعه

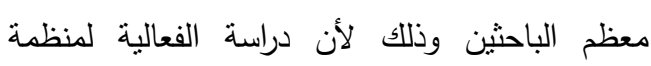

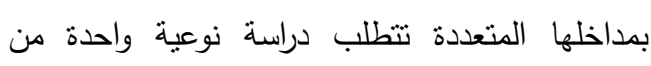
المنظمات وعلى الرغم من أن كل الجمعيات الأهلية

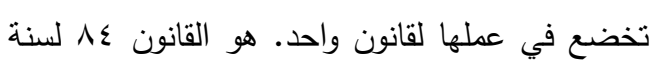

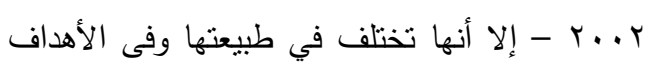

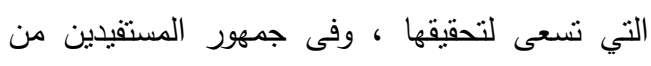

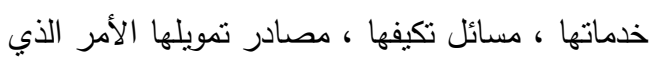

التنظيم. • 1-درجة الاستعداد في المنظمة للانطلاق بنجاح

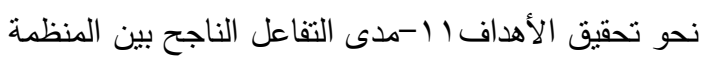

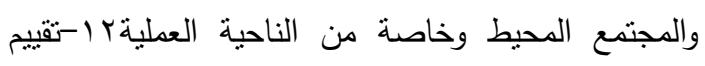
الإنجاز داخل المنظمة مقارنة بالمنظمات الأخرى

بالمجتمع.

روية تحليلية للاراسات السابقة

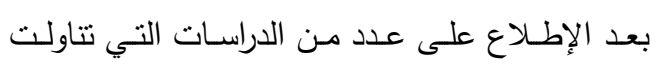

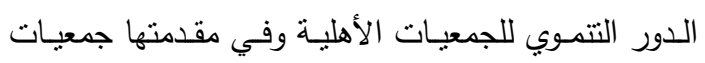

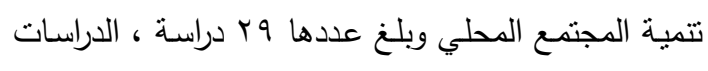
التي تناولت فعالية وكفاءة المنظمات الاجتماعية الريفية

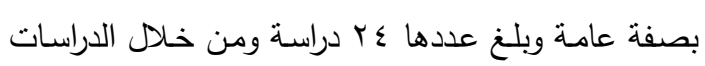
والأبحاث التي تناولت المنظمات غير الحكومية وجد انه

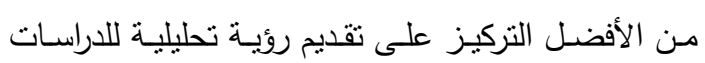
السابقة 1- تزايد عدد الدراسات التي تتعلق بالمنظمات غير

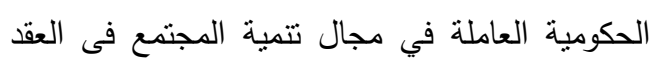
الأخير من القرن الماضي والعقد الأول من القرن

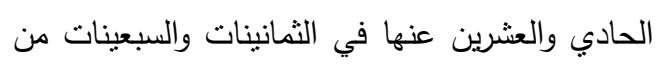

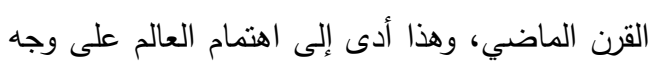

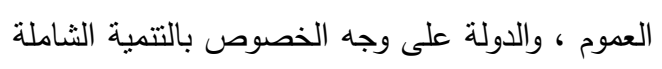

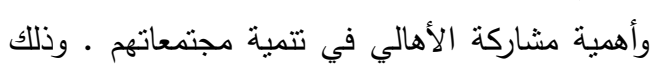
من خلال مشاركته في منظمات لها صفة الثرعية ممثلة في المنظمات غير الحكومية. r- حدوث تغيرات في نوعية الدراسات المرتمة بدراسة

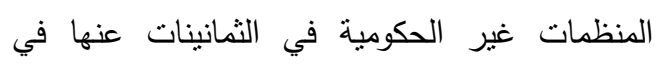
التسعينات من القرن الماضي والعقد الأول من القرن

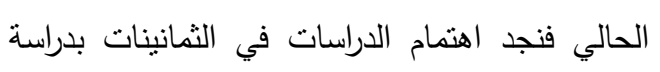
الحالة لمنظمة واحدة أو أكثر بينما في تسعينات القرن

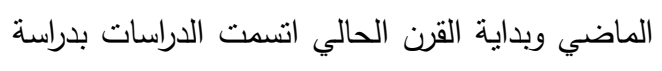
اكبر عدد من المنظمات على مستوى الجمهورية. r- اهتمت الغالبية العظمى من الدراسات المتعلقة بالمنظمات غير الحكومية في أواخر القرن الماضي الهني

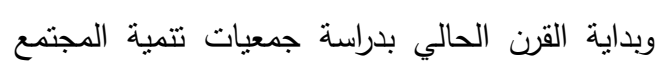
المحلى فقط . 


\section{الإجراءات البحثية \\ منطقة الدراسة}

اختيرت محافظة المنوفية كمجال جغرافي لإجراء هذه لأهنه

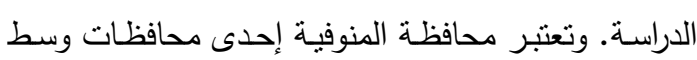

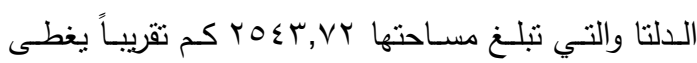

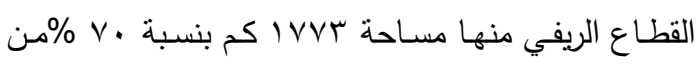

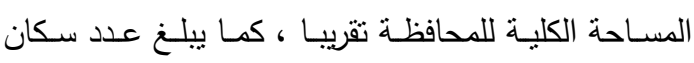

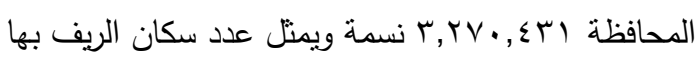

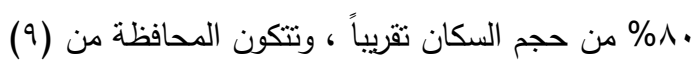

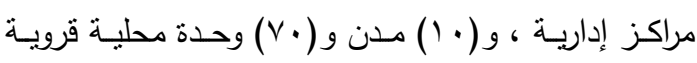

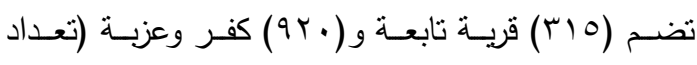

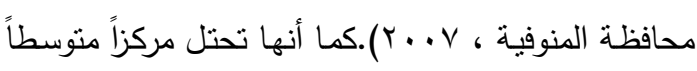

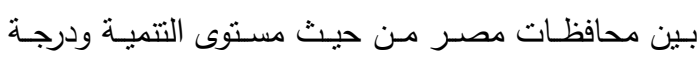

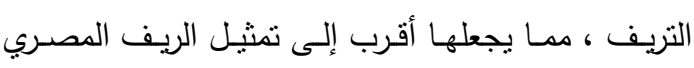

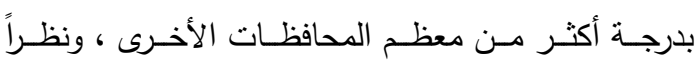
لصعوبة إجراء الدراسة على التسعة مراكز فقد رؤى إختيار

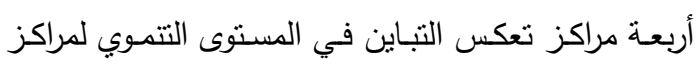

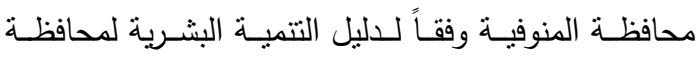

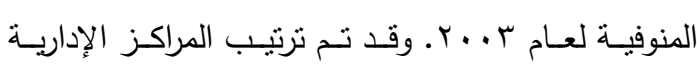

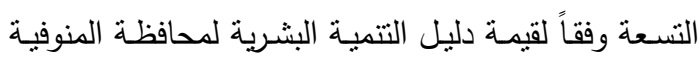

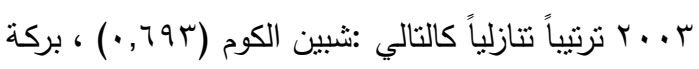

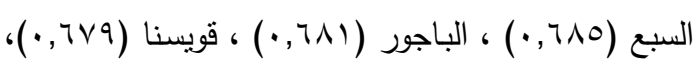

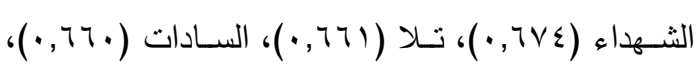

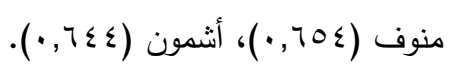

شاملة وعينة الاراسة تم اختبار أعلى مركزين من حيث المسنوى التتـوي

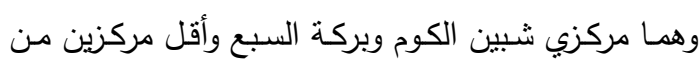
حيث المستوى التتموي وهما منوف وأنثمون. وييلغ عدد وندين

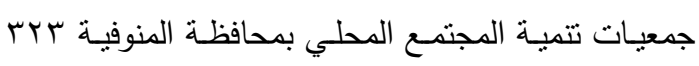

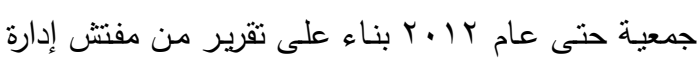

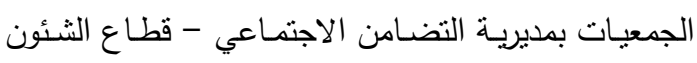

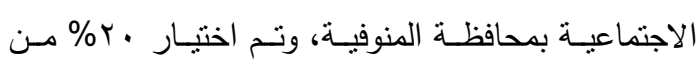
الجمعيات الموجودة في كل مركز من المراكز المختارة

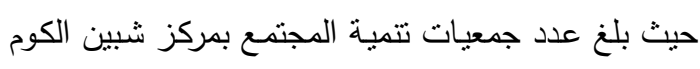

يصعب معه وضعها مجنمعة في فئة واحدة والتعامل

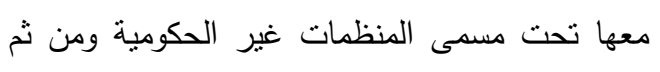
يصعب قياس فعاليتها بنفس الأسلوب وبنفس الطريقة باستخدام نفس المقاييس. ^- عدم النوازن في نوزيع أنشطة وخدمات الجمعيات

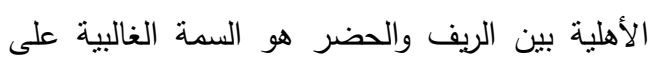
عمل القطاع الثالث فكان لا يزال الحضر مستأثراً

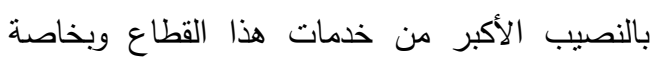
جمعيات الرعاية بينما تعتد الأنشطة الأهلية الريفية

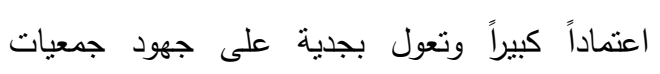
التنمية.

9- استهدفت الدراسات السابقة التعرف على مدى نجاح

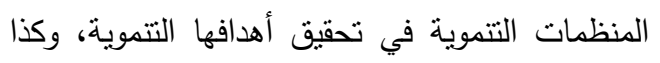
المعوقات التي نواجه تلك المنظمات وتحد من تحقيق الهن أهدافها . أمعوات . - واستخدمت تلك الدراسات عدة مناهج بحثية مثل المنهج الوصفى التحليلي، واعتمدت هذه الدراسات

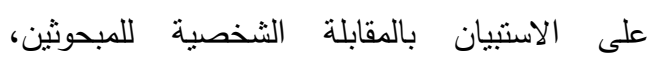

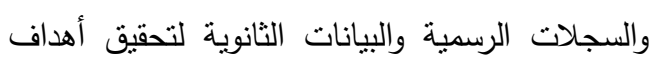

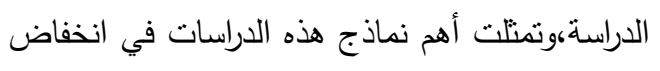

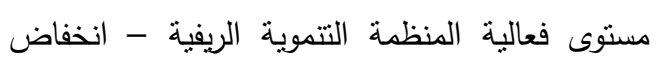
درجة الرضا لدى المستقيدين من أداء تلك المنظمات. 11 أوضحت النتائج وجود علاقة ارتباطية بين المتغيرات

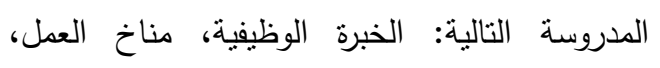

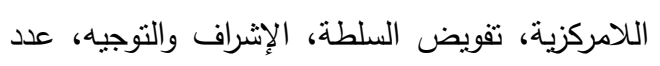

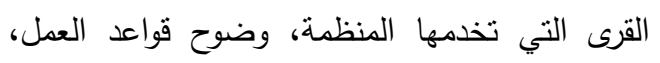

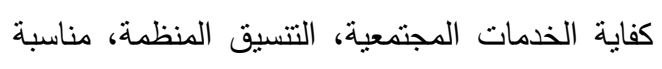

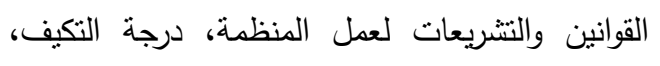

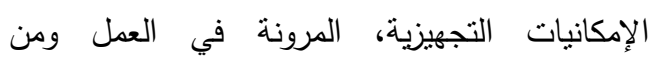

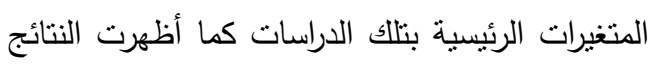

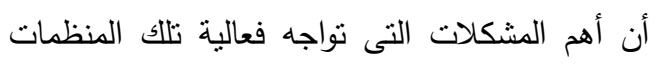

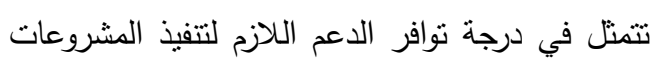

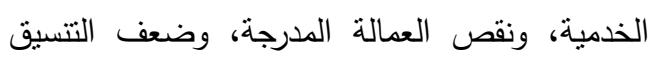

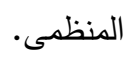




\section{جمعيات تنمية المجتمع المحلي}

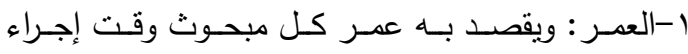

الدراسة، وتم قياسه بسؤال المبحوث مباشرة عن عمره

وقت إجراء الدقابلة لأقرب سنة ميلادية.

r- الحالة التعليمية للمبحوث: ويقصد بها مستوى تعليم

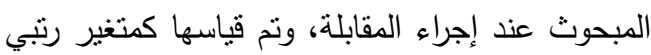

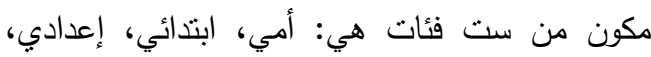

ثانوي، جامعي، فوق جامعي وأعطيت الدرجات من إني،

$$
\text { إلى } 1 \text { على التزتيب. }
$$

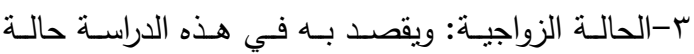

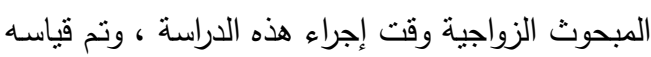

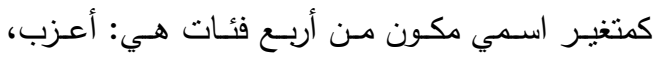

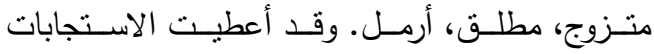
الدرجات من ا إلى ؛ على الترتيب.

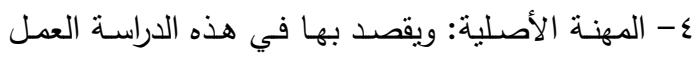

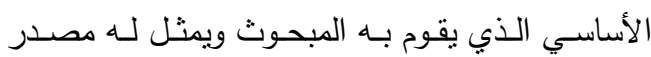

الدخل الأساسي، وتم قياسه بسؤال المبحوث عن مهنته

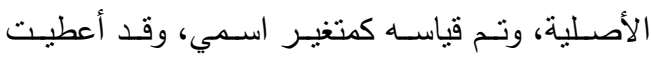

الاستجابات الدرجات التالية مزارع = ال، مزارع ومهنة

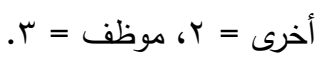

ه- مساحة الحيازة الزراعية بالقيراط : ويقصد بها مساحة الأراضي التي يقوم المبحوث باستغلالها في الأنثطة

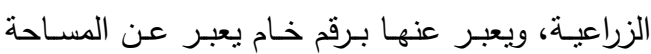

$$
\text { بالقيراط . }
$$

ז-عدد أفراد الأسرة: ويقصد به عدد أفراد أسرة المبحوث الذين يقيمون معهه في نفس المسكن ويعبر عنه برقم مطلق. V-الدخل الثهري: ويعبر عنه بقيمة الدخل الثهري لكل مبحوث مقدراً بالجنية المصري.

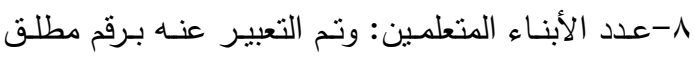

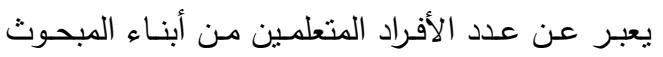
المستقيد من أنشطة جمعية تتمية المجتمع المحلي.

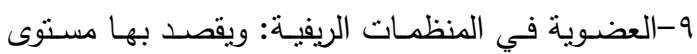

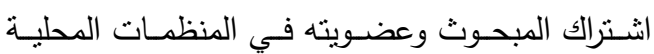
الريفيـة، وتــــــــاس هـذا المتغيـر مـن خـلال سـؤال

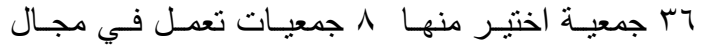
التتمية الريفية، و بلغ عدد جمعيات تتمية المجتمع بمركز

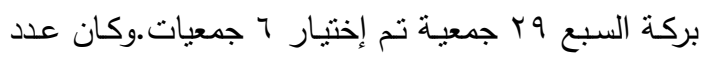

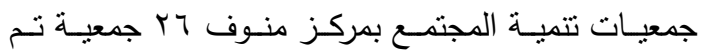

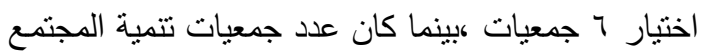

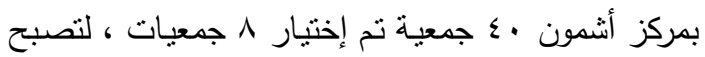

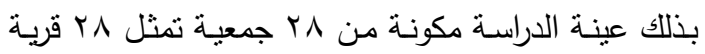

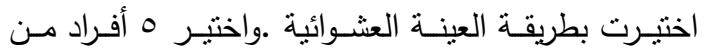
أعضـاء مجلس إدارة كل جمعية بطريقة عشوائية ليكون

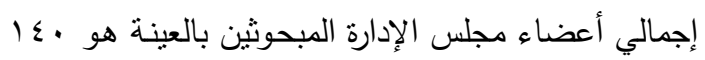

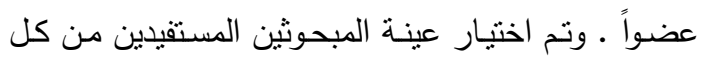

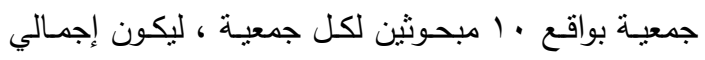

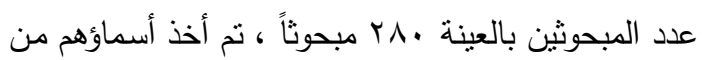

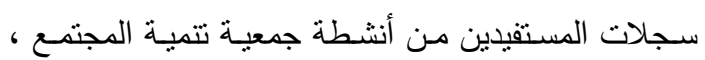

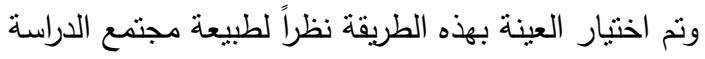
وطبيعة المعلومات المتاحة عنه. تم إعداد استمارتي استبيان لجمع بيانات هذا البحث الأولي للمبحوثين المستفيدين من أنثطة جمعيات تتميـة

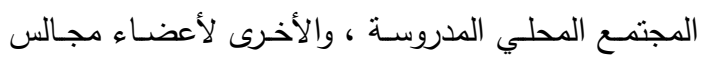

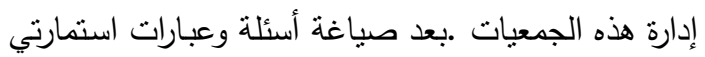
pretest الاستبيان بدقة تم عمل اختبار مبدئي

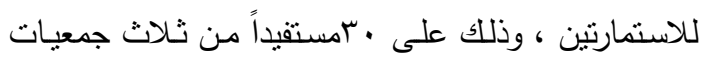

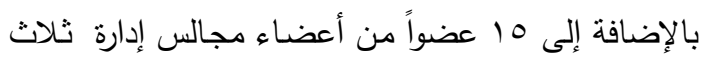

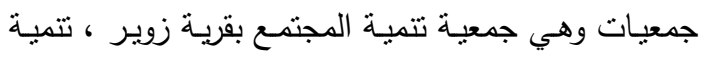

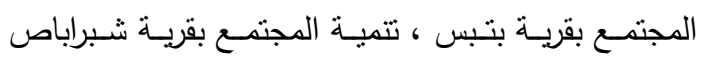
وجميعها تابعة لمركز شبين الكوم بمحافظة المنوفية ، وفي بني ضوء نتيجة هذا الاختبار نم تعديل صياغة بعض العبارات

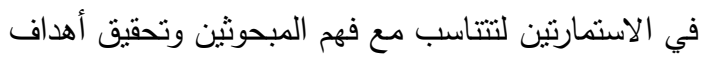

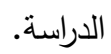

جمعت البيانـات اللازمـة للاراسـة ميدانياً خـلال ثثلاثة

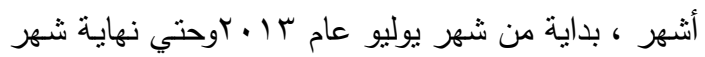

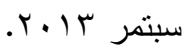

تعريف وقياس متغيرات الدراسة أولا : فيمسا يتعلق بـالمبحوثين المستفيدين مسن أنثـطة 
عـن درجــة تعـرض المبحـوث لمصــادر المعلومــات

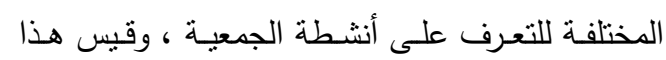
المتغير بسؤال المبحوث عن المصدر الذي يعرف من

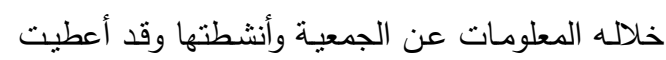

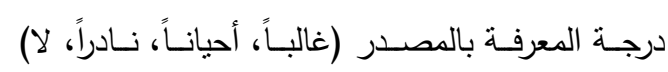

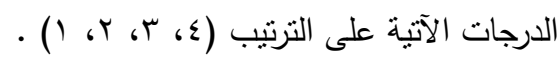

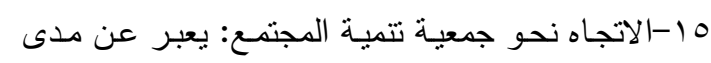

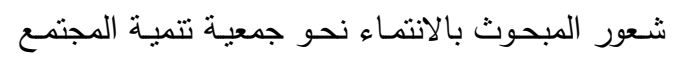
التي توجد في القرية التي يعيش فيها ، واستخدم لقياس

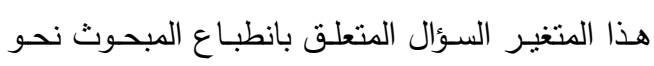

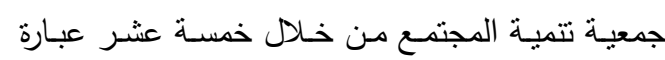
وأخذت الاستجابات ( موافق ، سبان ، غير موافق )

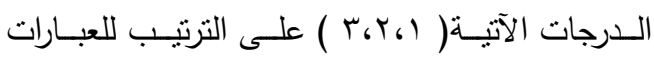

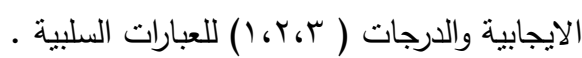
7 - 17

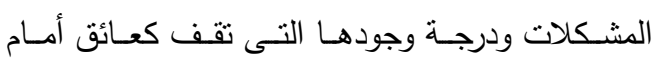

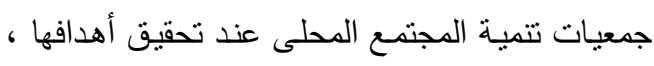
وتم قياس هذا المتغير بسؤال المبحوث عن مجموعة

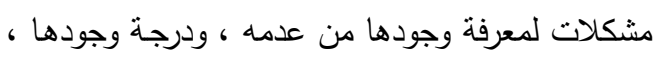
وما هو مقترح التغلب عليها حيث أخذت الاستجابات الدرجات التالية:موجودة (Y)،غير موجـودة( ( ).ودرجـة وجـود المشـكلة أخذت الاسـتجابات الـدرجات التاليـة:

$$
\text { كبيرة (Y)، متوسطة (Y)، ضعيفة (I) . }
$$

\section{تعريف وقياس مفهوم الفعالية المنظمية من وجهة}

نظر المستفيدين، نظرت هذه الدراسة إلى مفهوم الفعالية

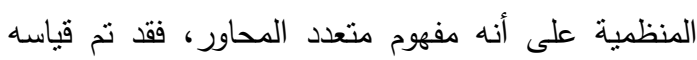

$$
\text { بمقياس مركب يتكون من أربعة أبعاد رئيسية : }
$$

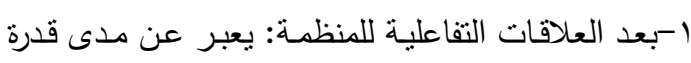

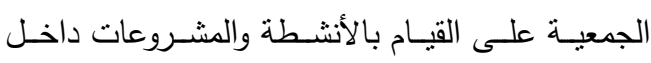

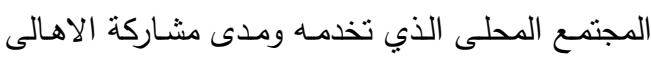
في هذه الأنشطة والمشروعات ، وتم قياس هذا المتغير عن طريق سؤال المبحوث مباشرة عن ما هي الأنشطة

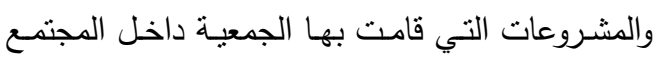

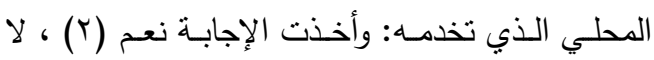

المبحوث عن نوع عضويته في ثمانية منظمات ريفية، وذللك على مقياس مكون من أربعـة استجابات (غير

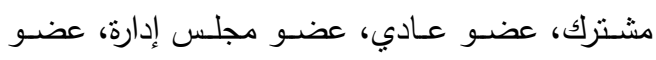

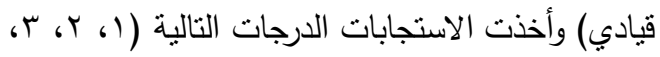
ع) على الترتيب.ثم سؤال المبحوث عن درجة حضوره

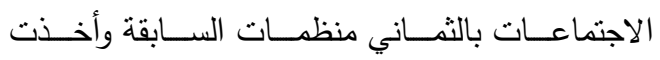
الاستجابات الدرجات التالية على التزتيب (كثيراً =ع،

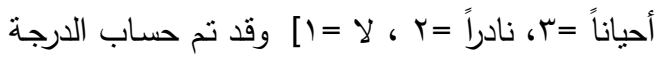
الكلية لتعبر عن عضوية المنظمات الريفية. • ا- الانفتاح الجغرافي: ويقصد بـه مدى تردد المبحوث على قرى ومراكز المحافظة والسفر للمحافظات داخل الجمهوربة وخارجها وذلك على مقياس مكون من خمس ومرجس مسـتويات (يوميـاً، أسـبوعياً، شـهرياً، سـنويا، لا أترددد]

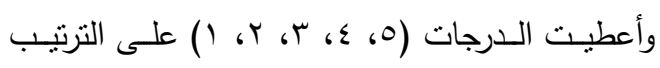
وأيضـاً تم سؤال المبحوث عن اسم المدينة التي يتردد عليها وتم قيـاس ذلك على مقيـاس مكسون من أربعـة مستوبات (عاصمة المركز ، عاصمة المحافظة، مدن أخرى، عاصمة الجمهورية) وأعطيث الدرجات ( (، ؟، r، ؛ ) على الترتيب وقد تم حساب الدرجة الكلية لتعبر عن درجة الانفتاح الجغرافي.

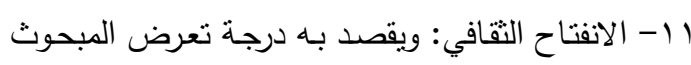

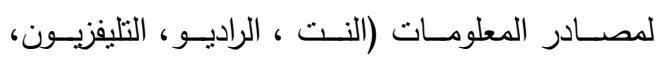
الجرائد) وذلك على مقياس مكون من أربع مستويات

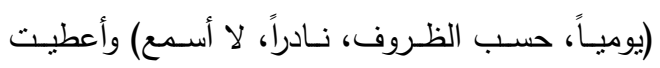

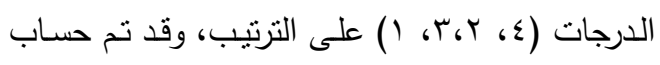

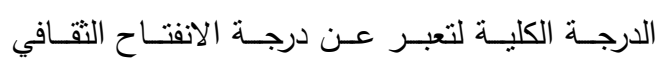

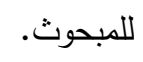

rا-مـدة التعرف على الجمعيـة : وتم قياسـه عن طريـق

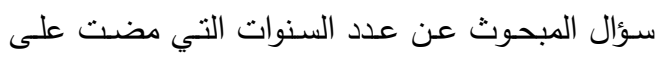
معرفـة المبحوث بالجمعيـة وأنشـطتها وتم قياسـه كرقم مطلق بالسنوات. با -فترة التعامل مـع الجمعيـة:وتم قياسـهـ بسؤال المبحوث بالث من عدد السـوات التي تعامـل فيهـا مـع الجمعيـة وتم قياسه كرقم مطلق بالسنين.

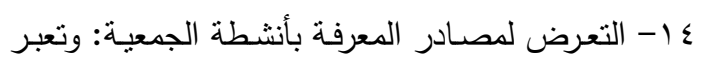


حصـل عليهـا المبحـوث عنـــ إجـراء المقابلـة ، وتــم

تقسيمها إلى أربع فئات هي مؤهل أقل من منتوسط ،

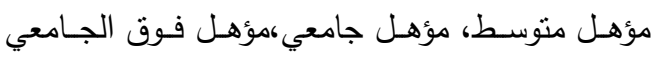

وأعطيت الدرجات من ا إلى ع على الترتيب.

r- الحالة الاجتماعية: ويقصد بها في هذه الدراسـة حالة

المبحـوث الزواجيـة وقت إجـراء الدراســة ، وتم قياســـ

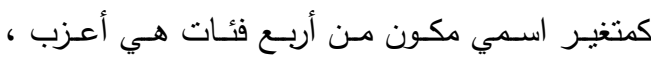

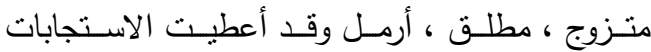

$$
\text { الدرجات من ا إلى ع على الترتيب. }
$$

ع- عدد أفراد الأسرة: ويقصد به عدد أفراد المبحوث الذين

يقيمون معه في نفس المسكن ويعبر عنه برقم مطلق.

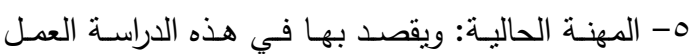
الأساسـي الذي يقوم بـه المبحسوث ويمثنل لـه مصسدر

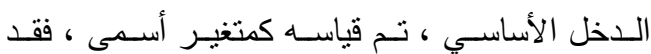

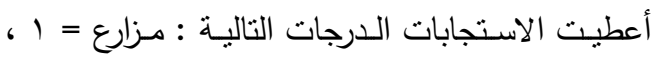

$$
\text { مزارع ومهنة أخرى= r r ، موظف }
$$

7- الاخل الشهري: وعبر عنها بقيمة الدخل الثـهري لكل

$$
\text { عضو مقدراً بالجنيه المصري. }
$$

- خبـرة عضـو مجلس إدارة الجمعيـة بالعمـل التطـوعي بالجمعيـة: تعبـر عـن الفتـرة الزمنيـة التـي قضــــاها المبحـوث كعضــو مجلـس إدارة فـي جمعيـة تتميـة المجتمـع، والفتـرة الزمنيــة التـي قضــــاها فـي العمـلـ التطوعي ، وتم قياسـه عن طريق سؤال المبحوث عن

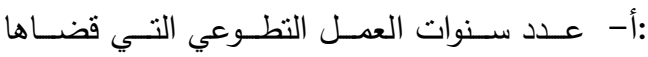
بالجمعية وتم التعبير عنه برقم مطلق يدل على عدد سنوات الخبرة.ب- سؤال المبحوث عن تاريخ انضمامه لمجلس إدارة الجمعيـة ويقصد بها عدد السنوات التي قضــاها المبحـوث فـي العمـل كعضـــ بمجلـس إدارة الجمعية ويعبر عنها برقم مطلق يدل على عدد سنوات

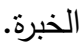
ᄉ- عضوية المبحوث في منظمات أهلية أخرى: ويقصد بها مستوى اشتراك المبحوث وعضويته في المنظمات المحليـة الريفيـة الأهليـة الأخـرى ، وتـم قياسـه بسؤال المبحوث عن مـا إذا كان قد اشترك في عضدية أي لي منظمة أو جمعية أهلية أخرى أو حزب سياسي وأخذت
(1) على الترتيبب. إذا كانت الإجابـة بـنعم يتتم سؤال المبحوث عن درجـة المشـاركة وأخذت فئات الإجابـة

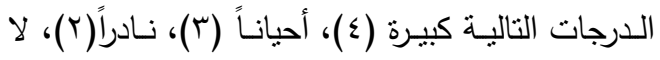

r- درجة تأثير أنشطة الجمعية داخل المجتمع: تعبر عن

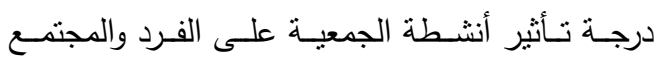
المحلى الذى توجد في نطاقه ، وتم قياس هذا المتغير بسؤال المبحوث عن درجة تأثثر أنشطة الجمعيـة على ونى الفرد من خلال • اعبارات ، وتأثنرها على المجتمع من خلال سبعة (V) عبارات وأخذت الاستجابات الدرجات التالية: كبيرة (ع)، منوسطة (ب)، ضعيفة (Y)، منعدمة

r- استفادة المبحوثين من أنشطة جمعيات ثتمية المجتمع المحلي: تعبر عن نوع استفادة المبحوثين من الأنشطة

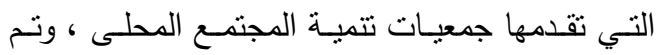
قياســه بسـؤال المبحـوث عـن مـا إذا كـان بيـتقفيد مـن الأنشـة التـي تقدمها الجمعيـة، وأخذت الاسـتجابات الارجات التالية: نعم (ץ)، لا ( () واذا كانت الإجابة بـ الإبـ (لا) يـتم سـؤال المبحـوث عـن مـا هـي أسـباب عـدم الاستفادة .

ع- درجة رضا المبحوثين عن الأنشطة والمشروعات التي تقدمها الجمعية داخل المجتمع المحلى ، وتم قياس هذا المتغير بسؤال المبحوث عن درجة رضاه عن الأنشطة والمشـروعات التـي تقدمها الجمعيـة داخـل المجتــع. وأخـذت الاسـتجابات الــدرجات التاليـة: راضـي (ب)، راضي لحد ما (Y)، غير راضي (l).

ثانيا : فيما يتعلق بأعضاء مجالس إدارة جمعيات تنمية

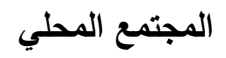

المتغيرات المستقلة

1- العمـر : وتم التعبير عنه برقم مطلق يعبر عن عمر كل عضو. تم قياسـه بسؤال المبحوث عن عمره وقت إجراء المقابلة لأقرب سنة ميلادية وتم التعبير عنه كرقم

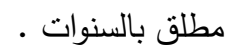

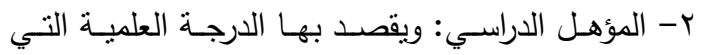


منذ تاريخ إثـهارها وحتي وقت إجراء الدراسـة، ويعبر عنه برقم مطلق.

1) - الإمكانيات البشرية: يقصد بـه التركيز على الأفراد

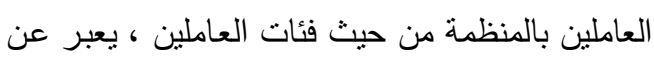
مقدار قوة العمل الفعلية في الجمعية وقد تم قياسـه:أإجمالي عدد الفنيين ، عدد الإداريين ، وعدد الكتبة ، وعدد العمال وتم التعبير عن الإمكانيات البشرية برقم مطلق.ب- كفاية الإمكانيات البشرية المتاحة للمنظمة: ويقصـد بـه تـوافر العـاملين في فئسات العهـل المختلفـة بالجمعيـة ، وتم قياس هذا المتغير من خلال استيفاء

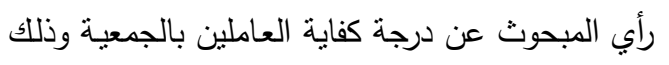

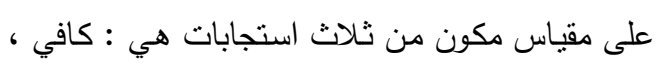

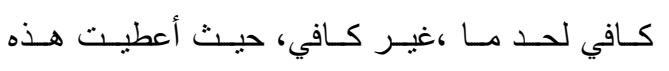
الاستجابات الدرجات (T، r، I ) على الترتيب.

r ا - الإمكانيات المكانية: يقصد بـه كل مـا يتعلق بمبنى

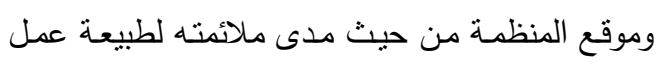

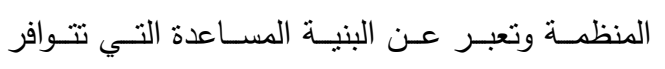
بالجمعية والتي تخدم في المقام الأول العامل والعاملين بها وهو متغير مركب تم قياسـه بسؤال المبحوث عن خمسة بنود رئيسية تخص مبنى الجمعية وهي:أ- وجود

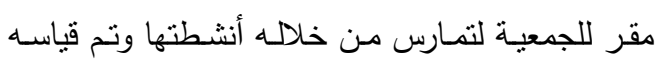
بسؤال المبحوث عن مـا إذا كـان هنـاك مقر للجمعيـة

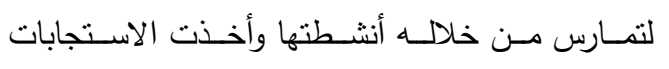

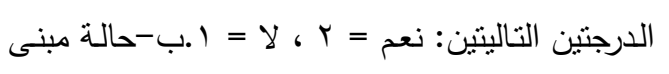

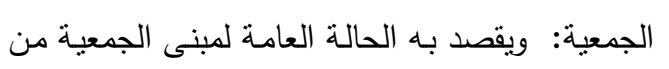
وجهة نظر المبحوثين من أعضاء مجلس الإدارة وذلك على مقياس مكون من ثناث استجابات هي (جيدة ، منوسـة ، رديئة ) حيـث أعطيـت هـذه الاسـتجابات

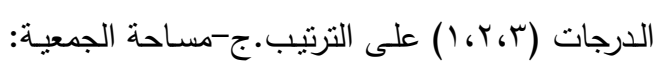
وتم التعبير عنـه برقم مطلق يعبر عن مسـاحة مبنى

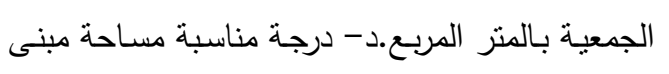

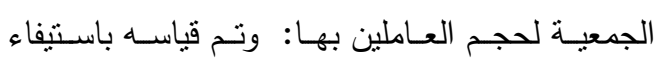
المبحـوث عـن درجـة مناسـبة مسـاحة مبنـى الجمعيـة لحجم العاملين بها وأخذت الاستجابات الدرجات التالية
الاستجابات الدرجات التالية نعم =r ، لا= الا وفي حالة الاستجابة بنعم تم سؤال المبحوث عن :عدد المنظمات التي يشترك المبحوث في عضويتها وتم التعبير عنها برقم مطلق يدل على عدد المنظمات التي يشارك فيها

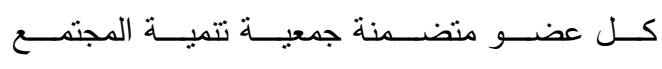
المحلي.وعـدد سـنوات العضــية : ويعبـر عنهـا بـرقم مطلـق بـدل على عـدد سـنوات عضـوية كـل عضــو

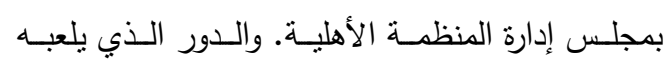
المبحـوث : ويعبـر عنـه بسـؤال المبحـوث عـن طبيعـة الدور الذي يقوم بـه كعضو في مجلس إدارة المنظمـة

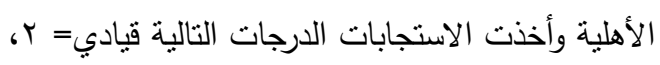

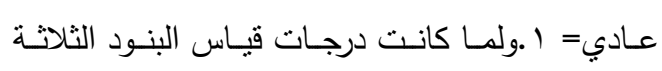
السـابقة مختلفة في وحدات قياسـها فقد تم معايرتها ثم جمعت لتكون في مجملها متغير عضوية المبحوث في وني المنظمات الأهلية بمتوسط حسابي مقداره ( •. ) درجة وانحراف معياري مقداره ( • () درجات لتكوين مستويات أو فئسات وصـفية وذلـك باســتخدام المعادلــة الآتيــة: $. T=10 z+50$

9- الاستفادة من الدورات التدربيية: يقصد بها في هذه الدراسة حضور عضو مجلس الإدارة الدورات التدربيية في مجال عمل الجمعيات الأهلية من قبل وحتى وقت التصل إجراء الدراسة ، تم قياسها عن طريق سؤال المبحوث : أ- مـا قد كان حصـل على دورات تدريبيـة في مجال عمـل الجمعيـة وأخـت الاسـتجابات الـرجات التاليـة:

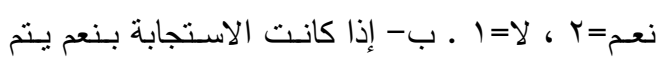
سؤال المبحوث عن درجـة اسـتفادته مـن هذه الدورات

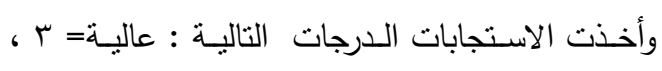
متوسطة= ب ، ضـعيفة =ا . ج- درجـة كفايسة الدورات

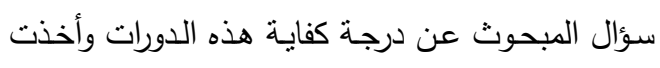

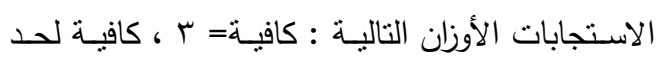

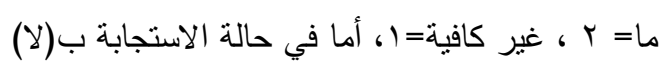

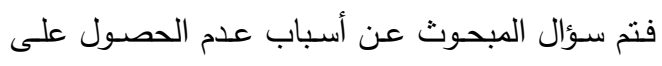
دورات

• 1 - عمر الجمعية: يقصد بـه عدد سنوات عمل المنظمة 
المبحوث عن:أ- حجم رأس مال الجمعية الحالي من

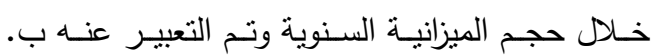
مطلـق بالجنيـة المصـري .ب- درجـة كفايــة ميزانيـة الجمعية : لتحقيق أهداف الجمعيـة ويقصد بها درجـة

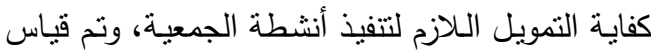
هذا المتغير من خـلال سؤال المبحوثين من أعضلـاء

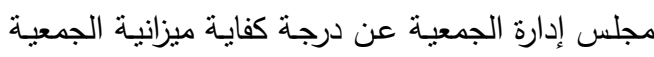

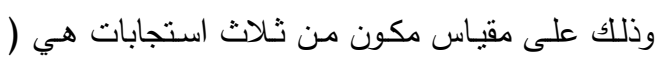

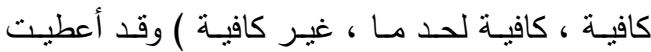

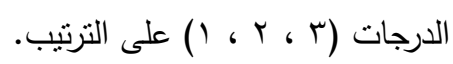

10- الإمكانيـات الإداريـة والسلوك التتظيـي: تعبر عن

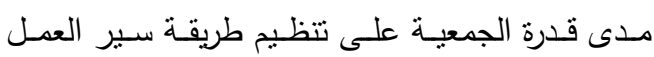
بداخلها ودرجة تقييم جوانب جمعيات تتمية المجتمعات المختلفة ، وتم قياس هذا المتغير بسؤال المبحوث عن جن الإمكانيات الإدارية والسلوك التتظيمي وعن درجة تقييم جوانـب جمعيـات تتميـة المجتمعـات المختلفـة التاليـة،

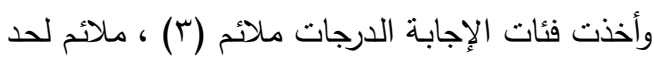

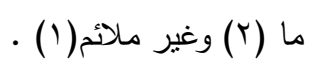

17 - بعد العلاقات التفاعلية للمنظمـة : وتم قياس هذا

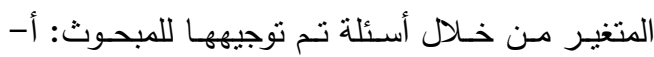
بختص بسؤال المبحوث هل هناك اشتراكات للعضوية

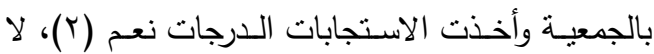

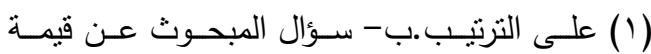
الاثـتراك السـوي لكل عضــو وتـم التعبيـر عنـهـ بـرقم مطلق يعبر عن قيمـة الاشتراك السنوي لكل عضدو.

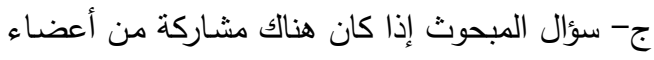
الجمعية في الأنشطة التي تقوم بها الجمعيـة ( توجد الجداك

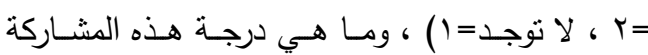

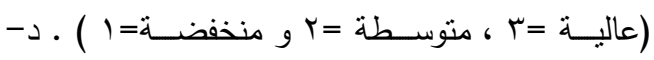

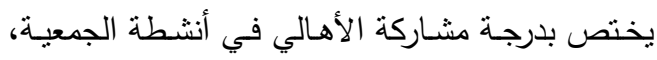

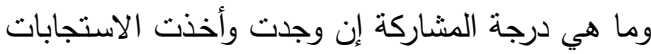

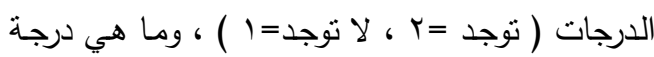

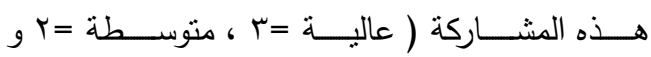
منخفضة= ( ) مده المنا
مناسـب =r ، مناسـب لحد مـا = r ، غيـر مناسـب

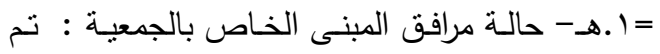

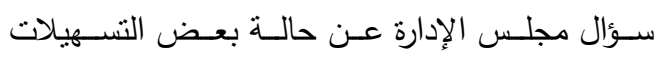
والتجهيزات في مبنى الجمعية كالآتي:أ ) حالة الكهرباء

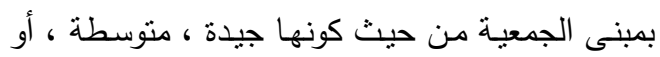

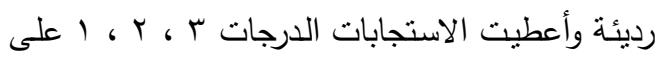

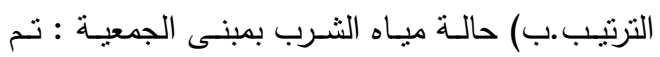
توجيه سؤال لعضو مجلس إدارة الجمعية عن حالة مياه

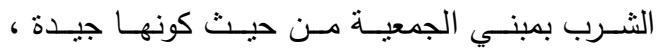

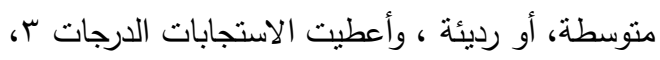

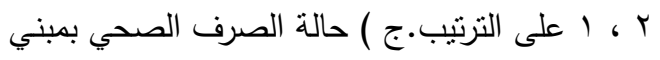

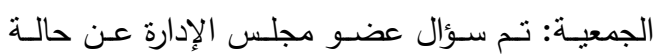
الصرف الصحي بمبنى الجمعية من حيث كونها جيدة

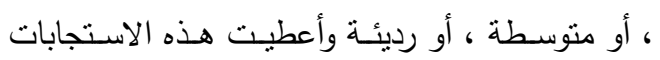

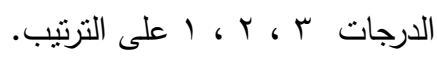

rا- الإمكانيـات التجهيزيـة :بقصد بها كافـة التجهيزات

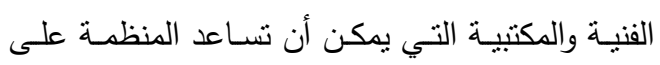

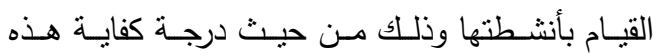

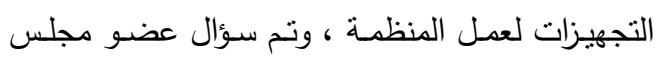
الإدارة عن مدى مناسبة هذه النسهيلات والتجهيزات في

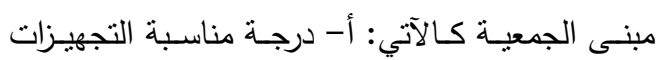

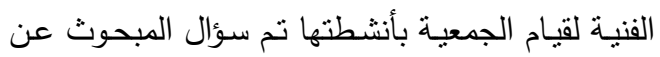

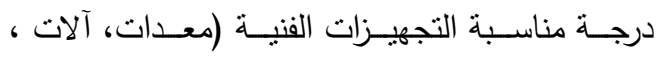

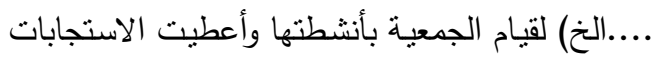

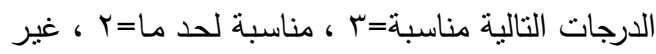
مناسبة=ا .ب- درجة مناسبة التجهيزات المكتبية لقيام الجمعية بأنشطتها تم سؤال المبحوث عن درجة مناسبة دئة

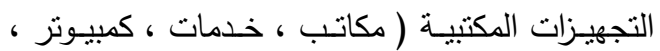

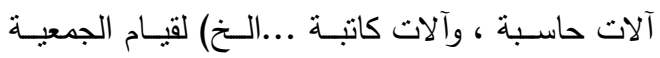

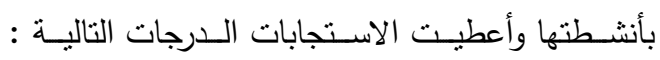
مناسبة=r ، مناسبة لحد ما =r ، غير مناسبة =1. ع ا- الإمكانيات المالية :يقصد بها كل ما ينعلق بالموارد المالية للمنظمة ومدى كفاية هذه الموارد لقيام المنظمة بأنشطنها على أكمل وجه ونم قياس هذا المتغير بسؤال 
مدى قيام جمعية تتمية المجتمع المحلي بتحقيق أهدافها، والتتسيق المنظمى، والصيانة والصحة التنظيمية، والقدرة على التكيف.

1- بعد تحقيق الأهداف (مدى قيام جمعية تتمية المجتمع

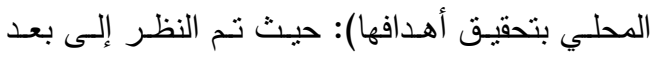
تحقيق الأهداف على أنه ذو عدة بنود رئيسية ، والتي تسعى معظم جمعيات العينة إلى محاولة تحقيقها كان

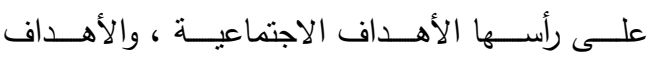

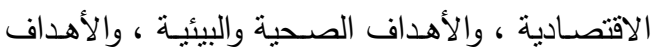

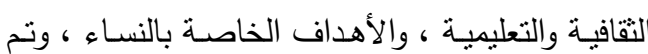
قياس هذا المتغير بسؤال المبحوث عن درجة تحقيق هذه الأهداف داخل الجمعيـة من خـلال خمسـة بنود

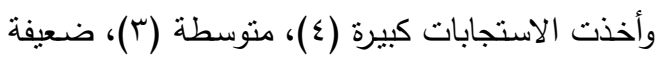

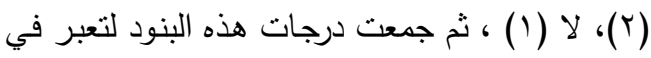
مجملها عن هذا البعد.

r- التنسيق المنظمي: ويقصد بـه درجـة المحافظـة على العى العلاقات الموجبـة بين الجمعيات والاتحادات النوعيـة

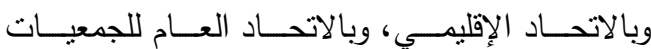

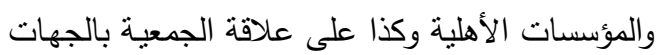

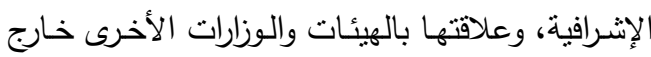

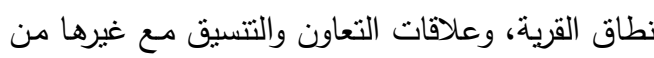
الجمعيـات الأهليـة الأخـرى بنطـاق القريـة، وعلاقتهـا

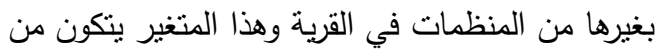

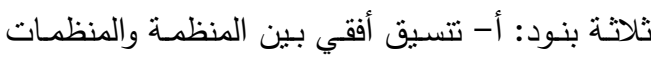

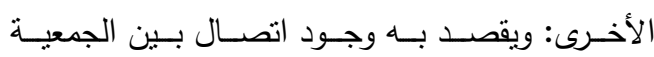

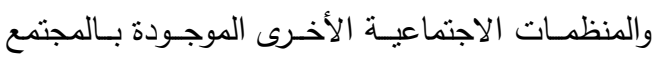
المحلي للجمعية. ب- تنسيق أفقي عبر القرى: ويقصد به وجود اتصال بين جمعية تتمية المجتمع وبين غيرها

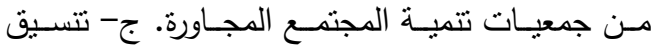
رأسي: ويقصد به وجود اتصال بين الجمعية والجهات الإثـرافية والرقابيـة والتي تخضـع الجمعيات لإثـرافها

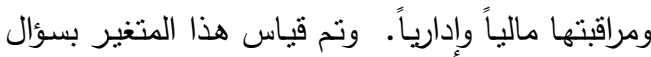

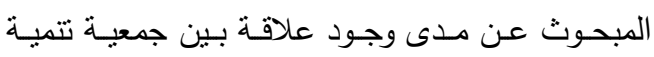

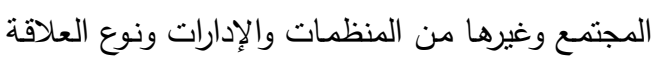

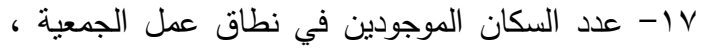
وتم التعبير عنه برقم مطلق يعبر عن عدد السكان الذين يمكن أن تقدم لهم خدمات من قبل جمعية تنمية

$$
\text { المجتمع الموجودة في القرية نفسها. }
$$

11- الدافعية للإنجاز : تم قياس هذا المتغير من خـلال

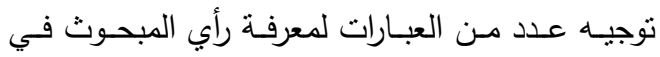

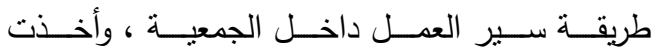
الاستجابات( موافق ، سيان ، غير موافق) الدرجات

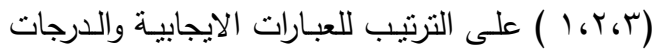

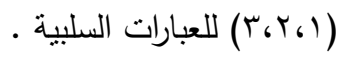

9 1- قدرة الجمعيـة على تلبيـة احتياجـات المجتمع، تعبر عن قدرة الجمعية على تقديم الخدمات المختلفة لنوعية

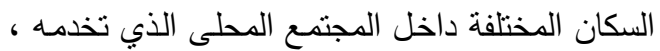
وتم قياس هذا المتغير من خلال سؤالين تم توجيههما للمبحوث:أ - يختص بنوعيـة السكان الذين تقدم لهم فئن الجمعيـة خـماتها وذلك على مقيـاس مكسون مـن 1

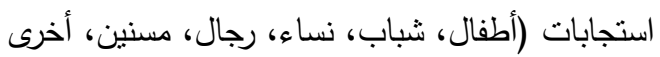
تذكر) وأعطيت درجة عند نقديم الخدمات لكل فئة على الترتيب حيث يعبر عن كل فئة بواحد صحيح وتحسب الاستجابة الكلية للمتغير من خلال عدد الفئات الذين

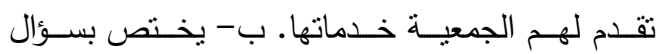
المبحـوث عـن قدرة الجمعيـة على تلبيـة احتياجـات

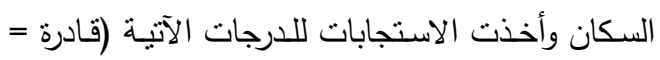
r، قادرة لحد ما = r، غير قادرة = (1) على الترتيب. •Y- درجـة رضـا الاهـالى عـن الأنشـطة التـي تقـدمها

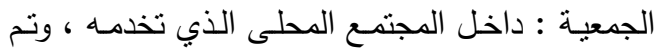

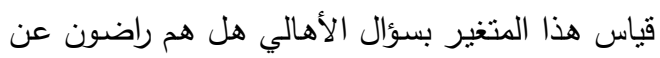
نشـاط الجمعيـة وأخــت الاسـتجابات الــرجات الآتيـة

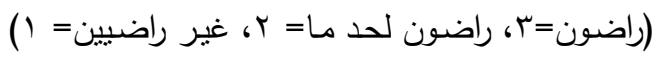
على الترنيب.

\section{تعريف وقياس مفهوم الفعالية المنظمية من وجهة} نظر أعضاء مجالس إدارة، نظرت هذه الدراسة إلى مفهوم الفعالية المنظمية على أنه مفهوم متعدد المحاور ، فقد تم

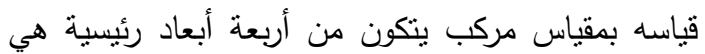


وحدات قياسها وقد استخدمت المعادلة الآتية في حساب T الدرجات التائية :50

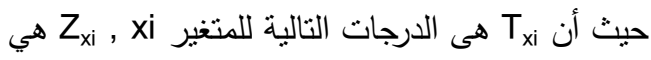
الــرجات المعياريـة المحسوبة للمتغيـر xi وفقــا للمعادلـة الآتية :

xi , xi مفردات المتغير xi حيث $Z_{* i}=x i$ - xi/si المتوسط xi المتوسط الحسابي si هي الانحراف المعياري (عـلام ، 910 ( ).كمـا استخدم معامـل الارتبـاط البسيط و تحليل الانحدار الخطى المتعدد التدرجي الصـاعد بطريقة Step-wise للتعرف على أهم محددات "فعالية جمعيات تتميـة المجتمـع الريفي المعنويـة"، والوقوف على الأهميـة النسبية لكل من هذه المحددات و ما يشرحه كل متغير من المتغيرات المستقلة المعنويـة في شـرح التباين المفسر في المتغير التابع وفى محاوره المتعددة ، كما استخدم معامل ثبات كرونباخ (ألفا) Reliability Coefficient لتقدير

مدى اتساق المكونات الداخلية للمتغيرات المركبة.

\section{وصف عينة البحث}

أولا : وصـف المتغيـرات المسـتقلة الخاصـة بـالمبحوثين المستفيدين من أنشطة جمعيات تتمية المجتمع :

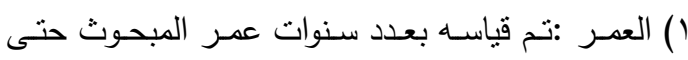
تاربخ جمع البيانـات لأقرب سنة ميلاديـة ، وقد بلغت

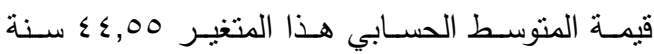
والانحراف المعياري 99 1, • 1 سنة والمدى عه سنة ، وبتوزيع المبحوثين وفقا لفئات العمر جدول ( أن Vr\% من المبحوثين في الفئة العمرية الأولى وبلغ

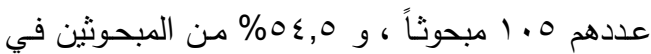

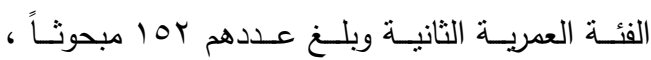
\%^, o

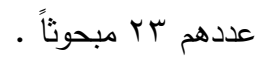

r) النوع : توضح النتائج الواردة جدول (1) أن أكثر من

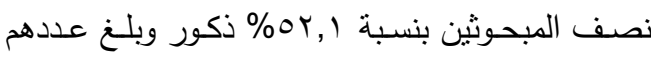

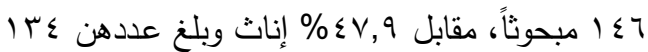

وأخذت فئات الاسـتجابات الدرجات ( توجد =r ، لا

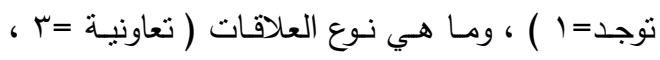

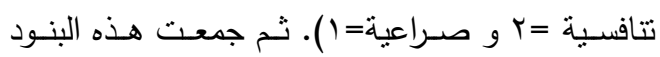
لتعبر في مجملها عن هذا البعد.

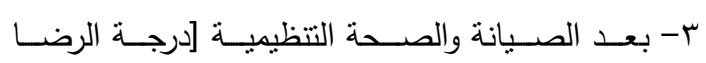
الــوظيفي] : ويقصــــــالصـيانة والصــــة التتظيميــة المحافظـة على كيان المنظمـة، والقدرة على مراجعـة مشـاكل العـاملين فيها والتغلب عليهـا، حيـث تضــن درجة رضـا العاملين عن أعمالهم واستمتاعهم بالعمل،

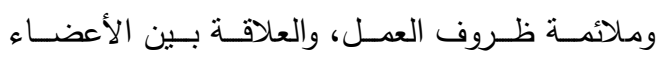
العاملين وبعضـهم البعض وبينهم وبين إدارة المنظمـة. وتم قياس هذا المتغير من خلال الإجابة على السؤال المتعلق بقياس بعد الصيانة والصحة التتظيمية والتي تتضـمن سـتة عثـر عبـارة وهـي تقبس درجـة اتجـاه المبحوث نحو ثلاثـة بنود تتعلق بالاستمتاع بالعملـ، ملأئمة ظروف العمل، العلاقة بين الأعضـاء العاملين

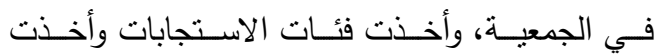
الاستجابات ( موافق ، سيان ، غير موافق ) الدرجات

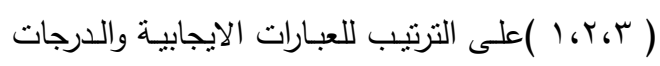

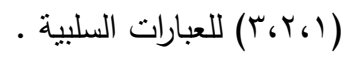

ع- بعد التكيف- درجة التتظيم الداخلي للجمعية: يعبر عـن مـدى قـدرة الجمعيـة على الاسـتجابة للتغيـرات الداخليـة والخارجيـة سـواء كان ذلك في محيط القربـة التي تعمل في نطاقها، أو على الصـعيد الوطني أو الدولي، ولقياس محور التكيف فقد نظر إليه على أنه يتركب من 10 عبارة تم توجيهها إلى المبحوث وأخذت

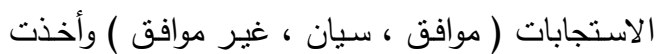

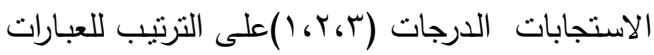

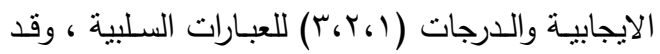
جمعت خمسة عشرة بنود لتكون في مجملها هذا البعد.

\section{الأساليب الإحصائية}

تم الاستعانة بعدة أساليب إحصائية لتحليل بيانات هذه الدراسة ، مثل الاستعانة بالمتوسط الحسابي والانحراف المعياري والنسبة المئوية والتكرارات لوصف المتغيرات في 


\section{Keneber and Shahen}

جدول (1): توزيع أفراد العينة البحثية ( المستفيدين من أنثطة جمعيات تتمية المجتمع ) وفقاً لمتغيرات الدراسة .

\begin{tabular}{|c|c|c|c|c|c|}
\hline المئوية & 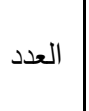 & 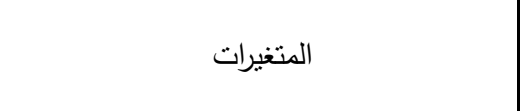 & المئوية & 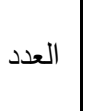 & 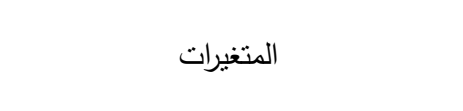 \\
\hline & & | V- عد أفراد الأسرة & & & 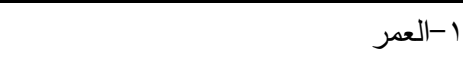 \\
\hline$\% 0, v$ & 17 & | أسرة صغيرة ( 1 ـ ب فرد) & $\% r v$ & 1.0 & لفئة العمرية الأولى : (Tr سنة-. ك سنة) \\
\hline$\% \tau r, r$ & $|\mathrm{M}|$ & | أسرة متوسطة (ع ـ ؟ فرد) & $\% 0 \leqslant, 0$ & $10 \%$ & الفئة العمرية الثانية: (إع سنة-Nه سنة) \\
\hline$\% r Y, 1$ & $v_{7}$ & أسرة كبيرة (v ـ 9 فرد) & $\% \wedge, 0$ & $r T$ & لفئة العمرية الثالثة: (هo سنة- VVV سنة) \\
\hline \multirow[t]{2}{*}{$\% 1 .}$. & rA. & 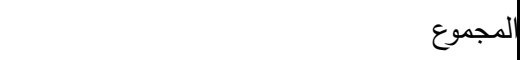 & $\% 1 \ldots$ & rA. & 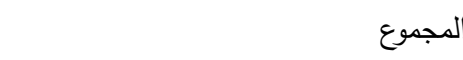 \\
\hline & & | ل إ- الدخل الثهري & \multicolumn{3}{|r|}{ ب - r-النوع } \\
\hline$\% \wedge r$ & rt. & ئئة الدخل المنخفض(صفر - 999 ( جنية) & $\% \circ r, 1$ & $1 \leqslant 7$ & 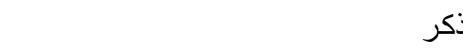 \\
\hline$\% 17$ & $\varepsilon \varepsilon$ & ئئة الدخل المتوسط( ... & $\% \leqslant \vee, q$ & $1 \pi \varepsilon$ & أنظى \\
\hline$\% r$ & 7 & لئئة الدخل المرتفع( . . ع- . . . جنية) & $\% 1 \ldots$ & rA. & 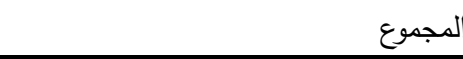 \\
\hline$\% 1 \cdots$ & rی. & | - المجموع & & & \\
\hline \multicolumn{6}{|r|}{ r- الحالة التعليمية للمبحوث } \\
\hline$\% \leqslant q, r$ & $1 \mathrm{k}$ & عدد أبناء متعلمين منخفض ( . . r, r) & $\% 10, v$ & $\leq \varepsilon$ & أمى \\
\hline$\% \leqslant r, r$ & $|r|$ & عدد أبناء متعلمين منوسط (r, r ـ 0,0) & $\% \wedge, q$ & ro & 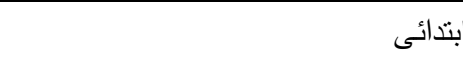 \\
\hline$\% \vee, ०$ & r) & 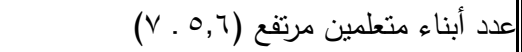 & $\% \bullet, V$ & 17 & 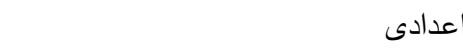 \\
\hline \multirow[t]{5}{*}{$\% 1 .}$. & rs. & 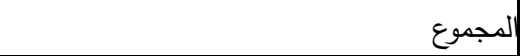 & $\% \leqslant 1,9$ & $11 \mathrm{~V}$ & انّانوى \\
\hline & & & $\%$ \%, 1 & $v$ & 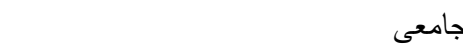 \\
\hline & & & $\% \cdot, \vee$ & $r$ & 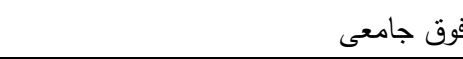 \\
\hline & & & $\% 1 \ldots$ & rA. & المجموع \\
\hline & & | 17 - العضوية في المنظمات الريفية & & & • - الحالة الزواجية \\
\hline$\% q$. & ror & |ررجة عضوية منخفضة (T ا- Tr درجة) & $\% \curlyvee, q$ & $\wedge$ & 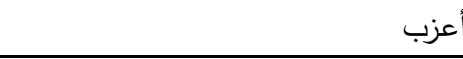 \\
\hline$\% \wedge, r$ & $r T$ & |ررجة عضوية متوسطة (ع ז- آ درجة) & $\% \wedge r, q$ & trt & م متزوج \\
\hline$\% \vee, ०$ & (1) & |رجة عضوية مرتفعة (r - - .؛ درجة) & $\% 1, \varepsilon$ & $\varepsilon$ & 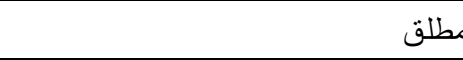 \\
\hline \multirow[t]{2}{*}{$\% 1 \ldots$} & $r \Lambda$. & 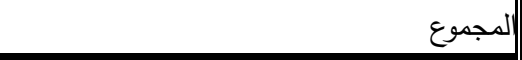 & $\% \backslash r, \wedge$ & r & 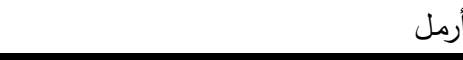 \\
\hline & & & $\% 1 \ldots$ & rی. & 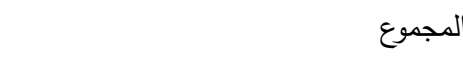 \\
\hline \multicolumn{6}{|r|}{ | } \\
\hline$\%\urcorner 9, r$ & $19 \varepsilon$ & |ر |رجة انفتاح جغرافي منخفضة (1 - Y.V درجة) & $\% r r, r$ & $9 \pi$ & 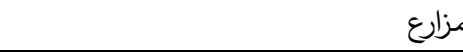 \\
\hline$\% r \leq$ & TV & 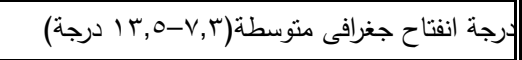 & $\% \wedge, \uparrow$ & $r \varepsilon$ & مزارع ومهنة أخرى \\
\hline$\% \uparrow, \vee$ & 19 & لرجة انفتاح جغرافى عالية(T,Y I - . Y درجة) & $\% \circ \wedge, r$ & 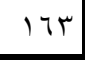 & 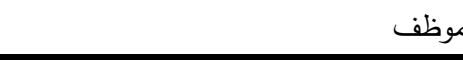 \\
\hline$\% 1 \ldots$ & rA. & 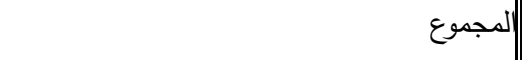 & $\% 1 \ldots$ & rA. & 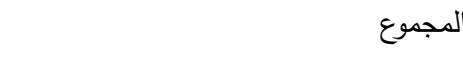 \\
\hline
\end{tabular}


(تابع) جدول ( ) : توزيع أفراد العينة البحثية ( المستفيدين من أنثطة جمعيات تنمية المجتمع ) وفقاً لمتغيرات الدراسة

\begin{tabular}{|c|c|c|c|c|c|}
\hline 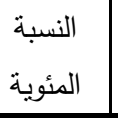 & 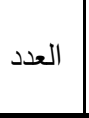 & 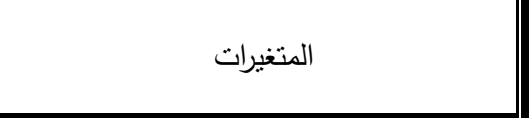 & 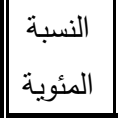 & 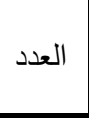 & 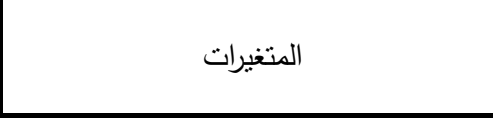 \\
\hline & & |N | - درجة الانفتاح الثقافي & & & r r- الحيازة الزراعية بالقيراط \\
\hline$\% \curlyvee, \wedge$ & 19 & |مستوى منخفض للانفتاح الثقافى (ع - 0.7 درجة) & $\% 99, r$ & rVN & حيازة صغيرة ( 1 ـ דو قيراط) \\
\hline$\% \varepsilon \cdot, v$ & $11 \varepsilon$ & مستوى متوسط للانفتاح الثقافى (1,7 - 1.9 درجة) & $\% \cdot, \varepsilon$ & 1 & 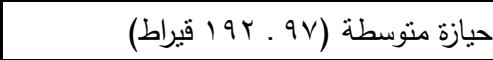 \\
\hline$\% \circ r, 0$ & $1 \leqslant \vee$ & 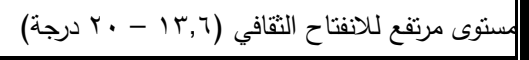 & $\% \cdot, \varepsilon$ & 1 & 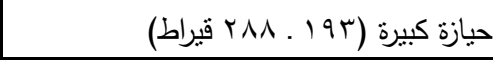 \\
\hline \multirow[t]{2}{*}{$\% 1 \ldots$} & rA. & 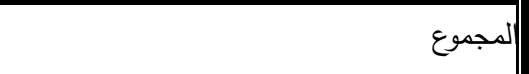 & $\% 1 \ldots$ & rA. & 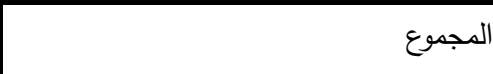 \\
\hline & & |9 1 - درجة فعالية جمعية تتمية المجتمع & & & rا - فترة بداية التعرف على الجمعية \\
\hline$\%$ \%r, q & 94 & 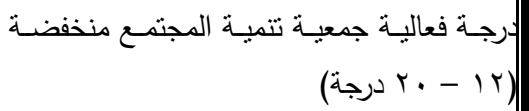 & $\% \vee \vee \neg, \wedge$ & rio & 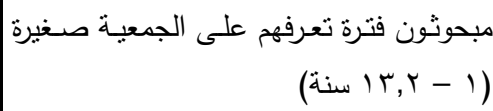 \\
\hline$\% 01, \varepsilon$ & $1 \leqslant \varepsilon$ & 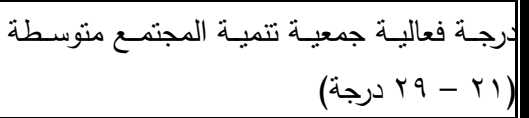 & $\% \backslash \vee, 0$ & $\leq q$ & 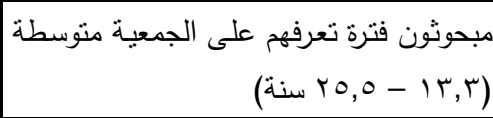 \\
\hline$\% 10, v$ & $\varepsilon \varepsilon$ & 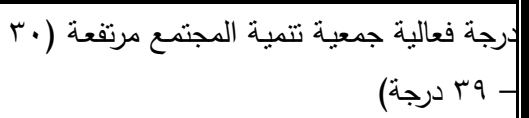 & $\% \circ, v$ & 17 & 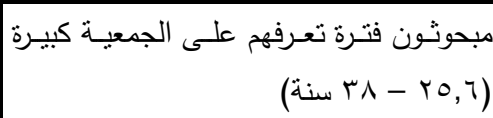 \\
\hline \multirow[t]{2}{*}{$\% 1 \ldots$} & $r \wedge$. & 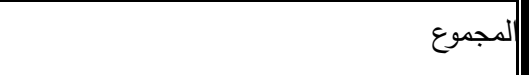 & $\% 1 \ldots$ & rA. & 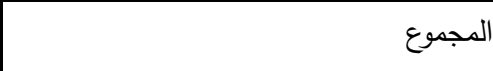 \\
\hline & & |لفرد والمجتمع بئـات درجـة تأثير أنثطة الجمعيـة على & & & ـ ا - فترة بداية التعامل مع الجمعية \\
\hline$\% 11$ & r & 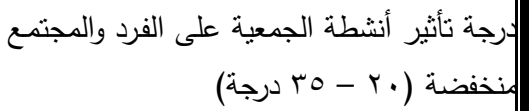 & $\% \wedge \wedge, \wedge$ & rrq & 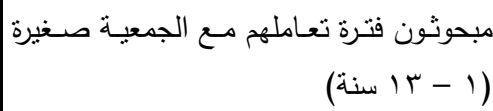 \\
\hline$\% \leqslant 0, \varepsilon$ & $\mid r v$ & 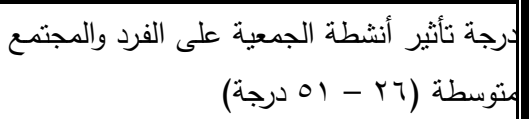 & $\% 10, \mathrm{~V}$ & $\leq \varepsilon$ & 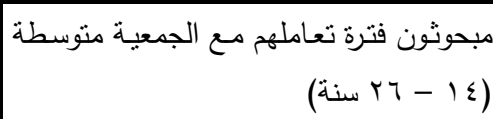 \\
\hline$\% \leqslant r, \uparrow$ & IrT & |مرتفعة (rاثنثير أنثطة الجمعية على الفرد والمجتمع درجة) & $\%$ \%,० & $\mathrm{v}$ & 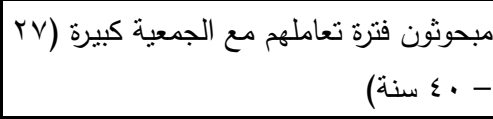 \\
\hline \multirow[t]{2}{*}{$\% 1 \ldots$} & rA. & 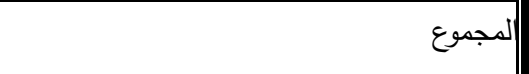 & $\% 1 \ldots$ & rA. & 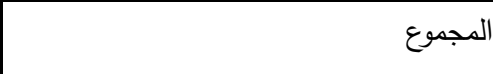 \\
\hline & & 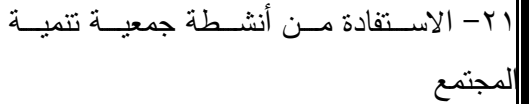 & & & 10 - الاتجاه نحو جمعية تتمية المجتمع \\
\hline$\% \leq \cdot, \vee$ & $11 \leqslant$ & 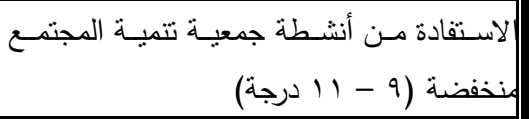 & $\%$ \%,o & $\mathrm{v}$ & 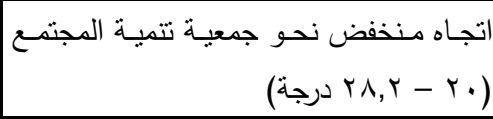 \\
\hline$\%$ ro & $9 \wedge$ & 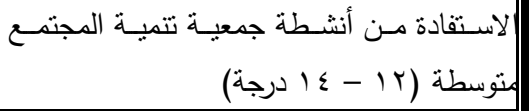 & $\%$ \%r, r & 10 & 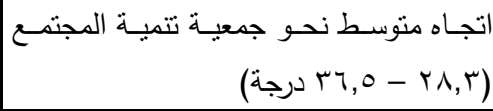 \\
\hline$\% r \varepsilon, r$ & $\uparrow \Lambda$ & لمرتفعة (10 - لاسـتفادة مـن أنثـطة جمعيـة تنميـة المجتهـع & $\% \vee \varepsilon, r$ & $r \cdot \Lambda$ & 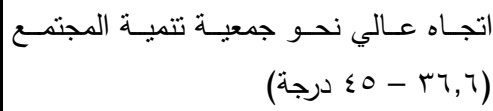 \\
\hline$\% 1 \ldots$ & rs. & 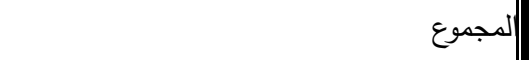 & $\% 1 \ldots$ & rA. & 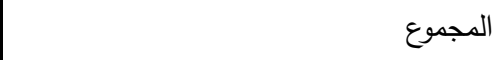 \\
\hline
\end{tabular}




\section{Keneber and Shahen}

(تابع) جدول (1): توزيع أفراد العينة البحثية ( المستفيدين من أنثطة جمعيات تنمية المجتمع ) وفقاً لمتغيرات الاراسة .

\begin{tabular}{|c|c|c|c|c|c|}
\hline 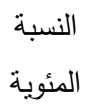 & 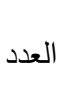 & المتغيرات & 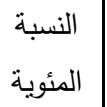 & 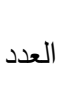 & المتغيرات \\
\hline & & |لإجتمع & & & rr- العلاقات التفاعلية بالجمعية \\
\hline$\% \diamond, \wedge$ & 17 & |غير راضى & $\% \circ 9, r$ & 177 & منخفضية (1 ـ ـ ـ ا درجة درجة علاقاتهم التفاعلية بالجمعيـة \\
\hline$\% T r, 1$ & IV & | إضى لحد ما & $\% r r, q$ & 94 & 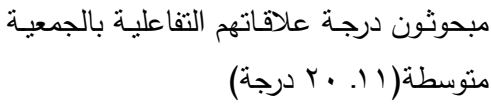 \\
\hline$\% r r, 1$ & 9 . & 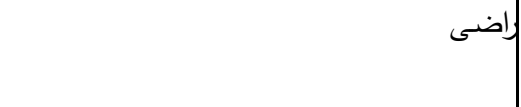 & $\% \vee, \wedge$ & rt & 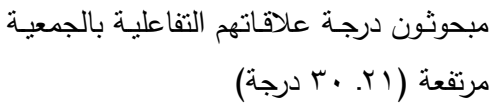 \\
\hline$\% 1 \ldots$ & rA. & | & $\% 1 \ldots$ & rA. & 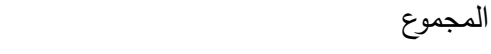 \\
\hline & & |ء r- مشكلات الجمعية ودرجة وجودها & & & \\
\hline$\%$ \%ч, 1 & $1 \cdot 1$ & 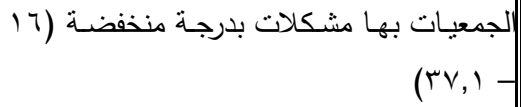 & & & \\
\hline$\% \leq 0, r$ & IrV & 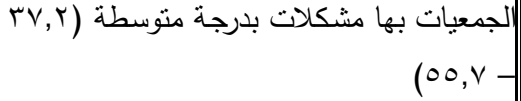 & & & \\
\hline$\% \backslash \wedge, 7$ & or & | الجمعيات بها مشكلات بدرجة كبيرة (VY) & & & \\
\hline$\% 1 \ldots$ & r^. & 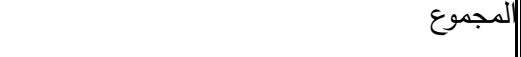 & & & \\
\hline
\end{tabular}

| مصدر : جمعت وحسبت من بيانات الدراسة الميدانية .

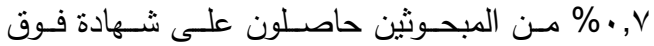

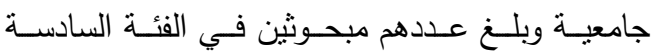
والنتائج تتير إلى أن الغالبية العظمى من المبحموثين

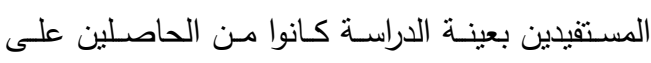

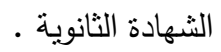

ع) الحالـة الزواجيـة : وبتوزيـع المبحوثين وفقـا للحالـة الزواجية وجد انخفاض نسبة المبحوثين غير المتزوجين

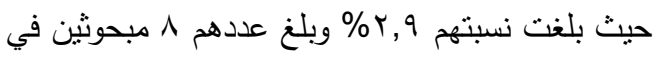
الفئة الأولى ، وارتفاع نسبة المبحوثين المتزوجين حيث

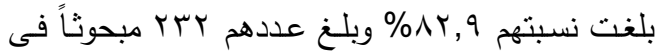

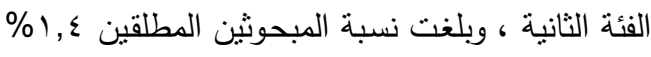

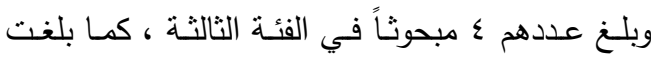

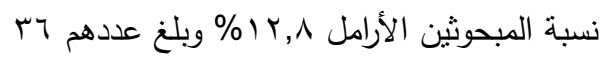

r) الحالـة التعليميـة للمبحـوث: قـد بلغتت قيمـة المتوسط

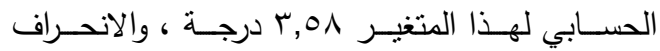

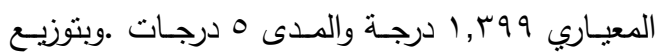

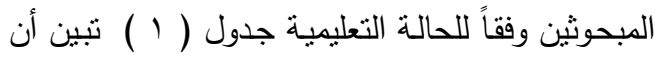
10,V

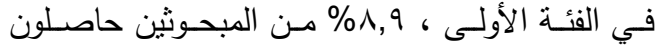

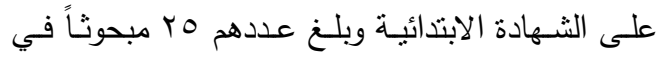

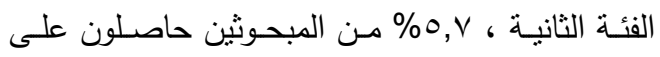

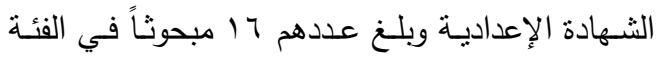

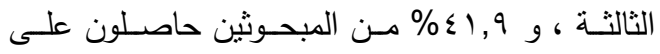
الثـهادة الثانويـة وبلـغ عددهم IIV مبحوثناً في الفئة

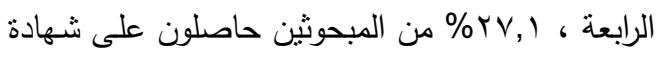

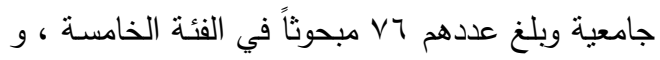


^) الدخل الثـهري : وتم قياسـهـ بإجمـالي المبالغ النقديـة

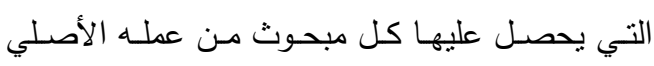
بالإضافة إلى أي عمل آخر يقوم به خلال الثهر مقدراً

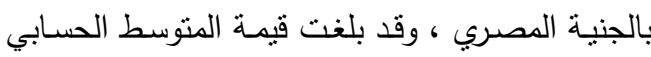

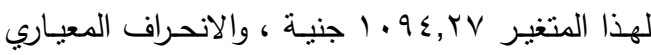

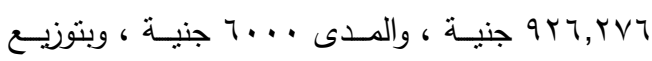

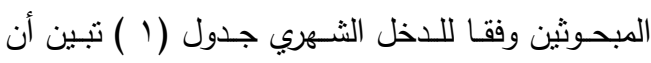

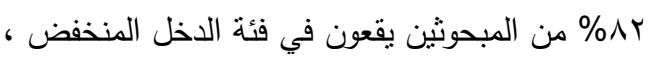

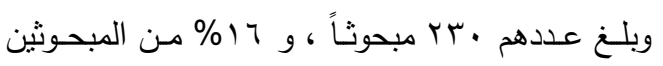

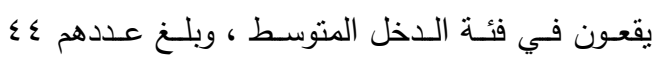

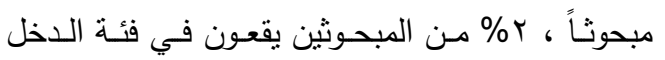

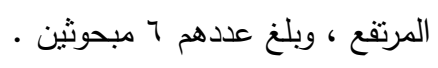

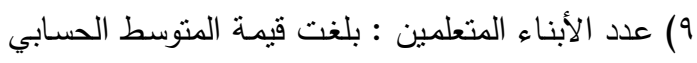

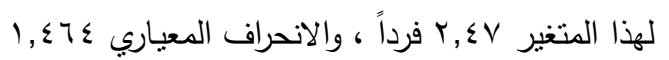

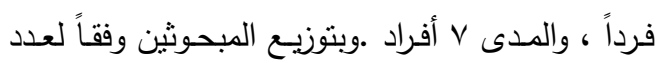

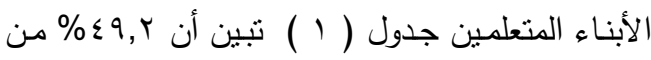

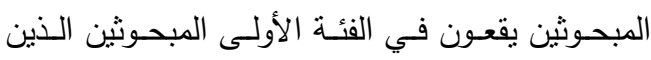

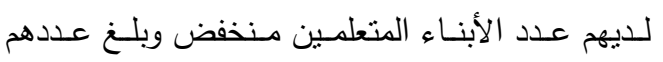

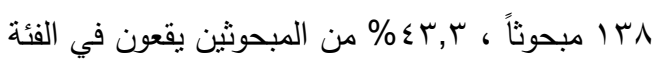

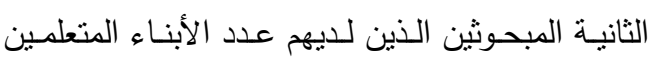

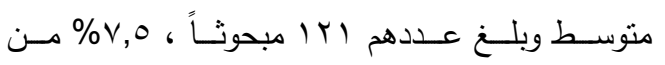
المبحوثين يقعون في الفئة الثالثة المبحوثين الذين لديهم

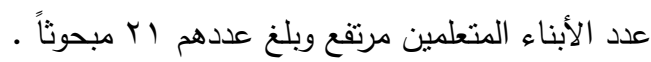

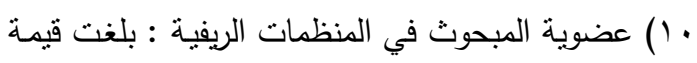

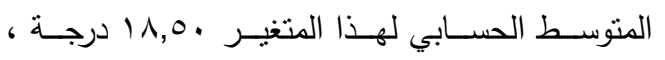

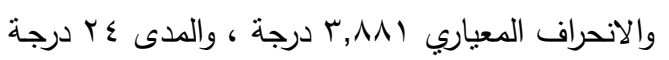

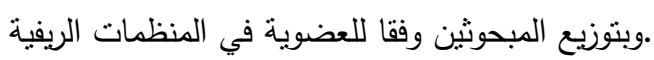

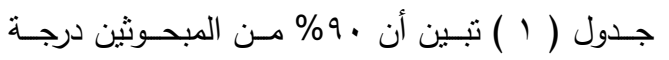

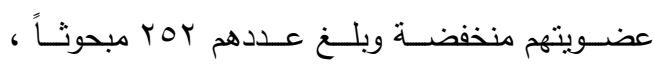

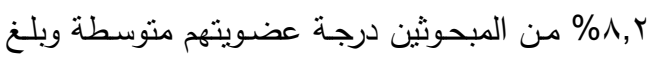

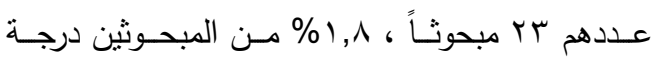
عضويتهم مرتفعة وبلغ عددهم ه (خمسة) مبحوثين.

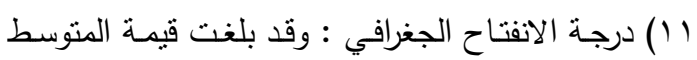

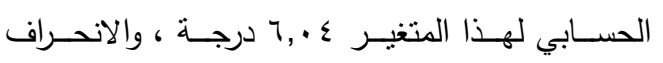

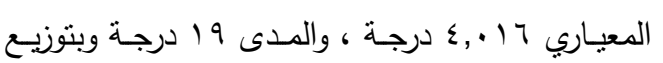

مبحوثاً في الفئة الرابعة وتتشير النتائج إلى أن أكثر من

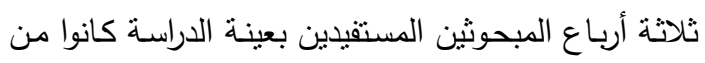

$$
\text { المتزوجين. }
$$

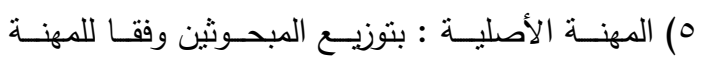

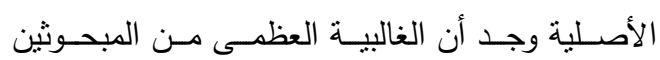

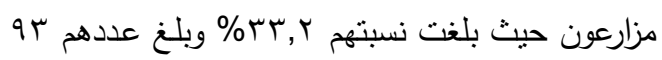

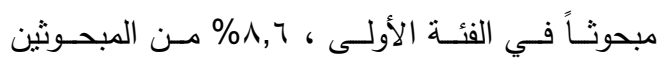

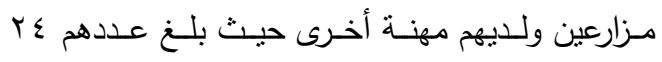
مبحوثاً وأن أكثر من نصف المبحوثين موظفون حيث

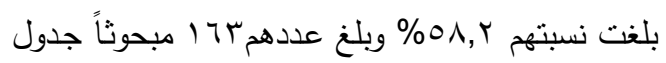

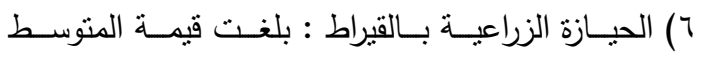

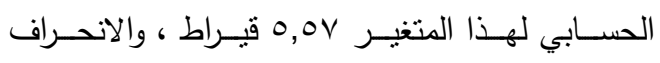

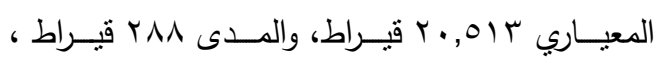

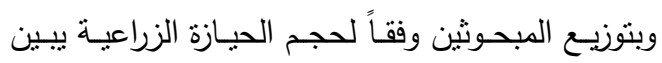

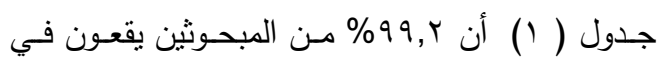

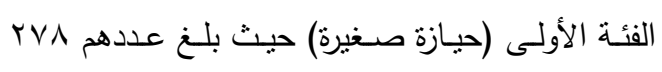

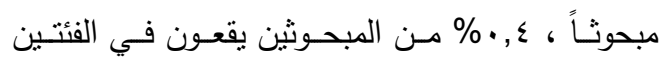

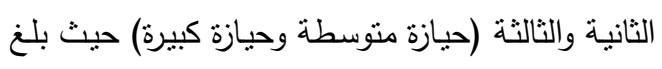

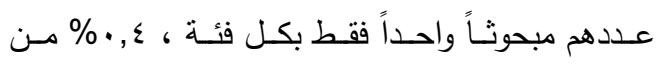

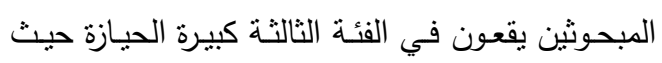
مبحوثاً فقط . (V عدد أفراد الأسرة : ويقصد به عدد أفراد أسرة المبحوث (V الذين يقيمون معهد في نفس المسكن ويعبر عنه برقم

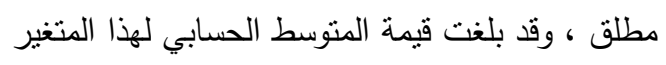

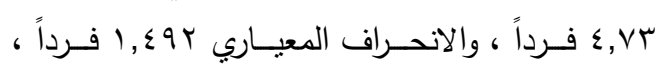

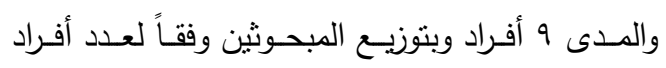

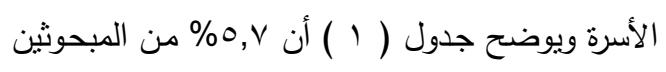

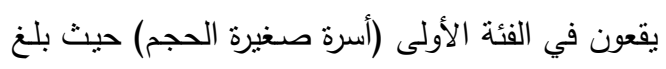

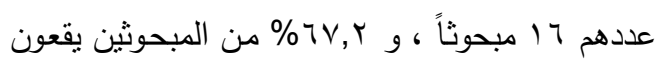

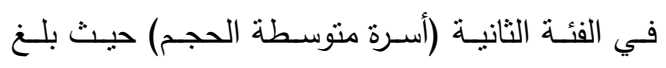

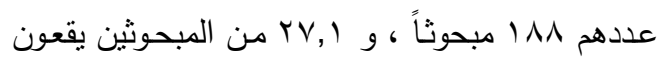

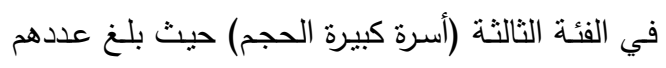

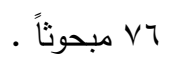


المبحوثين فترة تعـاملهم مـع الجمعيـة كبيرة حيث بلـغ عددهم 17 مبحوثاًا.

10) درجـة التعرض لمصـادر المعرفـة بأنشـطة الجمعيـة

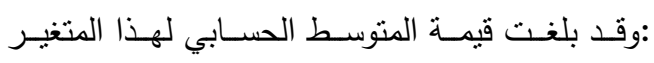

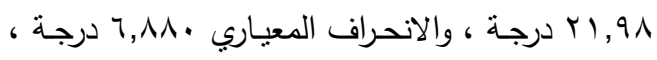

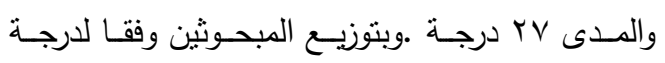

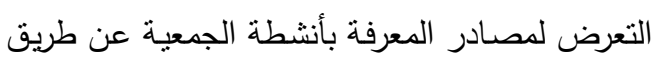

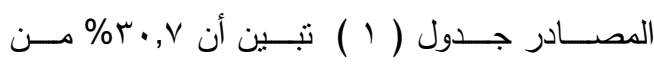
المبحوثين درجـة تعرضـهم لمصـادر المعرفـة بأنثطة

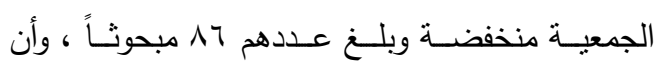

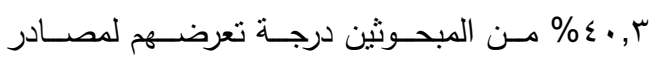

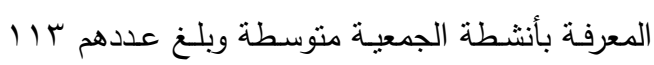

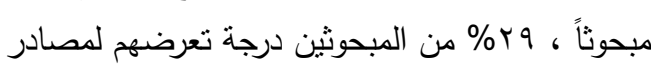

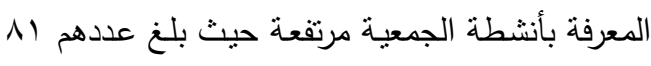
مبحوثاً. 17) الاتجاه نحو جمعية تتمية المجتمع:استخدم لقياس هذا

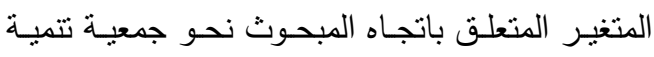
المجتمع من خلال خمسة عشر عبارة تعبر عن الاتجاه

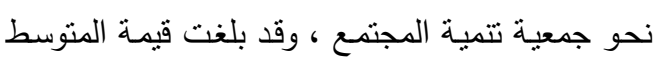

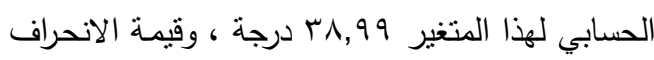

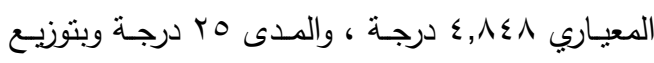

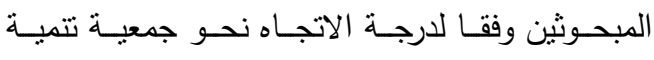

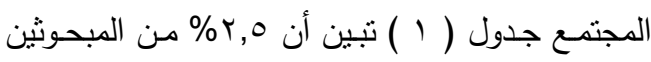

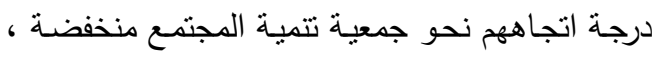

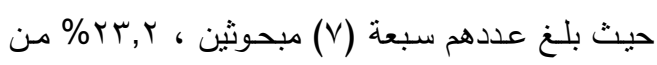

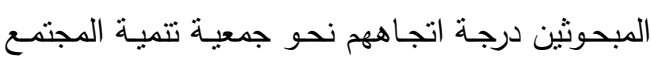

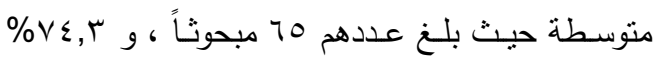

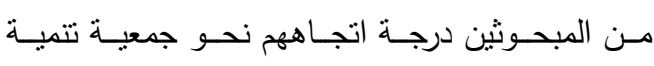

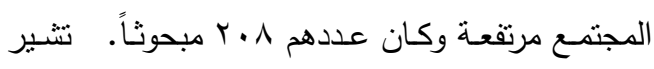

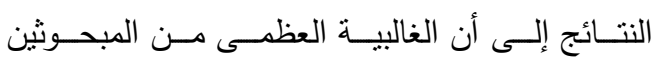

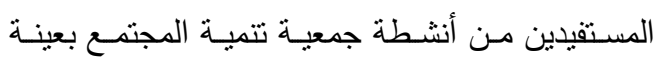

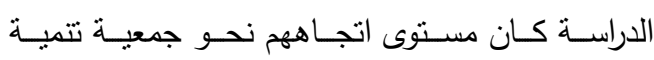

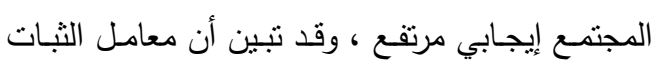

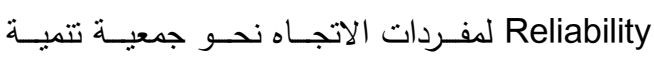

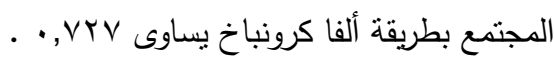

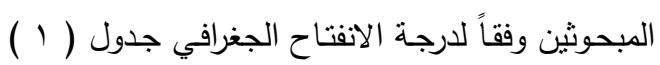

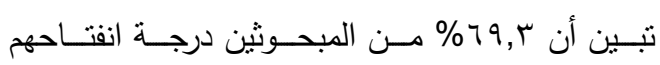

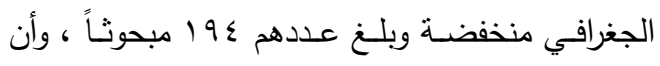

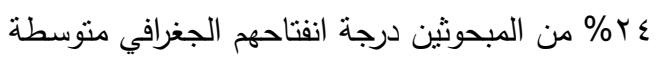

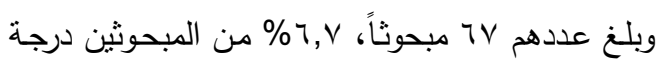

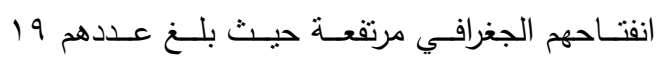
مبحوثاً.

r ( ) درجـة الانفتـاح الثقافي : وقد بلغت قيمـة المتوسط

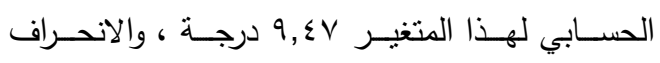

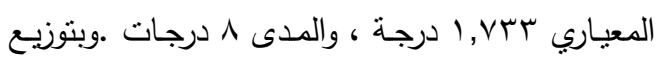

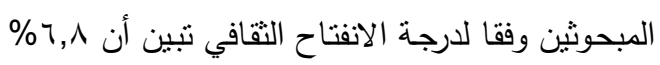

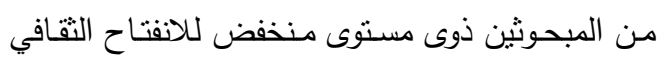

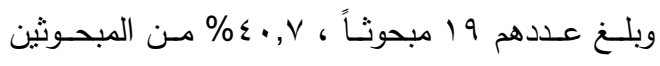

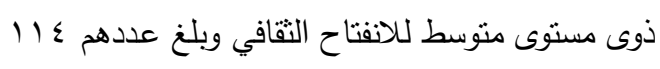

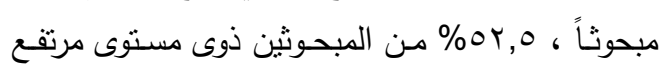

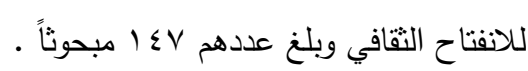

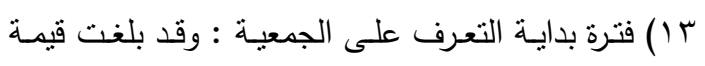

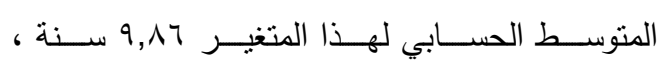

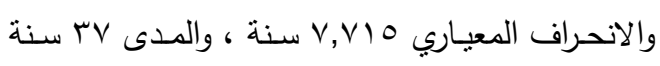

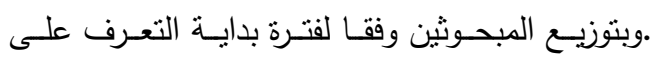

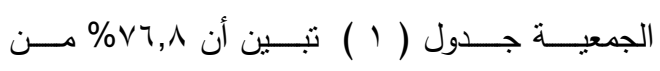

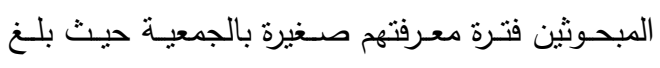

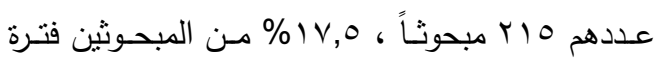
تعرفهم بالجمعية منوسطة حيث بلغ عددهم 9 ؛ مبحوثاً

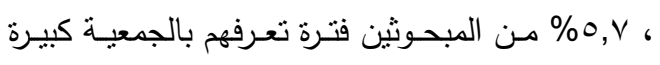

$$
\text { حيث بلغ عددهم } 17 \text { مبحوثاً . }
$$

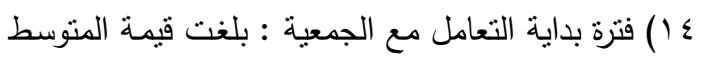

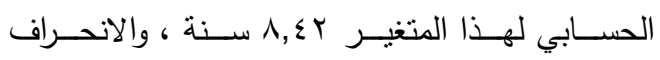

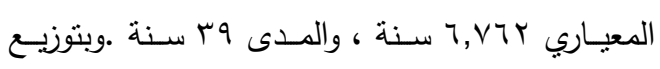

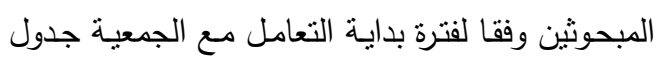

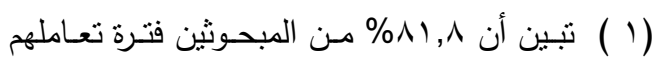

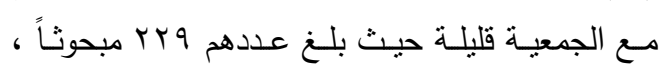

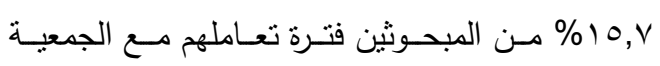

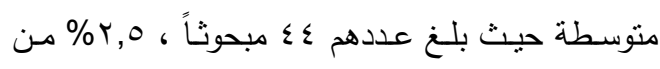




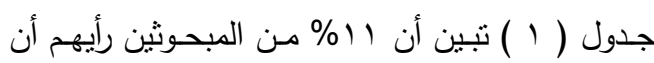

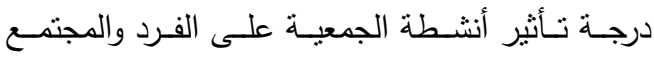

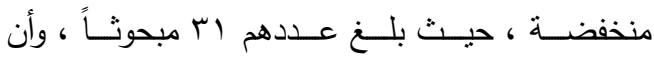

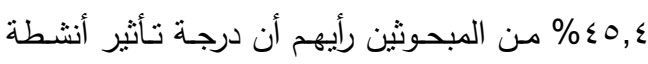

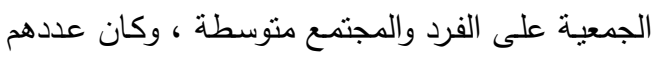

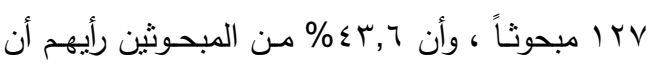

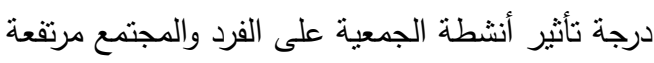

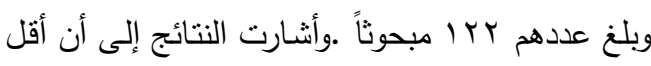

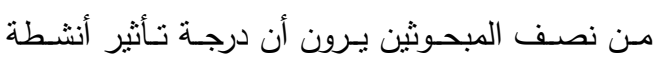
الجمعية على الفرد والمجتمع منوسطة .

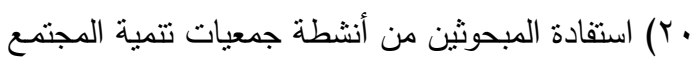

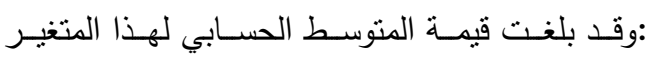

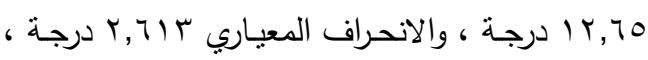

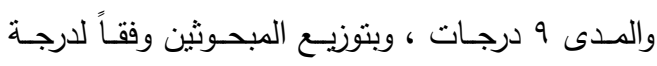

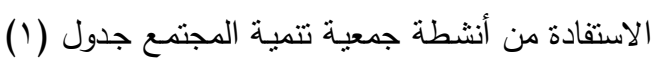

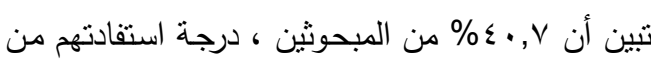

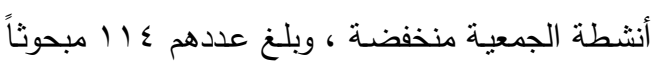

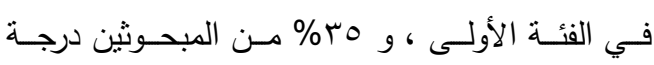
استفادتهم من أنشطة الجمعية منوسطة ، وبلغ ولغ عددهم

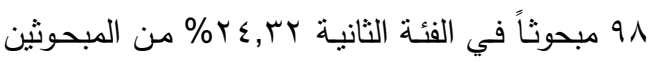

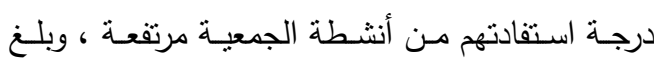

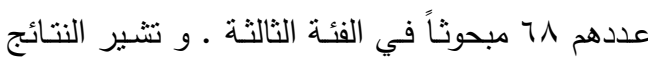

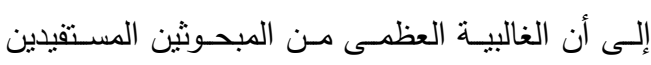

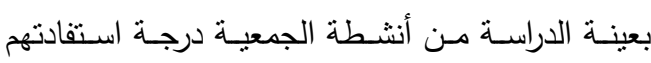
منخفضة .

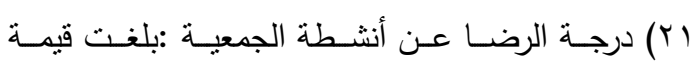

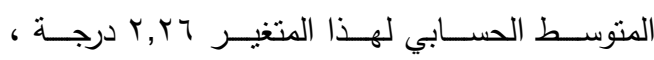
والاتحراف المعياري 00V, • درجة ، والمدى r درجة .

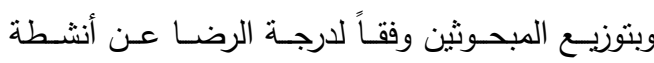

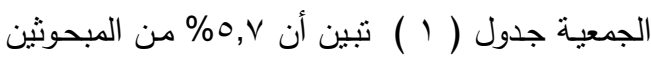

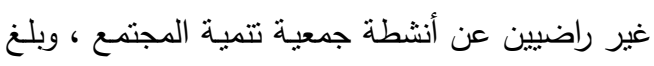

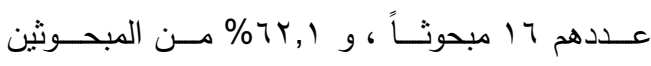

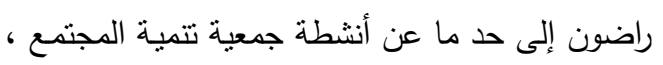

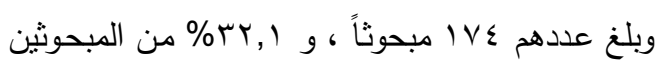

IV بعـد العلاقـات التفاعليـة للجمعيـة : تـم قيـاس هـذا المتغير عن طريق سؤال المبحوث مباشرة عن الأنشطة

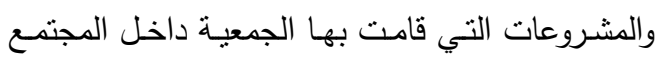
المحلى الذى تخدمه ، وهل يوجد مشـاركة من الأهالي

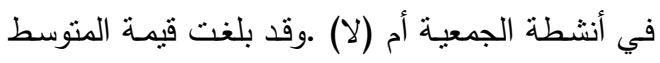

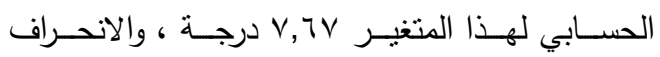

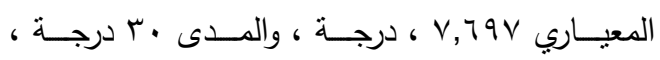

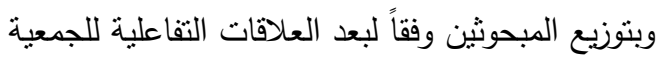

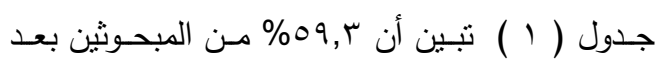

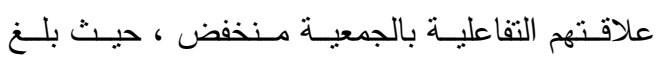

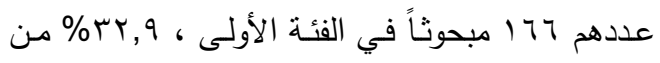

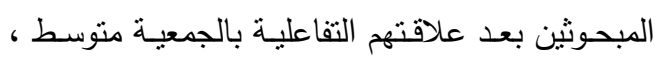

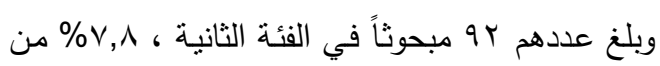

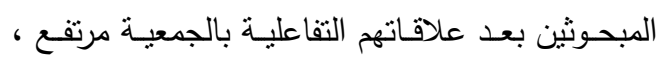
وكان عددهم r r مبحوثاً في الفئة الثالثة .

1 () درجة فعالية جمعية تتمية المجتمع : وقد بلغت قيمة

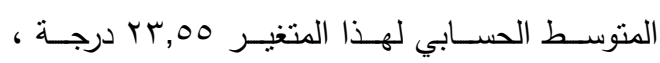

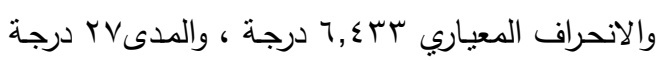

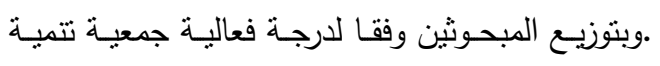

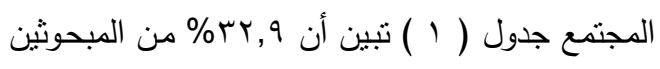

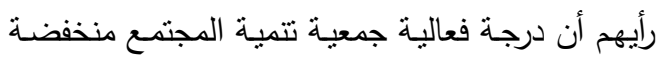

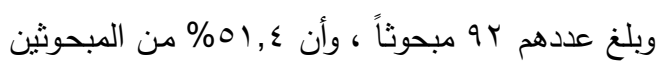

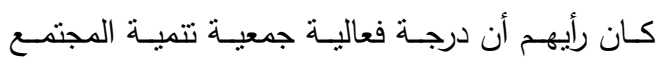

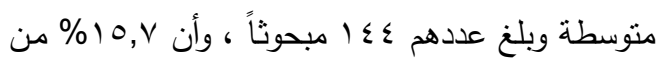

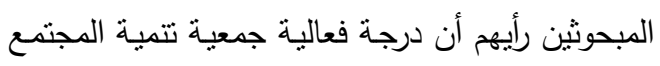

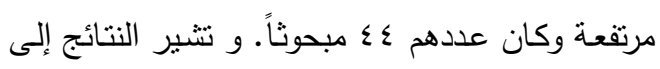
أن أكثر من نصف المبحوثين المستقيدين من أنثطة

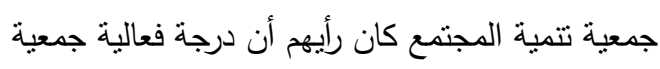
تتمية المجتمع متوسطة . 9 (1) درجة نأثثر أنثطة الجمعية على الفرد والمجتمع الذى لئ

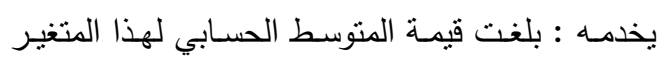

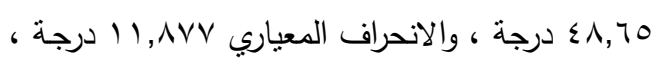

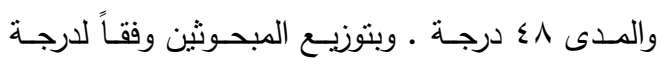

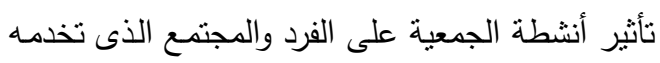




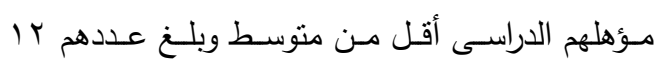

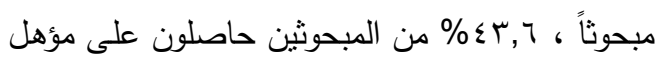

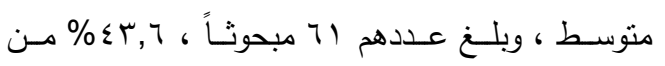

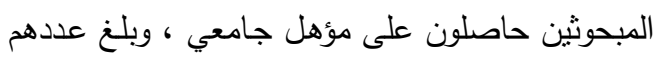

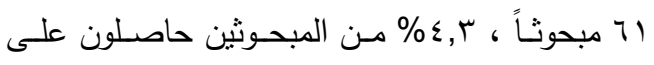

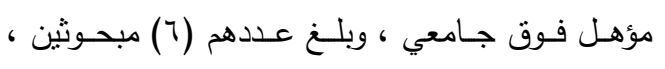

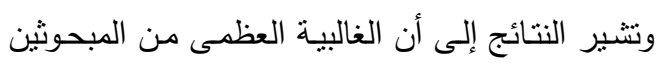

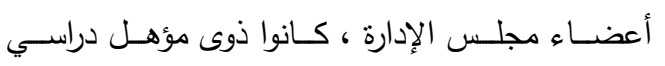
متوسط ، وأقل من متوسط بنفس النسبة .

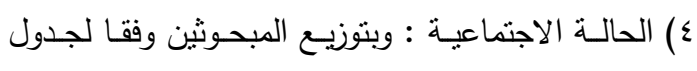
(Y) وجد انخفاض في نسبة المبحوثين غير المتزوجين

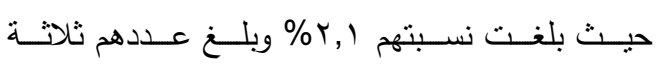
مبحـثين، وارتفـاع نسبة المبحوثين المتزوجين حيث

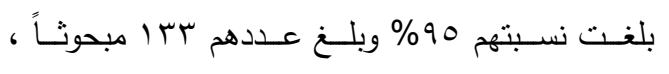

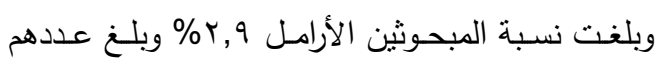

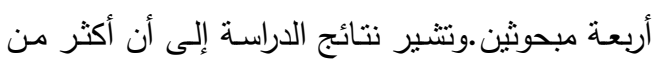

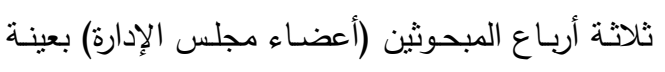

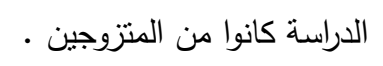
0) عدد أفراد الأسـرة : وبتوزيع المبحوثين وفقا لعدد أفراد العزئ

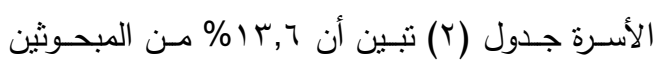

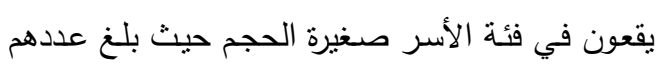

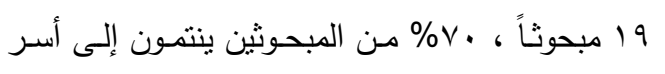

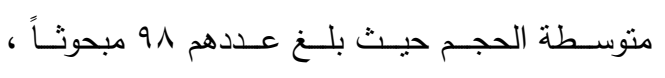

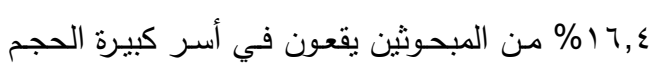

$$
\text { وبلغ عددهم r r مبحوثاً . }
$$

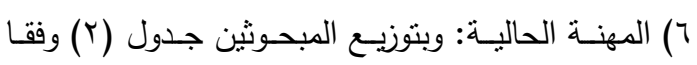

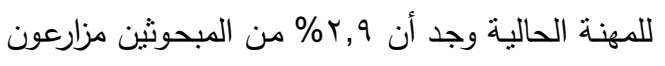

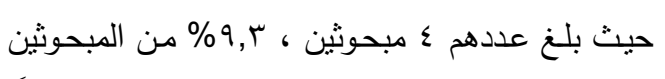
يعملون بالزراعة ومهنة أخرى وبلغ عددهم با با مبحوثاً،

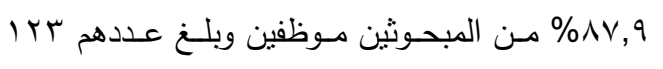
مبحوثاً ، وتتير النتائج إلى أن أكثر من ثناثنة أرباع

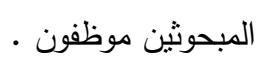

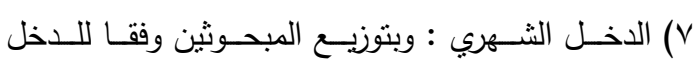

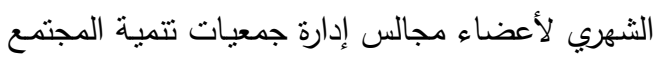

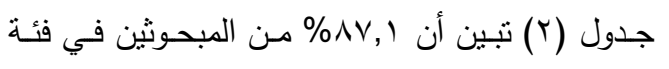

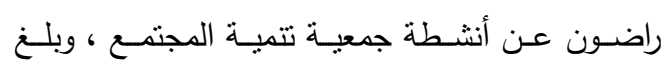

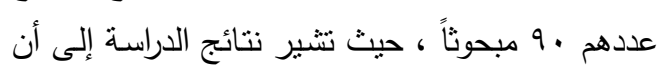

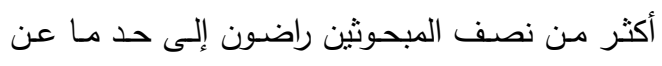

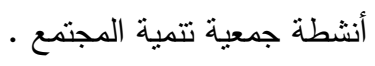

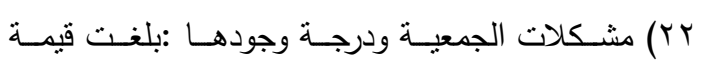

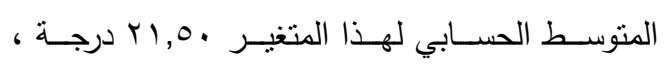

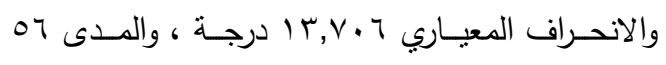

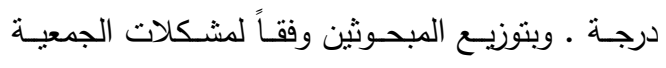

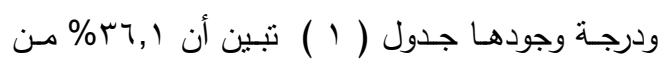

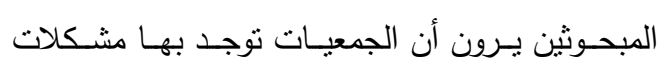

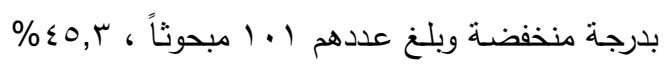

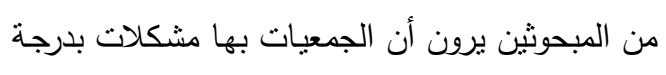

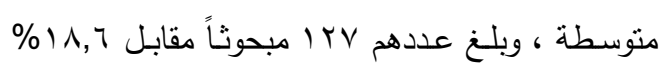

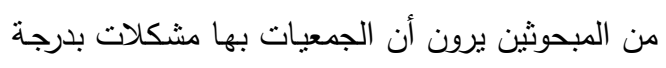

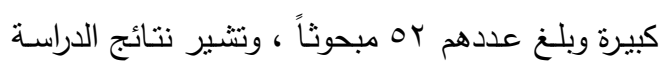

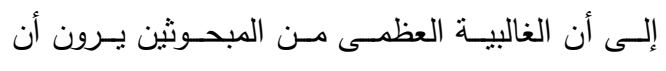
مشكلات الجمعية ودرجة وجودها منوسطة .

ثانيـا : وصـف المبحـوثين أعضـاء مجلس إدارة جمعيـة

\section{المجتمع المحلى : المبل}

( ) العمر : وقد بلغت قيمة المنوسط الحسابي لهذا المتغير

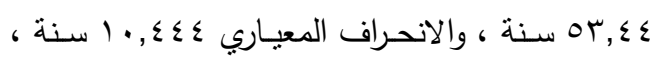

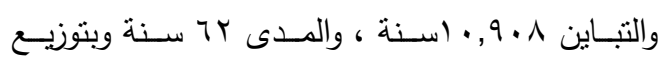

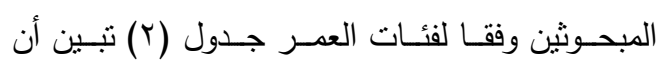

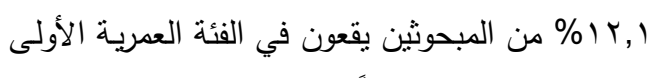

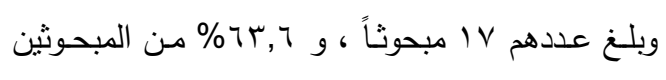

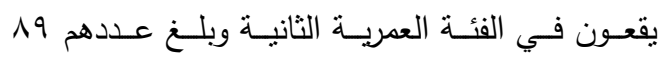

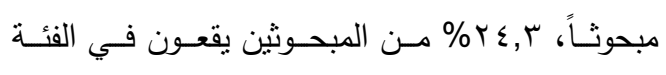
العمرية الثالثة وبلغ عددهم ع ب مبحوثاً . r) النوع: نوضـح النتائج الواردة بجدول ( r ) والخاصـة

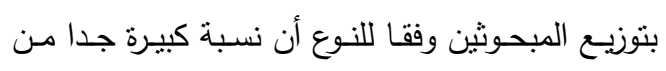

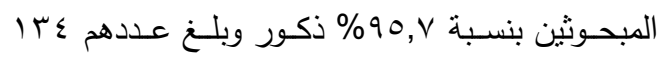

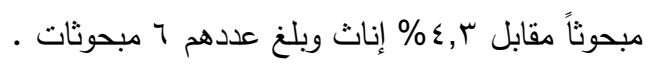

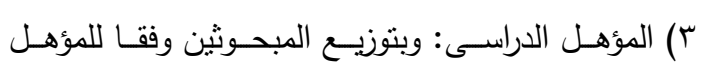

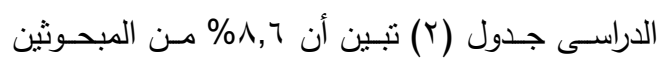




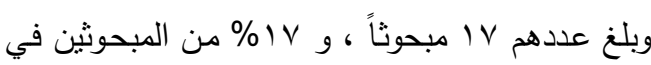

فئة الدخل المرتفع وعددهم مبحوث واحد فقط .

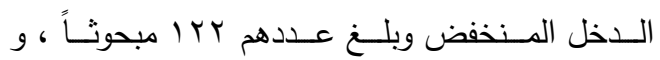

r, Y Y Y من المبحوثين يقعون في فئة الدخل المتوسط

جدول (Y): توزيع أفراد العينة البحثية ( أعضاء مجالس إدارة الجمعيات ) وفقاً لمتغيرات الدراسة .

\begin{tabular}{|c|c|c|c|c|c|}
\hline 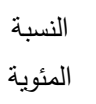 & العدد & المتغيرات & 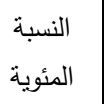 & العدد & 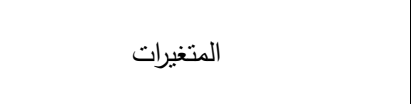 \\
\hline & & 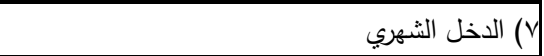 & & & 1-العمر \\
\hline$\% \wedge \vee, 1$ & IrT & 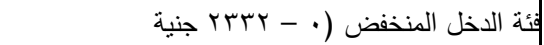 & $\% \mid r, 1$ & iv & الفئة العمرية الأولى (·• - ا (؟ سنة) \\
\hline$\%, r, r$ & iv & ئئة الدخل المتوسط (TrM Y - & $\% ヶ r, \uparrow$ & 19 & |الفئة العمرية الثانية (r؟ - كT سنة) \\
\hline$\% \cdot, v$ & 1 & 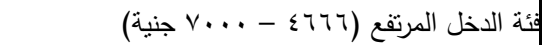 & $\% r \varepsilon, r$ & $r \varepsilon$ & الفئة العمرية الثالثة (rT - T سنةة) \\
\hline \multirow[t]{2}{*}{$\% 1 .}$. & $1 \leqslant$. & 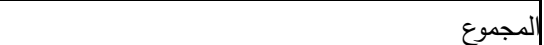 & $\% 1 \ldots$ & $1 \leqslant$. & 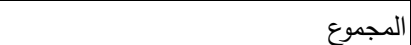 \\
\hline & & ل) خبرة عضو مجلس الإدارة بالعمل التطوعي بالجمعية & & & 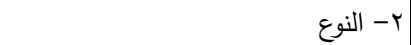 \\
\hline$\% \wedge$. & $11 \mathrm{r}$ & 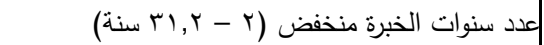 & $\% 90, v$ & $1 T \varepsilon$ & ذكر \\
\hline$\% 10, \mathrm{v}$ & r & 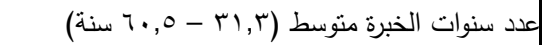 & $\% \varepsilon, r$ & 1 & أنثى \\
\hline$\% \varepsilon, r$ & 1 & عدد سنوات الخبرة مرتفع (T , • - . 9 سنة) & & & \\
\hline \multirow[t]{2}{*}{$\% 1 \ldots$} & $1 \leqslant$. & 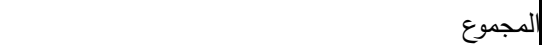 & $\% 1 \ldots$ & $1 \leqslant$. & المجموع \\
\hline & & |q) عضوية المنظمات الريفية & & & 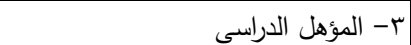 \\
\hline$\% \wedge r, 4$ & $11 \mathrm{~V}$ & 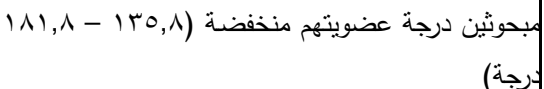 & $\% \wedge, \uparrow$ & ir & أقل من المتوسط \\
\hline$\% 10$ & r & 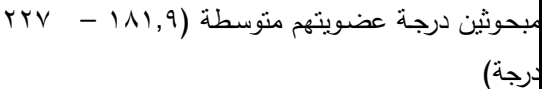 & $\% \varepsilon r, \uparrow$ & 71 & \\
\hline \multirow[t]{2}{*}{$\% 1, \varepsilon$} & r & 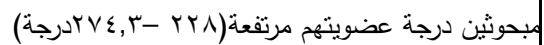 & $\% \varepsilon r, \uparrow$ & 7 & جامعي \\
\hline & & & $\% \varepsilon, r$ & 1 & 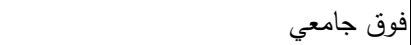 \\
\hline \multirow[t]{2}{*}{$\% 1 .}$. & $1 \leqslant$. & 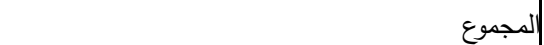 & $\% 1 \ldots$ & $1 \leqslant$. & 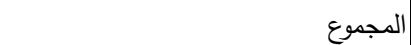 \\
\hline & & | | (1) مستوى التدريب : & & & | ع) الحالة الاجتماعية \\
\hline$\%$ \%, $\mathrm{v}$ & ar & 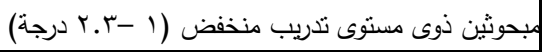 & $\% r, 1$ & r & أعزب \\
\hline$\% r, q$ & $\varepsilon$ & لمبحوثين ذوى مستوى تدريب متوسط (r, - -0,0 درجة) & $\% 90, \cdot$ & זr & متزوج \\
\hline \multirow[t]{2}{*}{$\% r 1, \varepsilon$} & $\varepsilon \varepsilon$ & مبحوثين ذوى مستوى تدريب مرتفع (T, 0, - درجة) & $\% \curlyvee, q$ & $\varepsilon$ & أرمل \\
\hline & & & -- & -- & مطلق \\
\hline \multirow[t]{2}{*}{$\% 1 .}$. & $1 \varepsilon$. & 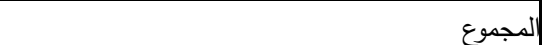 & $\% 1 \ldots$ & $1 \leqslant$. & 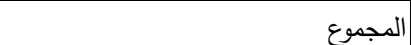 \\
\hline & & |) درجة الدافعيية للإنجاز لعضو مجلس إدارة الجمعيات & & & | (0) عدد أفراد الأسرة \\
\hline 1, & r & 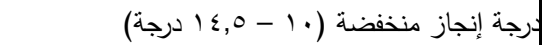 & $\% \mid r, \uparrow$ & 19 & أسر صغيرة الحجم (1 - 0.7 فرد) \\
\hline$\Lambda, \uparrow$ & ir & لرجة إنجاز متوسطة (1, أ - 19,1 درجة) & $\% \vee$. & १人 & أسر متوسطة الحجم (؟,r - ד. 1.7 فرد) \\
\hline q. & $1 \mathrm{~T}$ & لرجة إنجاز مرتفعة (r, 19 - گ د درجة) & $17, \leqslant \%$ & r & أسر كبيرة الحجم (ז, آ - 9 فرد) \\
\hline \multirow[t]{4}{*}{$1 \ldots$} & $1 \varepsilon$. & 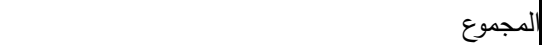 & $\% 1 \ldots$ & $1 \leqslant$. & 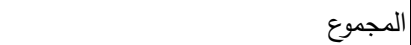 \\
\hline & & & & & (ج) ( ) الدهنة الحالية \\
\hline & & & $\% \curlyvee, q$ & $\varepsilon$ & 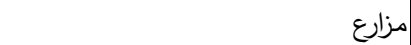 \\
\hline & & & $\% q, r$ & ir & 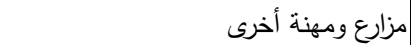 \\
\hline
\end{tabular}




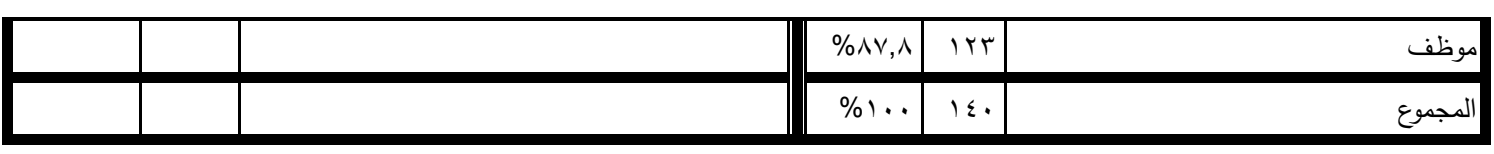

* المصدر : جمعت وحسبت من بيانات الدراسة الميدانية

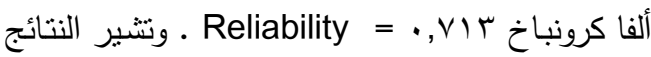

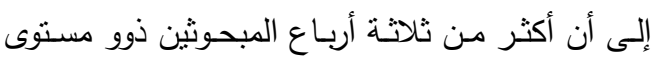

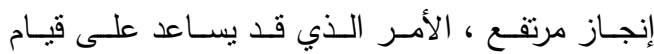

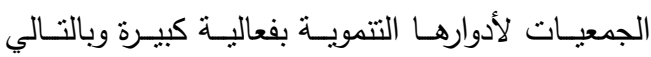
تسنطيع تحقيق أهدافها .

\section{النتائج التحليلية لبيانات الدراسة}

ينتظم العرض في وصف طبيعة العلاقات الارتباطية والعلاقات الانحدارية بين المتغيرات المستقلة وأبعاد فاعلية

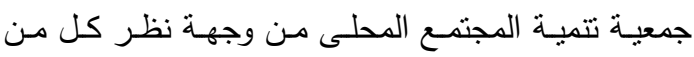

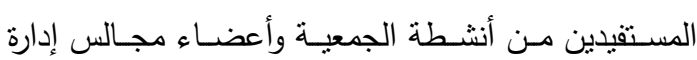
جمعيات تتمية المجتمع المحلى . أولا : وصف طبيعـة العلاقات الارتباطية بين المتغيرات

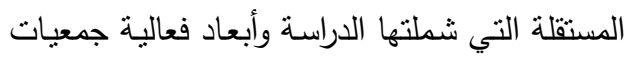

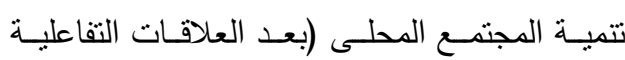
للجمعية - درجة رضا الاهالى عن أنشطة الجمعية - درجـة استفادة المبحوثين من أنشطة الجمعيـة درجـة تأثير أنشطة الجمعيـة عن الفرد والمجتمـع )

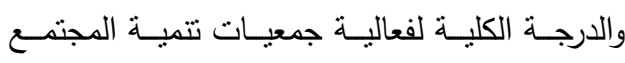

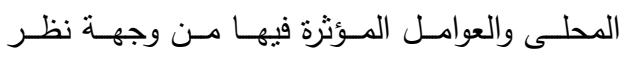
المستفيدين منها.

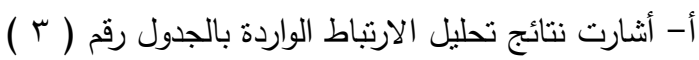

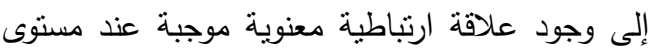

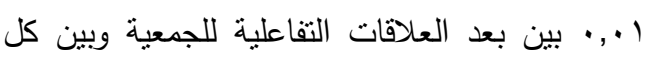
من المتغيرات المستقلة التالية والتي نم نرتيبها نتازلياً

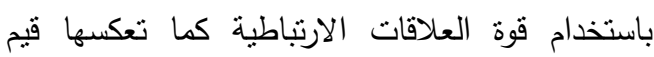

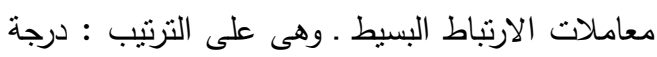

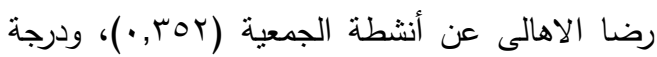

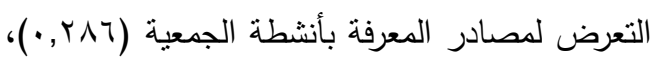

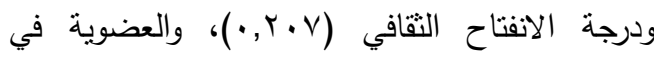

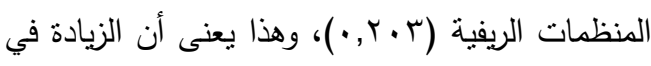

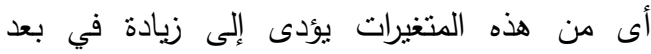
العلاقات التفاعلية للمنظمة ، ووجيرد التودي علاقة ارتباطية
^) خبرة عضو مجلس الإدارة بالعمل التطوعي بالجمعية :

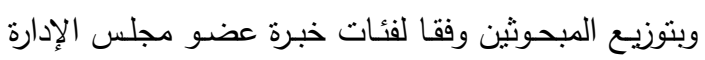

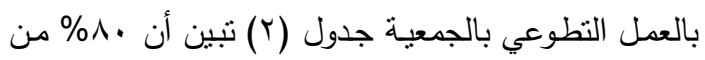

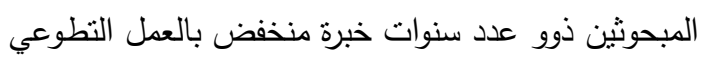

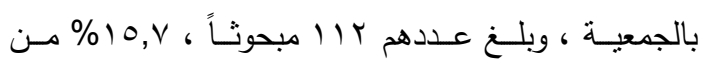
المبحوثين ذوو عدد سنوات خبرة متوسط بالعمل النطوعي

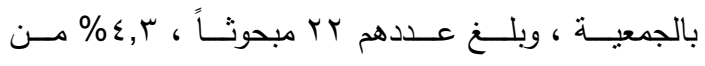

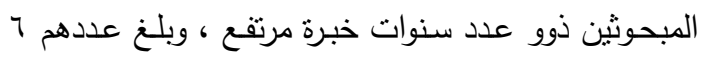

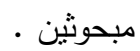

9) عضـوية المنظمـات الريفيـة: وبتوزيـع المبحـوثين وفقـا

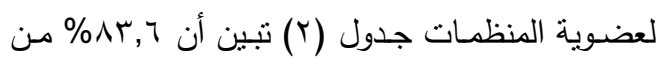
المبحوثين درجة عضويتهم بالمنظمات منخفضة ، وبلغ

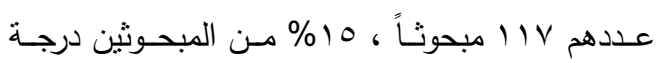

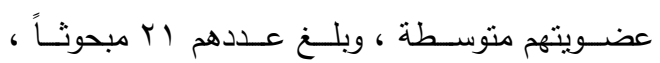

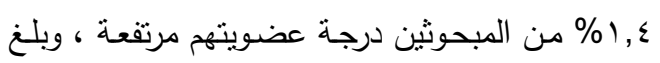

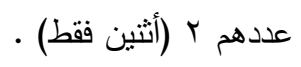

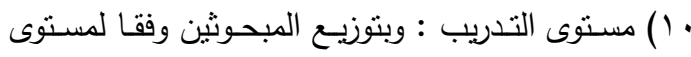

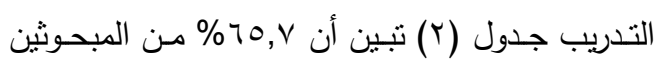

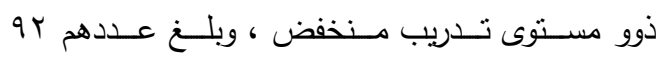

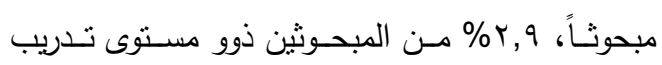

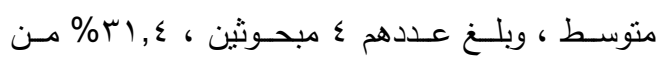

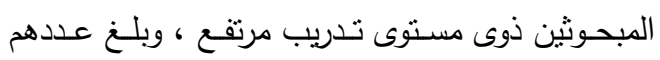
ـ 11) درجة الدافعية للإنجاز لعضو مجلس إدارة الجمعيات:

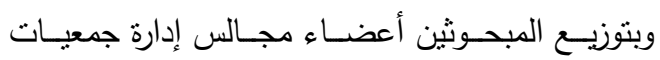

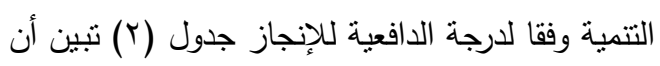

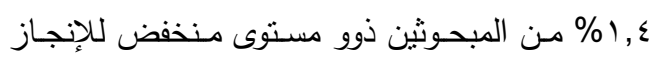

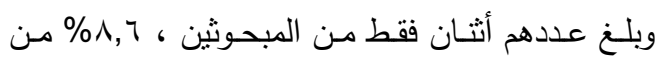
المبحوثين ذوى مسنوى إنجاز متوسط ، وبلـغ عددهم r r مبحوثاً ، ، 9\% من المبحوثين ذوو مستوى إنجاز

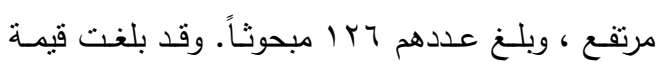

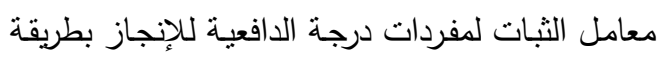


إلى زيادة في بعد العلاقات التفاعلية أي من داخل

الجمعية.
معنوية سالبة عند مستوى ا.,.• بين بعد العلاقات

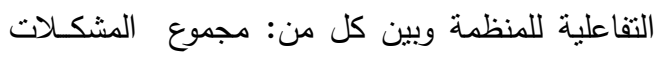

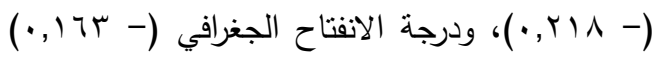

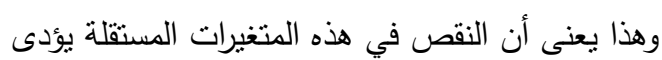

جدول رقم (؟): قيم معاملات الارتباط البسيط بين المتغيرات المستقلة المدروسة وأبعاد الفعالية والدارجة الكلية لفعالية

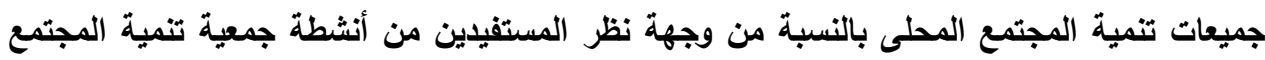

\begin{tabular}{|c|c|c|c|c|c|}
\hline \multirow{2}{*}{ المعالية جمعية تتمية الكلية } & \multicolumn{4}{|c|}{ أبعاد الفعالية } & \multirow[b]{2}{*}{ المتغيرات } \\
\hline & رضا الأهالي & الأستفادة من & تأثنر أنشطة & التفاعلية التية & \\
\hline$\cdot, \cdot 9 \cdot-$ & •, & $* * \cdot,|\vee|-$ & $\cdot, 1 \cdot r-$ & $\cdot, 1.0-$ & \\
\hline$\cdot, \cdot \wedge r$ & $\cdot, \cdot r_{-}-$ & $\cdot, \wedge r$ & $\cdot, \cdot 79$ & $\cdot, 11 \leq$ & نالة التعليمية للمبحوث \\
\hline$\cdot, \cdot r r-$ & $* \cdot, 1 r q-$ & $\cdot, \wedge 9-$ &., $.01-$ & $\cdot, \cdot r V-$ & يازة الزراعية بالقيراط \\
\hline$\cdot, .0 \cdot-$ & $\cdot, \cdot r \Lambda-$ & $\cdot, \cdots \varepsilon-$ & $\cdot, \cdot M_{4}-$ & $\cdot, \cdot \leq 1-$ & د أفراد الأسرة \\
\hline$\cdot, \cdot \wedge$. & $\cdot, .0 V-$ & $\cdot, \cdots 1$ & $\cdot, \cdots 9$ & $\cdot, \cdots \leq$ & ل ل اخل الشهري \\
\hline$\cdot, \cdot \vee v 1$ & $* * \cdot, \mid \vee 4$ & $* * \cdot,|7|$ & $* \cdot, 1 \leq \Lambda$ & $\cdot, \cdot 9 V$ & عدد الأبناء المتعلمين \\
\hline$* *, \Sigma)$. & $* * ., 107$ & ** & $* *, r 10$ & $* *, r \cdot r$ & ضوية في المنظمات الريفية \\
\hline$* *, r r \leq-$ & $\cdot, 1 \cdot \varepsilon-$ & $\cdot, 11 V-$ & $\cdot, .0 Y-$ & $* *, 17 r-$ & لَّ الانفتاح الجغرافي \\
\hline$* *, r \mu l$ & $* * \cdot, 1 \vee 0$ & $* *, r \cdot \tau$ & $* *, r\rceil \leq$ & $* *, r \cdot V$ & الانفتاح التقافي \\
\hline$\cdot, \cdot \leq$. & $\cdot, \cdot 1 \leq$ &., $.09-$ & $* \cdot, 10 \mathrm{r}-$ & $\cdot, \cdot 11$ & مَ بداية التعرف على الجمعية \\
\hline$* ., 1 \leq 7$ & $\cdot, \cdot \wedge 7$ & $\cdot, \cdots$ & $\cdot, \cdot r r-$ & $\cdot, \cdots 9$ & ة بداية التعامل مع الجمعية \\
\hline$* *, 0 \wedge r$ & $* *, Y>0$ & $* *$, or. & $* *, 0,1$ & 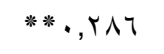 & جة التعرض لمصادر المعرفة بأنشطة \\
\hline$*, 1 \leq 1-$ & $* *, r T r$ & $* *, r V I$ & ** & $\cdot, .0 \leqslant$ & جة الاتجاه نحو جمعية تتمية المجتمع \\
\hline$* *, r \wedge \vee$ & & $* *, r \wedge \wedge$ & $* *, ., 077$ & $* *$, orr & جة رضا الأهالي عن أنشطة الجمعية \\
\hline$* *, Y Y,-$ & $* * \cdot, \Gamma ч \leq-$ & $* * \cdot, r \neg \wedge-$ & $* *,, \varepsilon \cdot q-$ & $* *, Y \backslash \wedge-$ & ع المشكلات \\
\hline
\end{tabular}

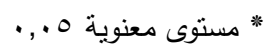

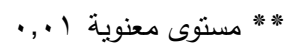

* المصدر : حسبت من بيانات الدراسة الميدانية باستخدام الحاسب الآلي .

وبين كل من المتغيرات المستقلة التالية ـ والتي تم ترتيبها

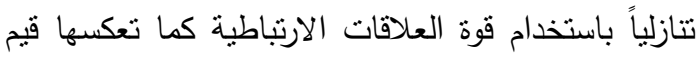

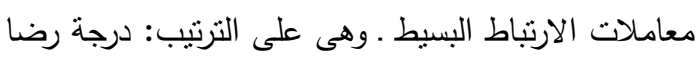

كما أوضحت نتائج تحليل الارتباط الواردة بجدول (r) إلى وجود علاقة ارتباطية معنوية موجبة عند مستوى لثائيل

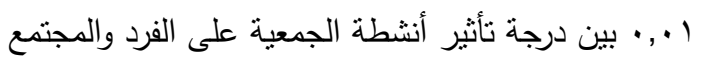


المجتمع ومجموع المشكلات ، والعمر ، حيث بلغت قيم

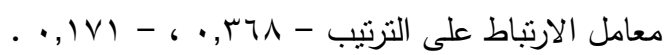
وتشير نتائج تحليل الارتباط الواردة بالجدول رقم ( r ) إلى وجود علاقة ارتباطية معنوية موجبة عند مستوى 1., بين درجة الرضا عن أنشطة جمعيات نتمية

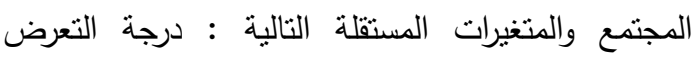
لمصادر المعرفة بأنشطة الجمعية، ودرجة الاتجاه نحو جمعية تتمية المجتمع ، وعدد الأبناء المتعلمين ، ودرجة الانفتاح الثقافي ، والعضوية في المنظمات الريفية حيث

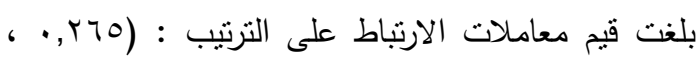

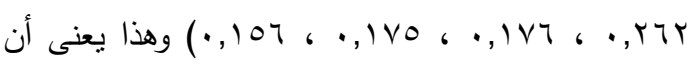
الزيادة في أي من هذه المتغيرات يؤدى إلى زيادة في درجة رضا الاهالى عن أنشطة الجمعية ، كما توجد علاقة هئل ارتباطية معنوية سالبة عند مستوى معنوية ال.,., بين درجة رضا الاهالى عن أنشطة جمعية تتمية المجتمع ومجموع المشكلات ، حيث بلغت قيم معامل الارتباط على رهي الترتيب : (- ع ؟r, •)، وأوضحت النتائج وجود علاقة

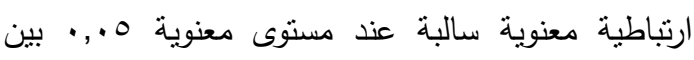
درجة رضا الأهالي عن أنشطة الجمعية والحيازة الزراعية

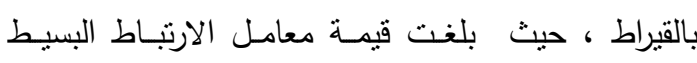

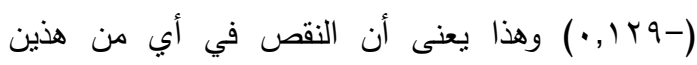

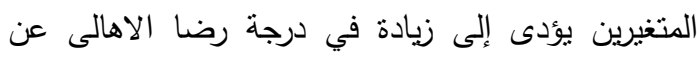

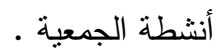
أوضـت نتائج تحليل الارتبـاط الواردة بالجدول رقم (r) إلى وجود علاقة ارتباطية معنوية موجبة عند مستوى 1 •, • بين درجة فعالية جمعية تتمية المجتمع وبين كل من المتغيرات المستقلة التالية والتي تم ترتيبها تتازلياً باستخدام قوة العلاقات الارتباطية كما تعكسها قيم معاملات الارتباط البسيط . وهـى على الترتيب : درجـة التعـرض لمصـادر

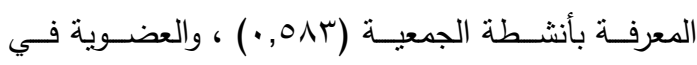

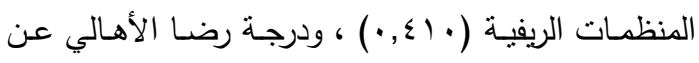

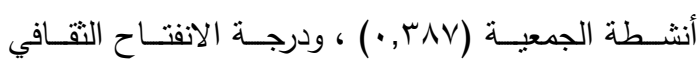

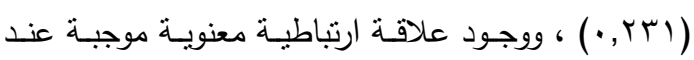

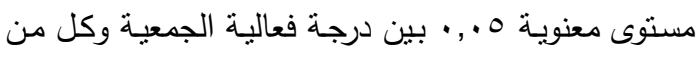

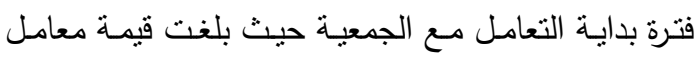

الأهالي عن أنشطة الجمعية (770, • ) ، ودرجة التعرض

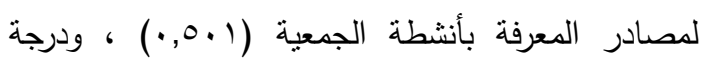

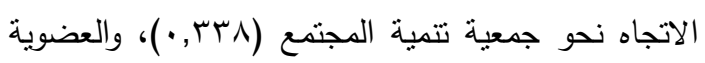
في المنظمات الريفية (0اب, ·)، ودرجة الانفتاح الثقافي (ع ب, • )، كما وجد علاقة ارتباطية معنوية موجبة عند مستوى معنوية ه., • بين درجة تأثير أنشطة الجمعية

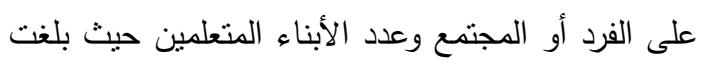

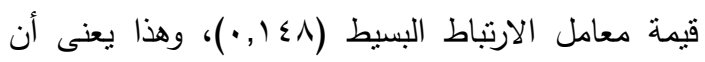
الزيادة في أى من المتغيرات السابقة يؤدى إلى زيادة في درجة تأثير أنشطة الجمعية على الفرد والمجنمع ، كما أوضحت النتائج أن هناك علاقة ارتباطية معنوية سالبة عند مستوى معنوية 1 ., , بين درجة تأثير أنشطة الجمعية على الفرد والمجنمع ومجموع المشكلات حيث بلغت قيمة معامل الارتباط (- 9 • ع, •)، وأيضا توجد علاقة ارتباطية معنوية سالبة عند مستوى معنوية 0 ., ، بين درجة تأثنر

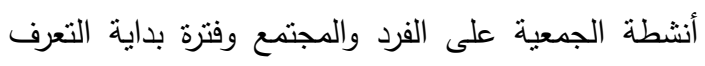

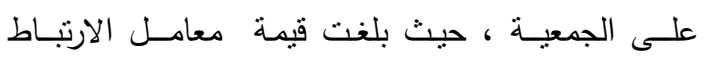
(- ب ( ) • )، وهذا يعنى أن النقص في أى من هذين

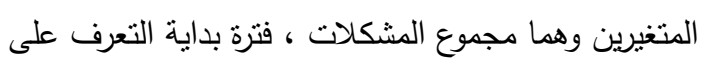
الجمعية ، يؤدى إلى زيادة في درجة تأثنير أنشطة الجمعية

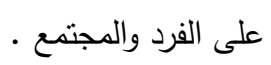
كما أوضحت نتائج تحليل الارتباط الواردة بالجدول رقم

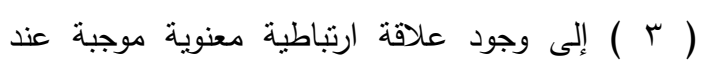
مستوى l +, · بين درجة الاستفادة من أنشطة جمعية تتمية

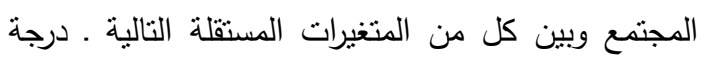
التعرض لمصادر المعرفة بأنشطة الجمعية، ودرجة رضا الأهالي عن أنشطة الجمعية ، والعضوية في المنظمات الريفية ، ودرجة الانفتاح الثقافي ، ودرجة الاتجاه نحو

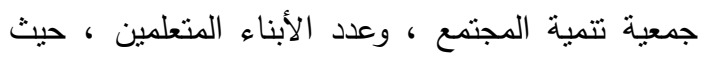

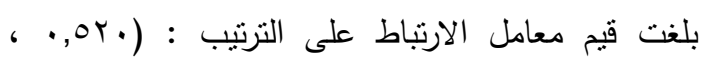

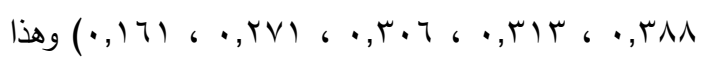
يعنى أن الزيادة في أى من هذه المتغيرات يؤدى إلى زيادة

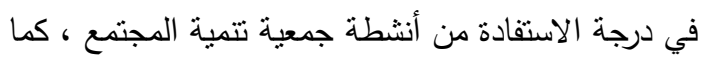
توجد علاقة ارتباطية معنوية سالبة عند مستوى معنوية l., بين درجة الاستفادة من أنشطة جمعية تتمية 
ثانيا : وصف طبيعة العلاقات الارتباطية بين المتغيرات

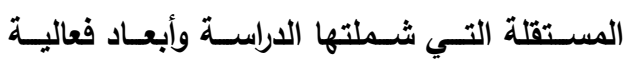

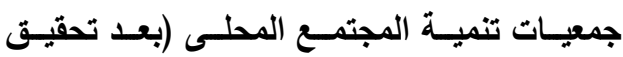
الأهداف - بعد التنسيق المنظمس - بعد الرضـا الوظيفي - بعد التنظيم الداخلي - والدرجة الكلية

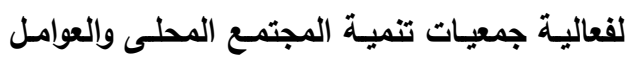

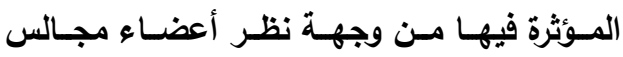

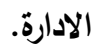

أ- تشير نتائج تحليل الارنباط الواردة بالجدول رقم ( )

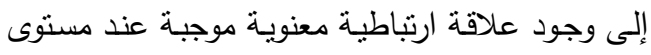

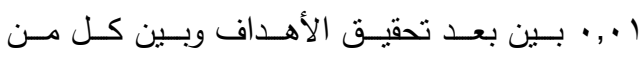

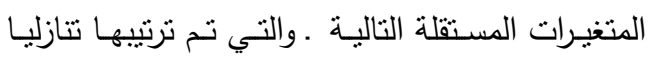

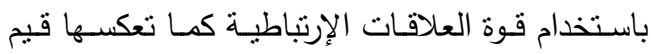
معاملات الارتباط البسيط ـ وهى على الترتيب : (درجة

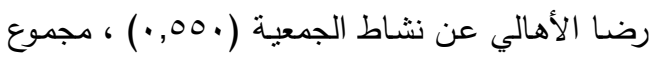

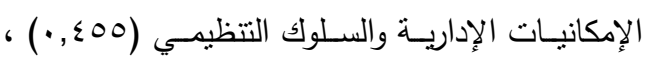

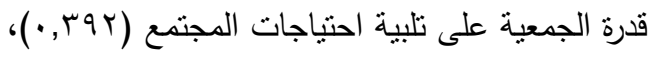

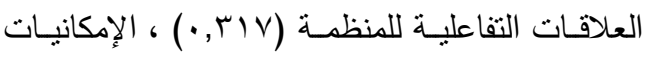

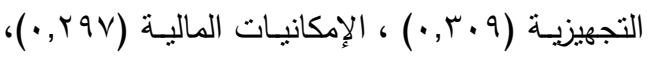

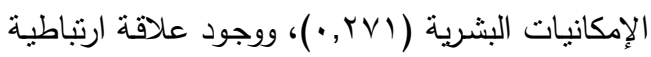

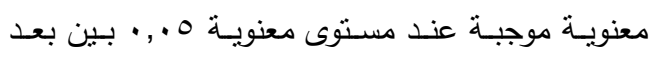
تحقيـق الأهـداف وبـين كل مـن المتغيـرات المستقلة

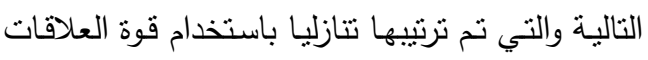

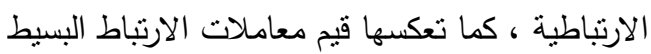

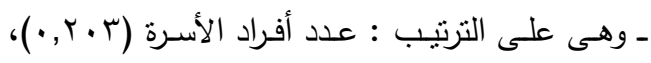

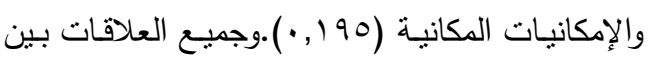

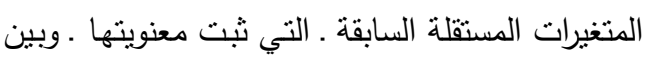

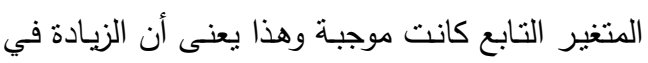

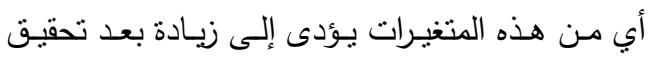

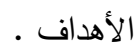

تشير نتائج تحليل الارتباط الواردة بالجدول رقم ( )

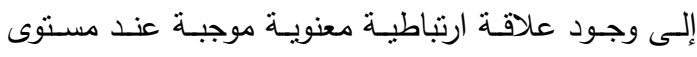

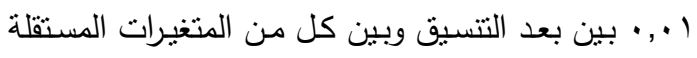

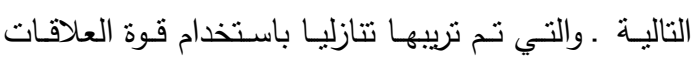

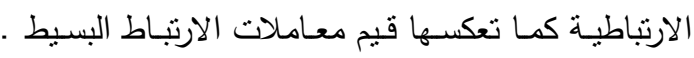

الارتبـاط البسيط (7 ( ا, •)، ودرجـة الاتجـاه نحو جمعيـة

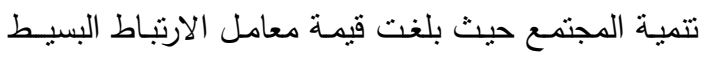

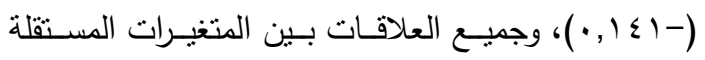

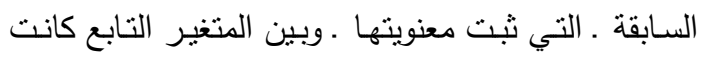
موجبة، وهذا بعنى أن الزيادة في أي من هذه المتغيرات

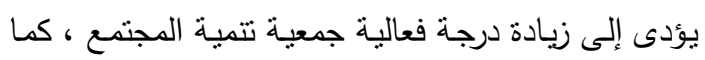

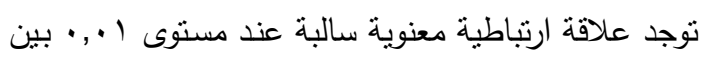
درجة فعالية جمعية تتمية المجتمع وكل من درجة الانفتاح

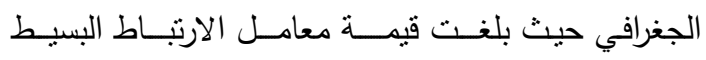

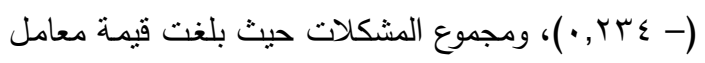

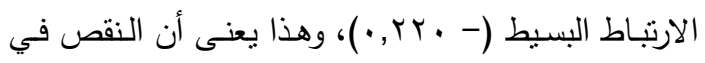

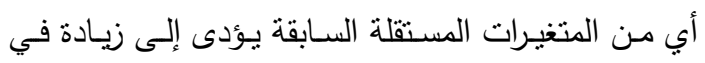
درجة فعالية جمعية تتمية المجتمع. ب- العوامل المؤثرة في درجة فعالية جمعية تتمية الهجتمع

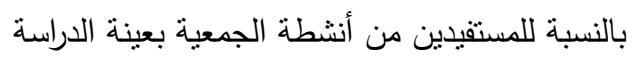

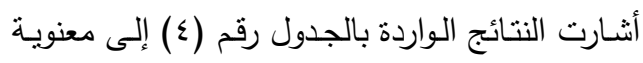

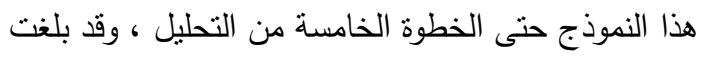

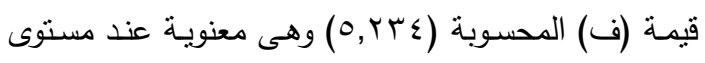

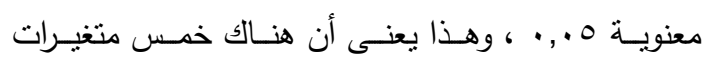

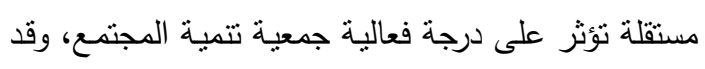

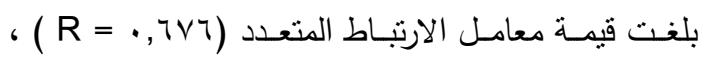

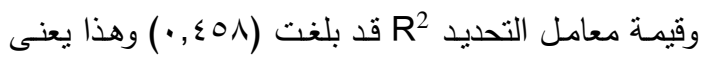
أن المتغيرات المستقلة الخمسة المؤثرة تبلغ نسبة مساهمتها مجتمعه في تفسير التباين الحادث في درجة فعالية جمعية

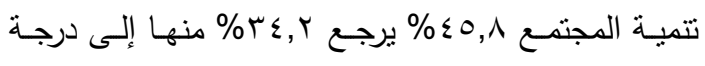

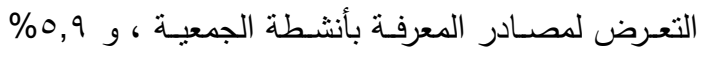

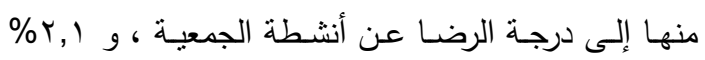

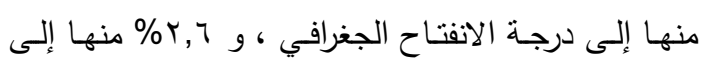
العضوية في المنظمات الريفية ، و ا 1\% منها إلى العمر .

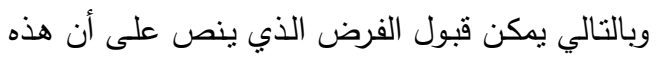

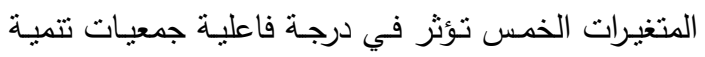

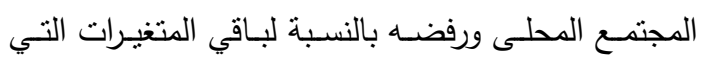

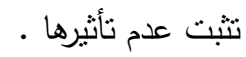


العلاقات الارتباطيـة كما تعكسها قيم معـاملات الارتبـاط البسـيط . وهـى على التزتيب : درجـة الدافعيـة للانجـاز

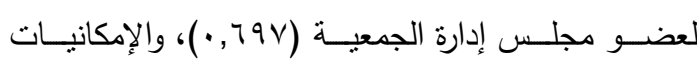

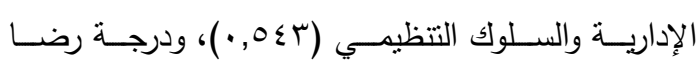

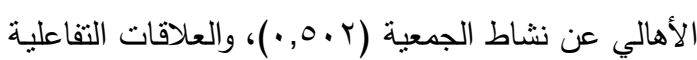

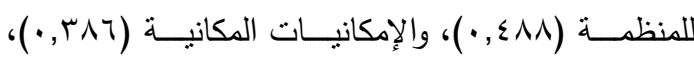

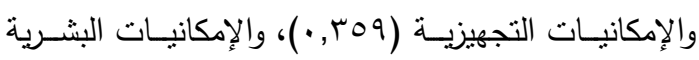

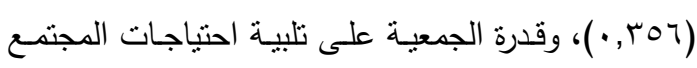

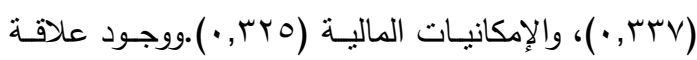

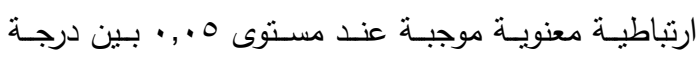
الرضا الوظيفي والعمر حيث بلغت قيمة معامل الارتباط البسيط (190 1, ·)، وعدد السكان الموجـودين في نطساق عمل الجمعية بحيث بلغت قيمة معامل الارتباط (199 (19., , )

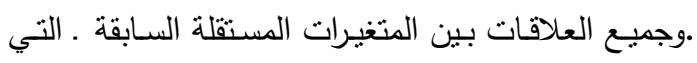

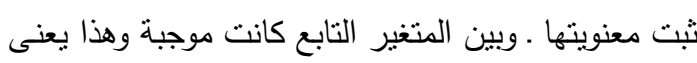

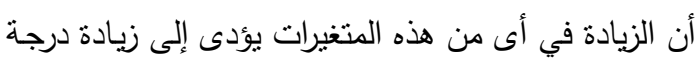

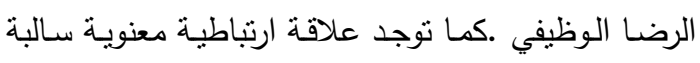

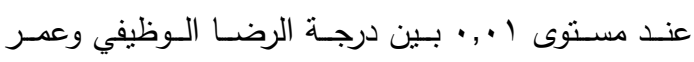

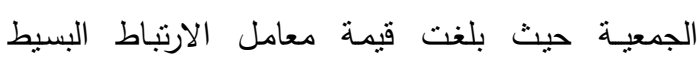
$\cdot(\cdot, r 00-)$
وهى على التزتيب: الإمكانيات الإدارية والسلوك التنظيهي

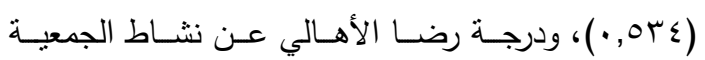

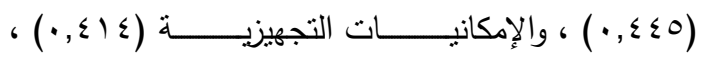

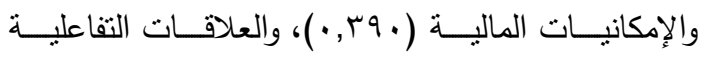

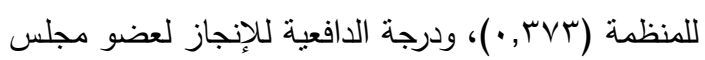

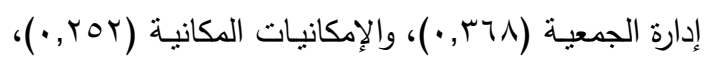

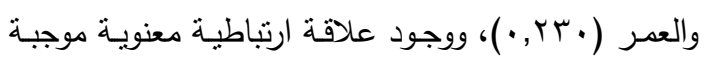

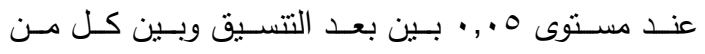
المتغيرات المستقلة التالية والتي تم ترتيبها تتازليا باستخدام

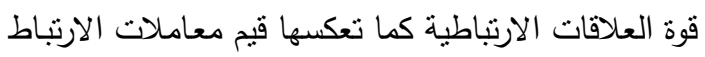

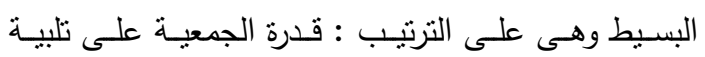

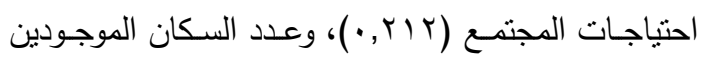

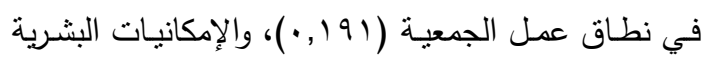

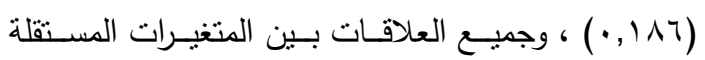

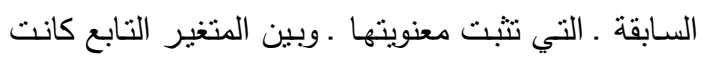

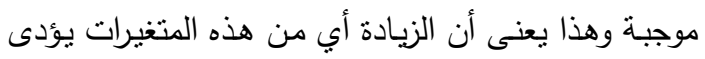

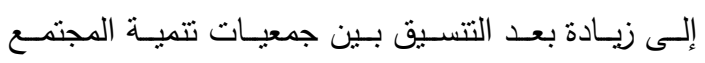
المحلى. تشير نتائج تحليل الارتباط الواردة بالجدول رقم ( )

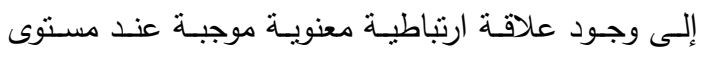

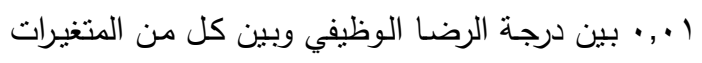

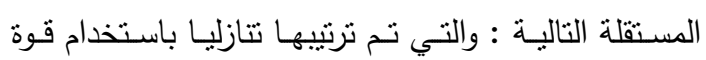

جدول ( ؛ ): نتائج التحليل الارتبـاطى والانحـاري المتعدد المتـدرج الصـاعد Step-wise لتحديـ الأهميـة النسـبية للمتغيرات المستقلة المؤثرة على درجة فعالية جمعية تنمية المجتمع من وجهة نظر المستفيدين

\begin{tabular}{|c|c|c|c|c|c|c|}
\hline \multicolumn{5}{|c|}{ درجة فعالية جمعية تتمية المجتمع } & \multirow[b]{2}{*}{ المتغيرات المؤثرة } & \multirow[b]{2}{*}{ خطوات } \\
\hline قيم (ف) لاختيار معنوية & في المتغير التابع & \begin{tabular}{|c|} 
Adjusted المعل معدل \\
R2
\end{tabular} & معامل لتحديد R2 & $\begin{array}{l}\text { قيم الارتباط } \\
\text { R Rتعدد }\end{array}$ & & \\
\hline ***। $\mid \leqslant r, 910$ & $r \varepsilon, r$ & $\cdot, r \varepsilon \cdot$ & $\cdot, r \leqslant r$ & $\cdot, 010$ & المعرفة بأنشطة التعمعية لمصادر & الخطوة \\
\hline$* * Y \varepsilon, \cdot Y T$ & 0,9 & $\cdot, r 94$ & $\cdot, \varepsilon \cdot 1$ & 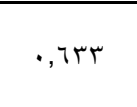 & درجة الرضا عن أنشطة & الخطوة \\
\hline$* * q, \vee \circ 9$ & $r, 1$ & $\cdot, \leqslant 10$ & $\cdot, \varepsilon Y)$ & $\cdot, 7 \leqslant 9$ & درجة الانفتاح الجغرافي & الخطوة \\
\hline$* *|r, \wedge Y|$ & $r, T$ & $\cdot, \leqslant$, & $\cdot, \varepsilon \leqslant V$ & $\cdot, 779$ & العضوية في المنظمات & الخطوة الرابعة \\
\hline$* 0, r T \leq$ & $1, \cdot$ & $\cdot, \varepsilon \leqslant \wedge$ & $\cdot, \leqslant 0 \wedge$ & $\cdot, T \vee 4$ & 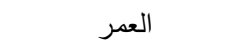 & 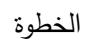 \\
\hline
\end{tabular}




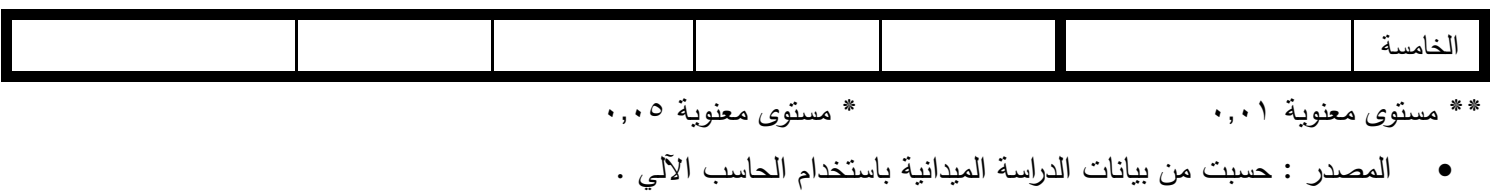

جدول رقم (0): قيم معاملات الارتباط البسيط بين المتغيرات المستقلة المدروسة وأبعاد الفعالية واللارجة الكلية لفعالية جميعات تنمية المجتمع المحلى من وجهة نظر أعضاء مجلس الإدارة .

\begin{tabular}{|c|c|c|c|c|c|}
\hline \multirow{2}{*}{ |الدرجة الكلية لفعالية| } & \multicolumn{4}{|c|}{ أبعاد الفعالية } & \multirow[b]{2}{*}{ المتغيرات } \\
\hline & التظظيم الداخلي & الرضا الوظيفي & |بعد التتسيق المنظمى| & بعد تلحقيق & \\
\hline **., ז & $* *, Y \circ \leq \varepsilon$ & $* \cdot, 190$ & $* *, r \mu$. & $\cdot, 1 \leq V$ & \\
\hline$\cdot, 1 \Gamma \cdot-$ & $\cdot, 100-$ & $\cdot, \cdot V V-$ & •, •Nr- & $\cdot|| Y \mid-$ & لمؤهل الدراسى \\
\hline$\cdot, 10 r$ & $\cdot, \cdot 90$ & $\cdot, \cdot \leq \Gamma$ & $\cdot, \cdot V V$ & $* \cdot, r \cdot r$ & عدد أفراد الأسرة \\
\hline • ITr & $\cdot, .0 r$ & $\cdot, \cdot$, to & $\cdot, 90$ & $\cdot, 174$ & لاخل الشهري \\
\hline$* \cdot, 1 \vee 9$ & $* \cdot, r \cdot q$ & $\cdot, 111$ & $\cdot, 1 \leq r$ & $\cdot, 1 \leq 1$ & 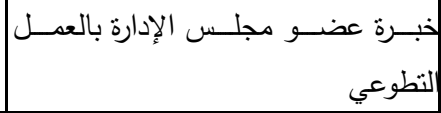 \\
\hline$\cdot, 1 Y 4-$ & $\cdot, \cdot 9 r-$ & $\cdot, 104-$ & $\cdot, .79-$ & $\cdot||_{1}-$ & عضوية المنظمات \\
\hline$\cdot, \cdot \leq \varepsilon-$ & $\cdot, \cdots$ & $\cdot, \cdot r$ & $\cdot, \cdot 9 r-$ & $\cdot, \cdot 19-$ & ل التدريب \\
\hline - & $*,, r \cdot \Sigma-$ & $* *,, \Gamma 00-$ & $\cdot, \cdot r V-$ &., $.09-$ & عمر الجمعية \\
\hline$* *, \pi 19$ & ס ס ש, • * & **, Tor & $* \cdot, 1 \wedge 7$ & $* *, r V I$ & لإمكانيات البشرية \\
\hline ו וr, & $* *,, \leq \leq 7$ & $* *$, r ז人 & $* *$, ror & $* \cdot, 190$ & لإمكانيات المكانية \\
\hline$* *,, \leq \leqslant \leq$ & $* *,, \varepsilon \cdot \Lambda$ & $* *, r \circ 9$ & $* *, \leq 1 \leq$ & $* *, r \cdot q$ & لإمكانيات التجهيزية \\
\hline$* *, \Sigma i r$ & $* *, r \leq 0$ & $* *$, rro & $* *, r q$. & $* *, r q \vee$ & لإمكانيات المالية \\
\hline$* * \cdot 7 \cdot 9$ & $* *, 0 \cdot V$ & $* * \cdot, 0 \leq r$ & $* *$, or $\leq$ & $* *,, \leq 00$ & الإمكانيات الإدارية والسلوك النتظيمي \\
\hline$* *, \leq \uparrow$ & $* *, \leq T Y$ & $* *,, \varepsilon \wedge \wedge$ & $* *, r \vee r$ & $* *, \Pi \mathrm{V}$ & لعلاقات التفاعلية للمنظمة \\
\hline • & $\cdot, .79$ & $* \cdot, 179$ & $* \cdot, 191$ & $\cdot, \cdot \leq r$ & لجدد السكان الموجودين في نطاق عمل \\
\hline$* *,, \varepsilon r r$ & $* *, 0 \leq 1$ & $* *, 79 V$ & $* *, r \uparrow \wedge$ & $\cdot, 1 \leq 9$ & لـالإدارة \\
\hline$* *, r \wedge r$ & $* *, r T V$ & $* *, r r V$ & $* \cdot, r \mid r$ & $* *, r q r$ & لـدرة الجمعيــة علـى تلبيــة احتياجـات \\
\hline$* * \cdot, 7 \cdot 9$ & $* *,, \Sigma \wedge \wedge$ & $* *, 0 \cdot r$ & $* * \cdot, \varepsilon \leqslant 0$ & $* *, 00$ & ترجة رضا الأهالي عن نشاط الجمعية \\
\hline
\end{tabular}

من المتغيرات المستقلة التالية : والتي نم ترتيبها تتازليا

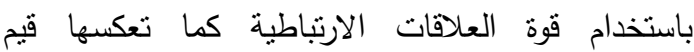
معاملات الارتباط البسيط . وهى على الترتيب : درجة
تثير نتائج تحليل الارتباط الواردة بالجدول رقم ( )

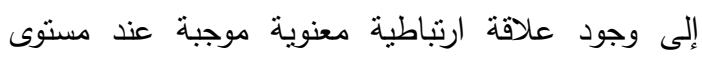
ا ب.,· بين بين درجة التنظيم الداخلي للجمعية وبين كله 
ا ,., بين درجة فعالية الجمعية وبين كل من المتغيرات المستقلة التالية ـ والتي تم ترتيبها تنازلياً باستخدام قوة العلاقات الارتباطية كما تعكسها قيم معاملات الارتباط

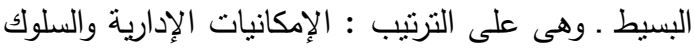

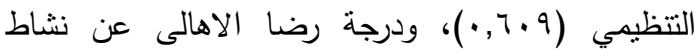

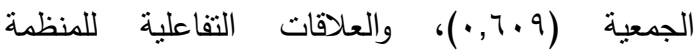

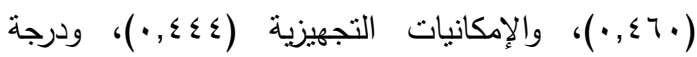

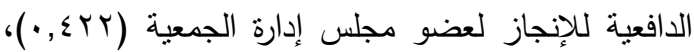
والإمكانيات المالية (r (ع,.•)، وقدرة الجمعية على تلبية احتياجات المجتمع (r/r,·)، والإمكانيات المكانية

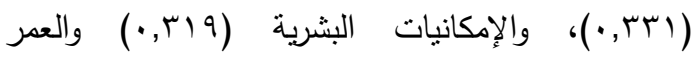

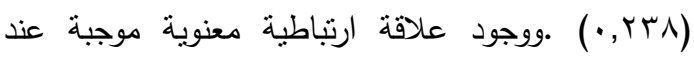
مسنوى 0., · بين درجة فعالية الجمعية وخبرة عضو مجلس الإدارة بالعمل النطوعي بالجمعية حيث بلغت قيمة معامل الارتباط البسيط (1V9, , ) وجميع العلاقات بين المتغيرات المستقلة السابقة ـ التي ثبت معنويتها ـ وبين

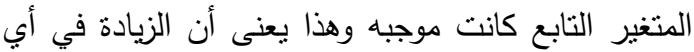
من هذه المتغيرات يؤدى إلى زيادة في درجة فعالية

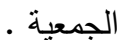

ب- العوامل المؤثرة في درجة فعالية جمعيات تتمية

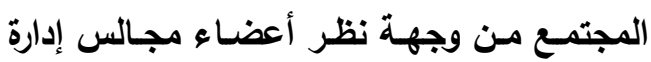
الجمعية

أنشارت النتائج الواردة بالجدول رقم ( 1 ) إلى معنوية هذا النموذج حتى الخطوة السابعة من التحليل ، وقد بلغت

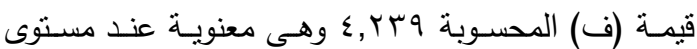
معنوية 0 . . . ، وهذا يعنى أن هناك سبع متغيرات مستقلة تؤُثر على درجة فعالية الجمعية ، وقد بلغت قيمة معامل

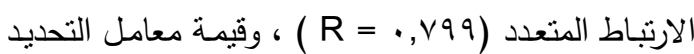

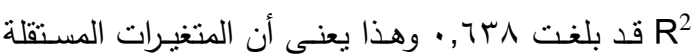
الثمانية المؤثرة تبلـغ نسبة مسـاهنتها مجتمعهد في تفسير التباين الحادث في درجة فعالية الجمعية 9, بآ\% يرجع

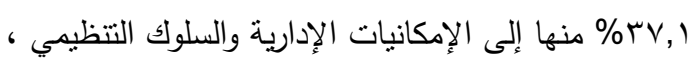
ع , ا 1 \% منها إلى درجة رضا الأهالي عن نشاط الجمعية

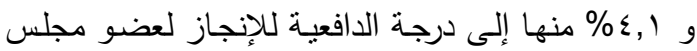

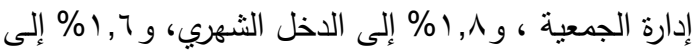

الدافعية للانجاز لعضو مجلس إدارة جمعية تتمية المجتمع

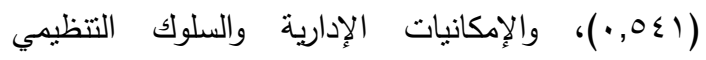

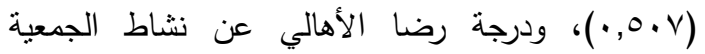

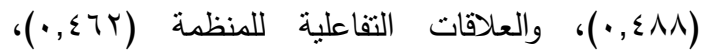
والإمكانبات المكانية (7؟ \&,·)، والإمكانيات التجهيزية

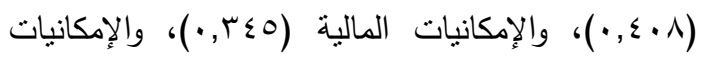
البشرية (هrr,·)، وقدرة الجمعية على تلبية احتياجات

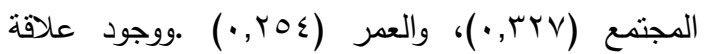
ارتباطية معنوية موجبة عند مستوى ه.,. بين درجة

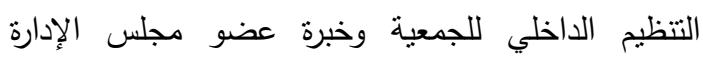
بالعمل النطوعي بالجمعية حيث بلغت قيمة معامل

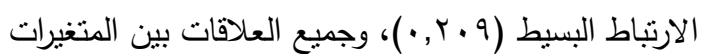

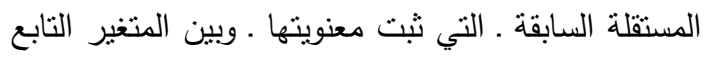

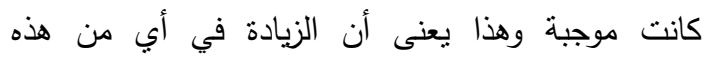

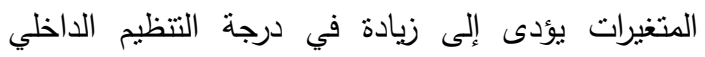
للجمعية .كما توجد علاقة ارتباطية معنوية سالبة عند

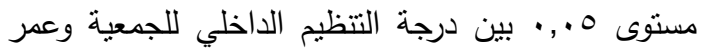
الجمعية حيث بلغت قيمة معامل الارتباط البسيط (-)

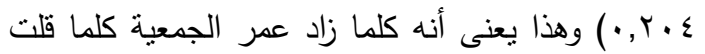

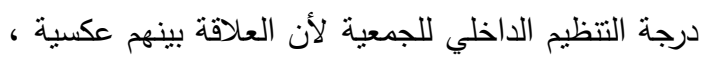
ويمكن تفسير ذلك في ضوء تقارب أعمار الجمعيات الددروسة حيث أوضحت نتائج نوزيع الجمعيات وفقاً

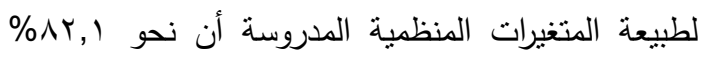
من اجمالى الجمعيات أعمارهم فى الفئة (VT سنة فأكثر) ، وهذه النتيجة تضعف من الاعتماد على هذا المتغير (عمر الجمعية) في قياس درجة التنظيم الداخلي للجمعية ،فكلما زاد عمر الجمعية لا بعكس زيادة درجة التتظيم الاخلي للجمعية حيث يمر عدد كبير من السنوات على لئل

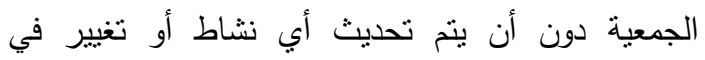
الإمكانيات الإدارية، والسلوك التتظيمي ، والإمكانيات المالية ، والإمكانيات التجهيزية ، والإمكانيات البشرية ، الإلكات الإنات والإمكانيات المكانية ـ وبالتالي لا يساهم عمر الجمعية في والئية زيادة درجة التظظيم الداخلي لها. تتشير نتائج تحليل الارتباط الواردة بالجدول رقم (0) إلى وجود علاقة ارتباطية معنوية موجبة عند مستوى 
في درجة فاعلية جمعيات تتمية المجتمع المحلى ورفضـه

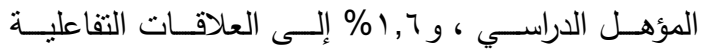

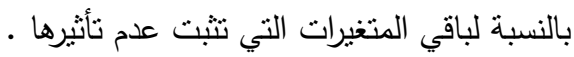

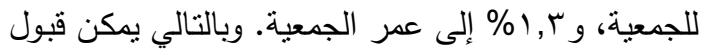

الفرض الذي ينص على أن هذه المتغيرات الثماني تؤثر

جدول ( 7 ): نتائج التحليل الارتباط والانحداري المتعدد المتدرج الصاعد Step-wise لتحديد الأهمية النسبية للمتغيرات المستقلة المؤثرة على درجة فعالية الجمعية من وجهة نظر أعضاء مجلس الإدارة.

\begin{tabular}{|c|c|c|c|c|c|c|}
\hline \multicolumn{5}{|c|}{ درجة فعالية الجمعية } & \multirow[b]{2}{*}{ المتغيرات المؤثرة } & \multirow[b]{2}{*}{ خطوات } \\
\hline ققيم (ف) لاختيار معنوياً & 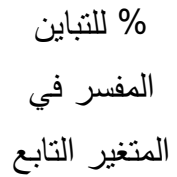 & $\begin{array}{c}\text { معامل التحديد } \\
\text { Adjusted R2 }\end{array}$ & معامل لتحديد & 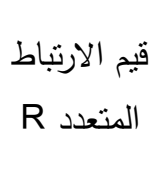 & & \\
\hline$* * \wedge 1,0 \leq 1$ & $r v, 1$ & (עדז, & $\cdot, r v i$ & $\cdot, 7 \cdot 9$ & الإلكانيات الإدارية & الخطوة \\
\hline$* * \varepsilon \wedge, \varepsilon 99$ & $17, \varepsilon$ & $\cdot, 0 Y 9$ & 4ד & $\cdot, V M Y$ & درجة رضا الاهالى عن & الخطانية \\
\hline$* * \wedge, \cdots \wedge$ & $\varepsilon, 1$ & $\cdot, 00 Y$ & $\cdot, 07 Y$ & $\cdot, \vee \leqslant 9$ & لدرجة الدافعية للانجاز & الخطوة \\
\hline$* \varepsilon, 9 \vee 1$ & 1,7 &., 070 & $\cdot, O V V$ & $\cdot, \vee \vee \neg$. & المؤهل الدراسى & الخطوة \\
\hline$* * 0, \wedge) \vee$ & $1, \Lambda$ & $\cdot, 0 \wedge$ &., 090 & $\cdot, \vee \vee V 1$ & الدخل الثهري & الخطوة \\
\hline$* \varepsilon, Y \Gamma q$ & $1, r$ & $\cdot, 09$ & $\cdot, 7 \cdot V$ & $\cdot, \vee \vee q$ & عمر الجمعية & السادسة \\
\hline$* * 0,091$ & 1,7 & $\cdot, T \cdot r$ & ת זTד, & $\cdot, \vee \wedge q$ & بعد العلاقات التفاعلية & السابعة \\
\hline
\end{tabular}

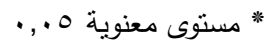

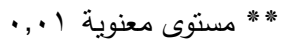
• المصدر : حسبت من بيانات الدراسة الميدانية باستخدام الحاسب الآلي .

تتميـة المجتمع منوسطة وبلغ عددهم ؟ ؟ ا مبحوثاً ، وأن

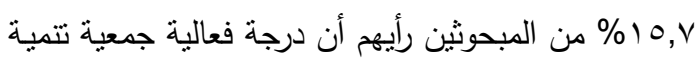

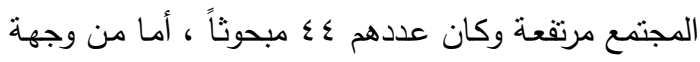

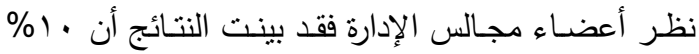

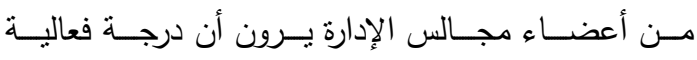

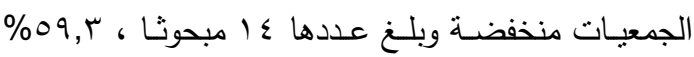
يرون ان درجة فعاليتها متوسطة وبلغ عددهم r م مبحوثا ،
ثالثا : فعالية جمعية تنمية المجتمع من وجهة نظر كل من المستفيدين وأعضاء مجالس الإدارة

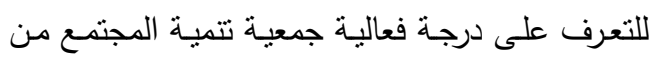
وجهة نظر المستفيدين فقد أثنارت النتائج الواردة في جدوله لتهبه

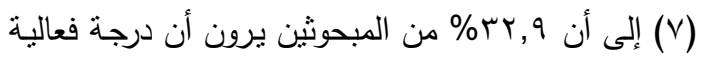

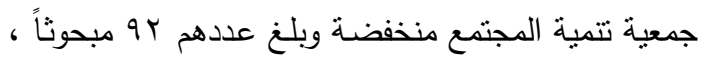
وأن ₹ , إ\% من المبحوثين يرون أن درجة فعالية جمعية 
الإدارة كان رأيهم أن درجـة فعاليـة جمعية تتميـة المجتمع

منوسطة.

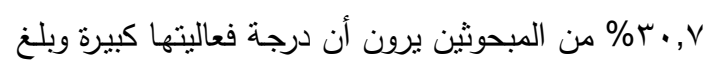

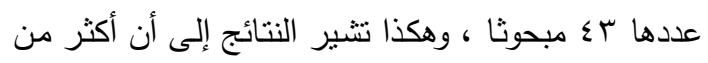

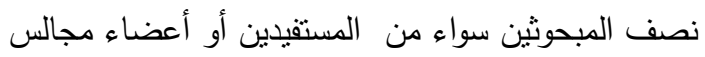

جدول (V) : درجة فعالية جمعية تتمية المجتمع من وجهة نظر كل من المستفيدين وأعضاء مجالس الإدارة .

\begin{tabular}{|c|c|c|c|c|c|}
\hline \multicolumn{6}{|c|}{ لدرجة فعالية جمعية تنمية المجتمع } \\
\hline \multicolumn{3}{|c|}{ من وجهة نظر أعضاء مجالس الإدارة } & \multicolumn{3}{|c|}{ من وجهة نظر المستفيدين } \\
\hline$\%$ & العدد & الفئات & $\%$ & العدد & 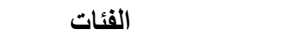 \\
\hline$\% 1$. & $1 \varepsilon$ & منخفضة (0 9 - 0, \& צ 1 درجة) & $\% r r, q$ & Qr & منخفضة (r - - r درجة) \\
\hline$\% \circ ৭, r$ & Ar & 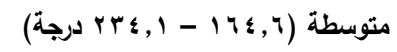 & $\% 01, \varepsilon$ & $1 \leqslant \leqslant$ & متوسطة ( ب - q ^ درجة) \\
\hline$\% r \cdot, v$ & $\varepsilon r$ & كبيرة (r, § זr - \& •r درجة) & $\% 10, v$ & $\leqslant \varepsilon$ & مرتفعة (·ץ - qץ درجة) \\
\hline$\% 1 \ldots$ & $1 \leqslant$. & المجموع & $\% 1 \ldots$ & YA. & 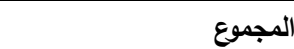 \\
\hline
\end{tabular}

* المصدر : جمعت وحسبت من بيانات الاراسة الميدانية .

المختلفـة ووضـع وبلـورة الأسس التي يمكن من خلالهـا تعقيب

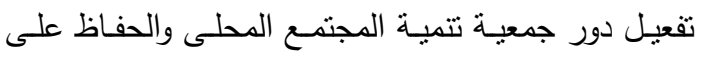

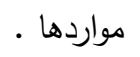

نظرا لما أظهرته النتائج توصى الاراسة بما يلي :

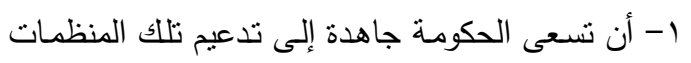

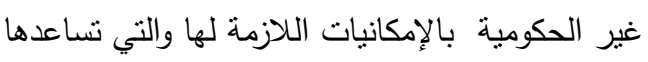
على زيادة كثافة أنشطتها وتتوعها مما يخدم الريفيين حتى ينضموا للعضوية في تلك المنظمات .

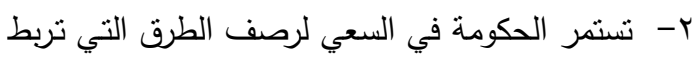

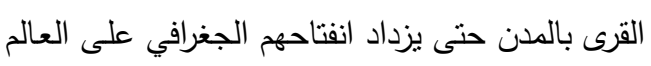
الخارجي،حيث تثبر النتائج إلى تأثنير درجة الانفتاح

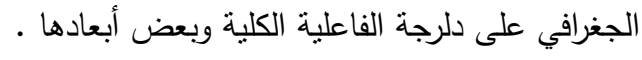

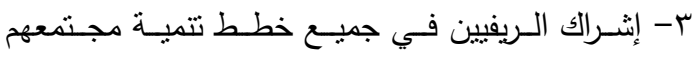
المحلى حتى يشعروا بأنها نابعة منهم وبالنالي تتمية جمعياتهم مما يؤدى إلى زيادة فعاليتها والقيام بأدوارها

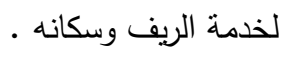
ـ - بـــث بـرامج إذاعيـة وتليفزيونيـة تهـدف إلـى توعيـة الريفيين وكذلك الدعوة إلى فتح فصول لمحو الأمية

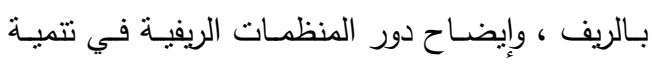

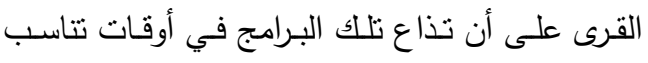

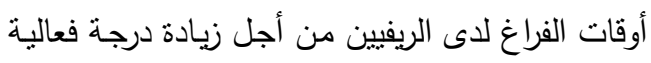
يعد البحث الحالي واحداً من البحوث التي تناولت

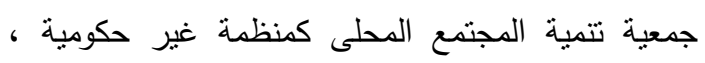

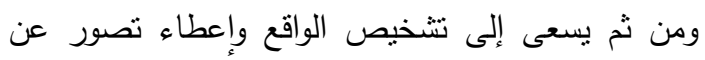

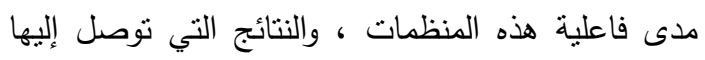

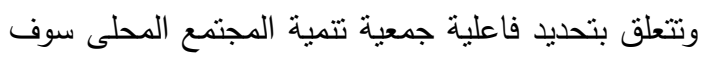
تمكن العاملين والمسئولين من الوقوف على مدى قدئ قدرتها

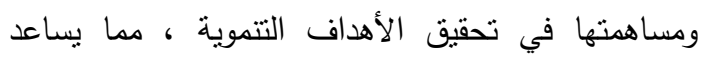
بطريقة فعالة في التخطيط والتنفيذ لوضع الأسس السليمة

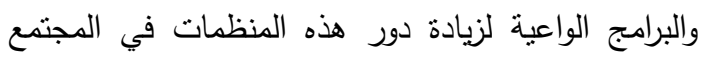

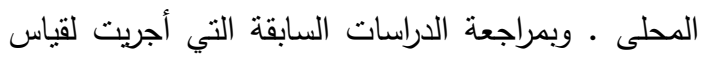

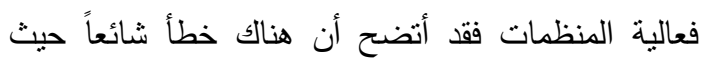

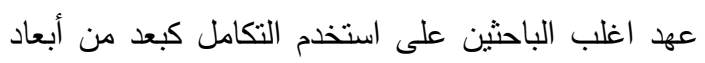
الفعالية مرادفاً للنتسيق بالرغم من الاختلاف الكبير بينهما

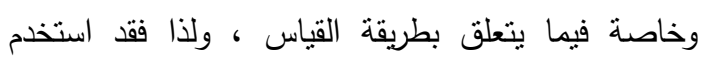

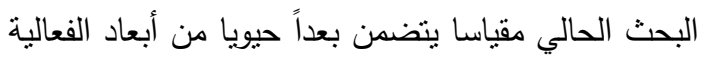
وهو التتسيق المنظمى . كما كثفت النتائج عن أكثر المتغيرات ذات العلاقة بفاعلية المنظمات وبالتالي يمكن دعم المتغيرات الايجابية،

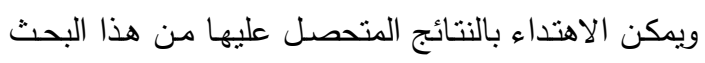

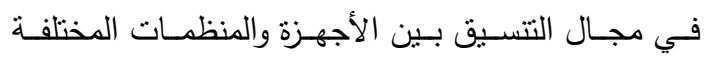
المسئولة عن تتمية المجتمع الريفى للمحافظة على الموارد 
الجنايني، كاميليا يوسف حسن, تقويم الفعالية التنظيمية

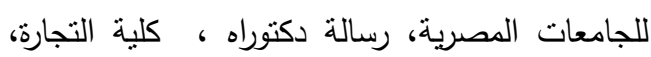

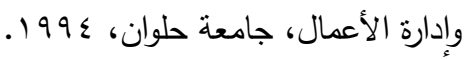
الحسيني، السيد محمد، النظرية الاجتماعية ودراسة التنظيم - سلسلة علم الاجتماع المعاصر - الكتاب الثامن عشر - دار المعارف بمصر، 19v0.

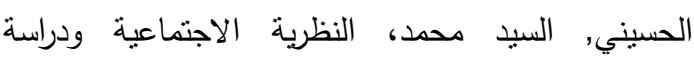
التتظيم، سلسلة علم الاجتماع المعاصر , الكتاب الثامن

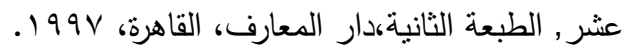
الحنفي، محمد غانم، بعض عوامل المنظمة القروية المؤثرة على فعالية الوحدات المحلية القروية، رسالة دكتوراه، كلية الزراعة، جامعة الإسكندرية، 191V.

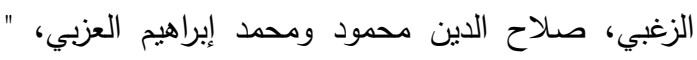

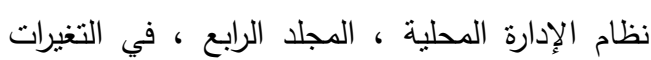

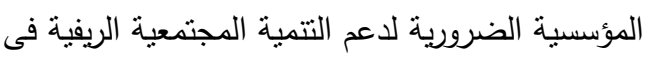

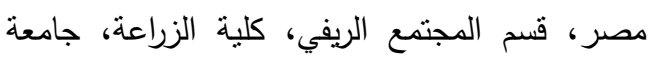

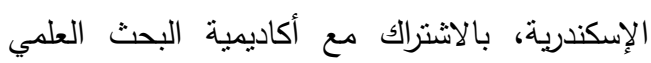
والتكنولوجيا، الإسكندرية، 1990 ـ

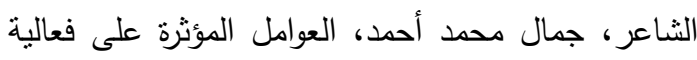
جمعيات نتمية المجتمع المحلي بريف محافظة كفر العرال

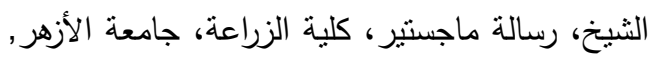

$$
.+. .1
$$

الشرقاوي، أحمد عز الدين, دور المنظمات الاجتماعية في

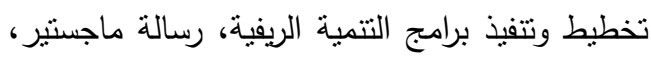

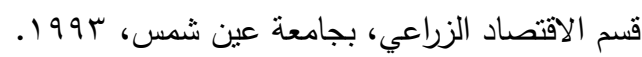
الضرغامى، أمين فؤاد ، قياس فعالية المنظمات ، مجلة الإدارة ، اتحاد جمعيات التتمية الإدارية ، العدد الأول فئل فئل

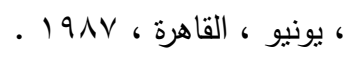

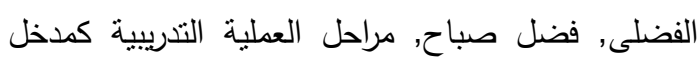
لتقييم فعالية برامج التدريب والتتمية الإدارية، مجلة

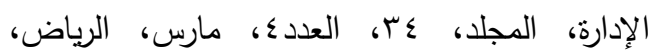
المملكة العربية السعودية، 1990.

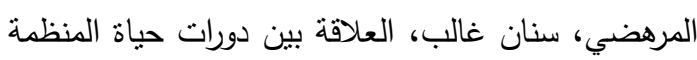
ومؤشرات قياس الفعالية، دراسة مقارنة على عينة من المنظمات الصناعية في اليمن، والأردن، والعراق،
المنظمـات بصفة عامـة ، وجمعيـات تتميـة المجتهـع المحلى بصفة خاصة. 0- أن يقوم العاملين بتلك الجمعيات بتحسين العلاقـات بينهم وبين المستفيدين وجعلها علاقات طييـة ووديـة والتحرر من القيود الروتينية في التعامل مع المستفيدين

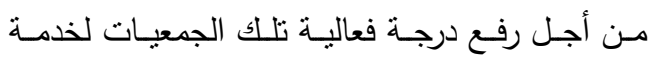

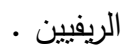

ج- إجـراء دراســات أخـرى لقيـاس درجــة التتسـيق بـين جمعيات تتمية المجتمع المحلى والجمعيات الإشرافية

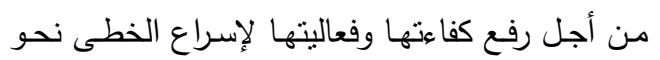
تتمية الريف وتحسين مستويات معيشة أهله .

\section{أولا : المراجع العربية}

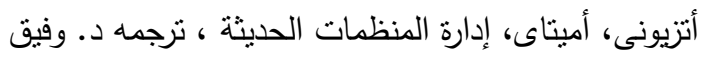

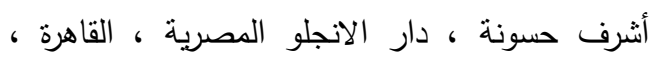
$.191 \mathrm{~V}$ الإمام, محمد السيد وابتهال محمد كمال أبو حسين, نموذج تصوري لقياس فعالية التظظيم الاجتماعي "دراسة اجتماعية بنائية", ندوة المنطلبات المجتمعية للإصلاح

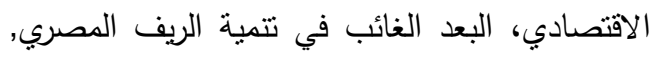

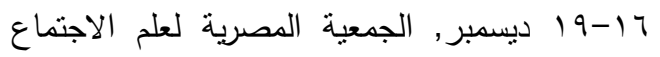

الريفي ومؤسسة فريدريش ناومان، القاهرة، 1990 .

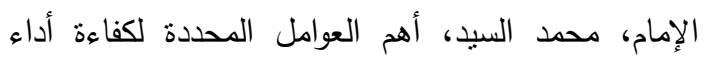

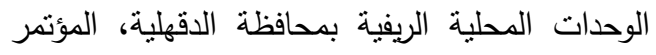
الثاني للاقتصاد والتتمية في مصر والبلاد العربية،

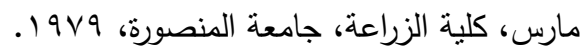

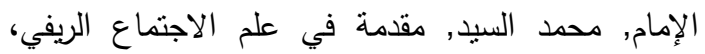
المكتبة المصرية للنشر والتوزيع، المنصورة، 9. . ب.

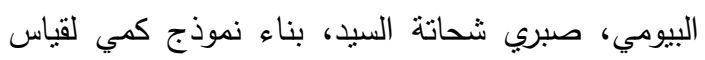
الفعالية التتظيمية في الشركات المشتركة في جمهورية مصر العربية، رسالة دكتوراة, كلية التجارة، جامعة

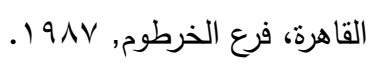

الجمل، محمود محمد عبد الله مصطفى، بعض العوامل المؤثرة على كفاءة العمل الإرشادي الزراعي، رسالة

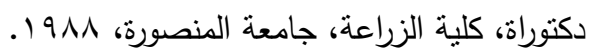


حلوة،علي محمد، دراسات في السلوك الإنساني والتنظيم ، مكتبة عين شمس، القاهرة, 1910 .

خاطر ، أحمد مصطفى، الإدارة وتقويم مشروعات الرعاية الرماية الاجتماعية، المكتب الجامعي الحديث، الإسكندرية،

.199.

خطاب، عايدة سيد علي، نأثبر ثقافة المنظمة على الفعالية

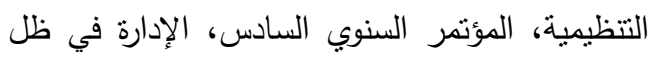

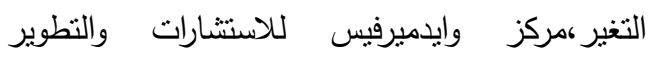

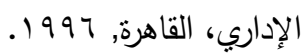

خليفة، محروس محمود، دليل تحليلي لإدارة المؤسسات

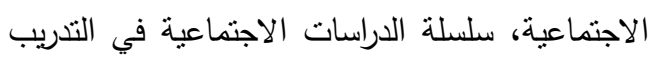

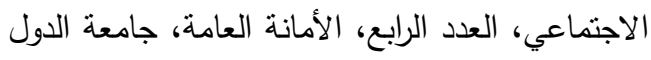

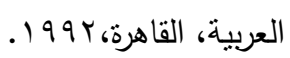

خليل، نبيل محمد مرسي: معايير الفعالية التظيمية: دراسة لتأثير بعض المتئيرات المنوقفة على الفعالية، رسالة

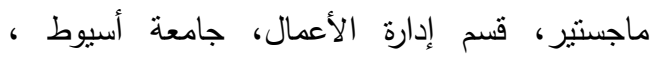
.1914

سليمان، حنفي محمود، السلوك الإداري وتطوير المنظمات، دار الجامعات المصرية،الإسكندرية، (غير الإدري

$$
\text { مبين سنة النشر) . }
$$

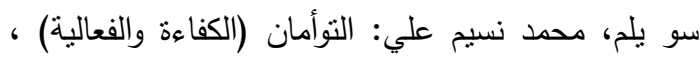

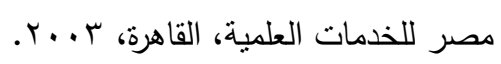

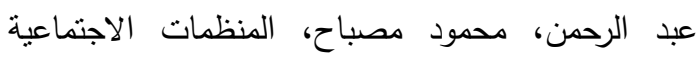
الريفية، محاضرات غير منشورة لطلاب الدراسات

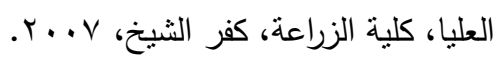

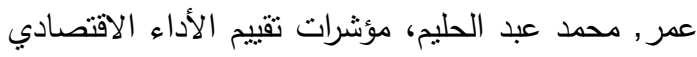

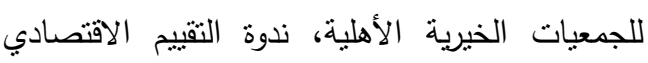

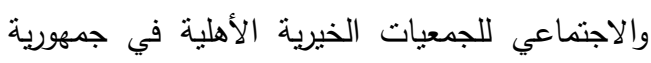

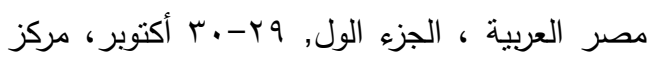

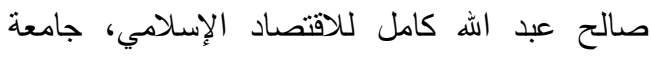

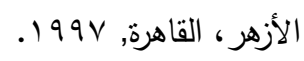

غيث, محمد عاطف, علم الاجتماع, الجزء الثاني, دار

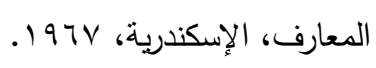

قنصوة، عوني محمد نوفيق، دراسة للتعرف على فاعلية النتظيمات في المؤسسات التعليمية في تحقيق أهداف دربة
المجلة المصرية للاراسات التجارية، المجلد ؟ب، العدد

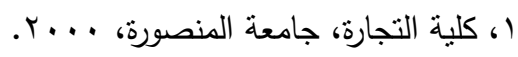
المعاذ، السيد حمدي مصطفى، أثز المستوى الوظيفي على جلى لئه

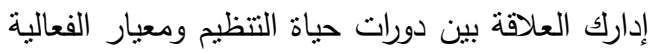

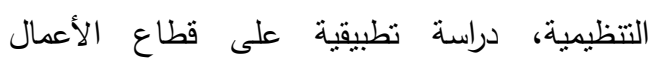
المصري، المجلة المصرية للاراسات التجارية، المجلد

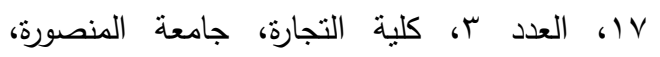
.1994 بدوي، أحمد زكي، معجم دصطلحات العلوم الاجتماعية، مكتبة لبنان، بيروت، (غير مبين سنة النشر).

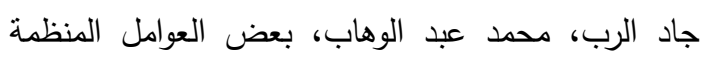
والمجتمعية الريفية المحلية المؤثرة على فعلى لعالية النعاونيات الزراعية المحلية متعددة الأغراض في العية بعض قرى محافظتي الغربية وكفر الثيخ، رسالة

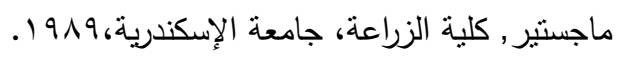

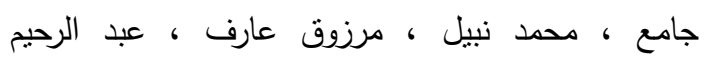

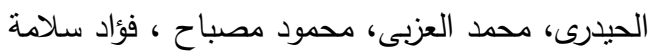

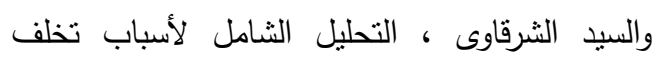

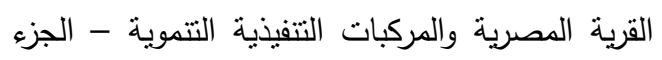

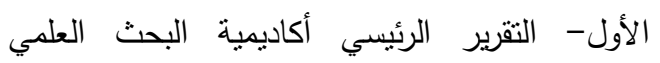

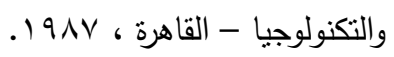

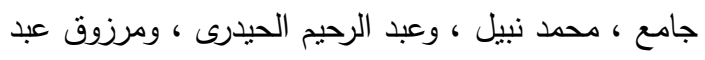
الرحيم عارف: الوحدة المحلية القروية - البناء والأداء فى تتمية القرية المصرية - فى التحليل لثامل الأسباب تخلف القرية المصرية، الجزء الثاني: تحديث

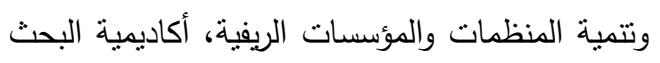
العلمي والتكنولوجيا، مجلس بحوث الغذاء والزراعة

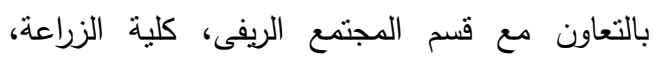
جامعة الإسكندرية، 19NV.

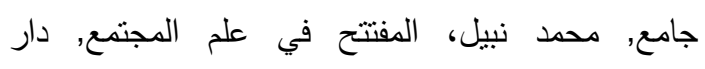

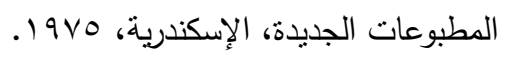

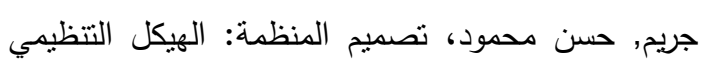

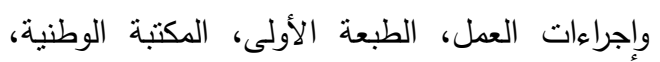

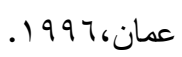


Daft, R., Organization Theory and Design Lathed. New York: West Publishing, 1992.

David Sole,: The Use of Material In Teaching of Arithmetic, Dissertation Abstracts International A., Vol, 36, 110, 7, 1975.

Deen.J, Champion. "Sociology of Organizations, MC Graw-Hiu, Book Company, New York, 1975.

Dessler, Gary, Organization Theory Integrating Structure and Behavior, Second Edition, Prentice - Hall International Inc. Florida International University, USA, 1986.

Donnelly, H. James, James, L. Gibson, John, and $M$, Invancevech, Organizations: Behavior Structure, Processes, Sixth Edition, Business Publications Inc. Plano, Texas, USA, 1988.

James L. Price: "Organizational Effectiveness: An Inventory of Proposition", Richard D. Irwin, Inc., 1969.

John, C.R. The Effects of Media Production, and Media Experiences on The Learning Achievement and Attitude of Elementary School Students, Dissertation Abstracts International, Michigan Univ. Microfilm International, Vol, 40, No, 10, 1980.

Mulford, L. Charles, \& Others, Organizational Effectiveness and Impact: A Planning Guide, A Guide For University Extension, Sociology Report, No, 136 August, Department of Sociology and Anthropology, lowa State University, Ames, lowa, USA, 1997.

Oldcorn, R.,\& Parker, S, The Strategic Investment Decision: Evaluating Opportunities In Dynamic Markets, London: Pitman, 1996.

Prawl, Worren, Medline, Roger, And Gross, John, Adult And Continuing Education Through the Cooperative Extension Service. The Extension Division, University of Missouri - Columbia, Missouri, USA, 1984.

Stress, M. Richard, Problems In The Measurement of Organizational Effectiveness, Administrative Science Quarterly, Vol, 20 California, USA, 1975.

Thompson, J. Strategic Management: Awareness and Change, 3rd Edition. London: International Thomson Business Press, 1997.

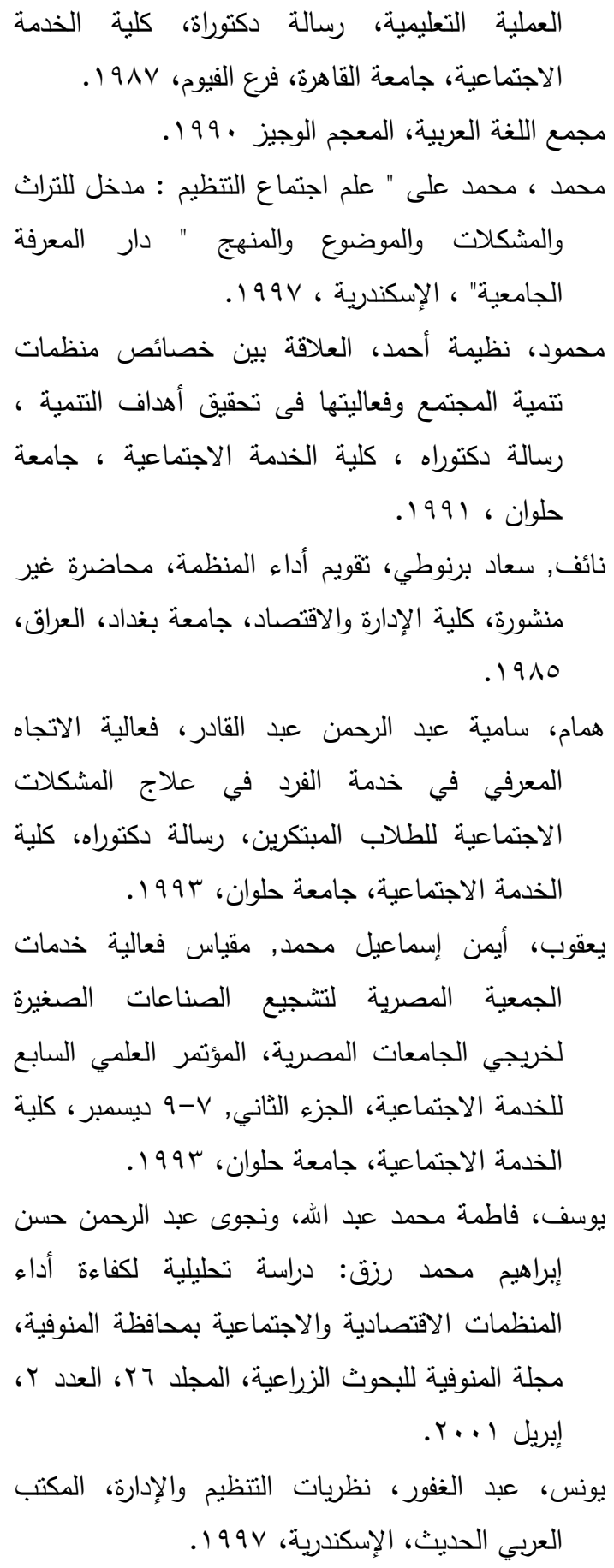

Baulhersy And Kenneth $H$. Blanchard Management of Organizational Behavior New Jersey: 2nd Edition Prentice - Hall, Inc. 1972.

Bedeian, G. Arthur, Organizations: Theory and Analysis, Second Edition, Holt Sanders, Japan, 1984. 


\title{
EFFECTIVENESS CORRELATES OF RURAL COMMUNITY DEVELOPMENT ASSOCIATION IN MENOUFIYA GOVERNORATE.
}

\author{
Kh. A. Keneber(1) and Reda M.Shahen ${ }^{(2)}$ \\ (1) Dept. of Agric. Ext. and Rural Sociology , College of Agric., Menoufia University \\ (2) Institute of Agric. Ext. and Rural Development- Agricultural Research Center.
}

\begin{abstract}
This study aimed mainly at: Recognizing the correlative relationship between the studied independent variables and the dimensions of effectiveness of rural community development association from point of view of the beneficiaries that benefit from activities of (R.C.D.A), determine the variables that affected effectiveness of rural community development association from the point of view of the beneficiaries, recognizing the correlative relationship between the studied independent variables and the effectiveness dimensions of rural community development association from point of view of the board of directors ' members of (R.C.D.A). Determine the variables that affect at the effectiveness of rural community development association, determine the degree of the effectiveness of (R.C.D.A) from the point of view of the beneficiaries and from the point of view of the board of directors ' members of (R.C.D.A).

To achieve these objects, four districts were chosen (Shebin El-Kom,Berket El-Saba') to represent the more developed distracts and (Menouf and Ashmoun) to represent the less developed districts in Human Development Index. Data were collected from 280 beneficiaries and 140 members of the board of directors. Data were collected through personal interviewers by questionnaires after pre-tested and modified in their final shapes. Data were analyzed by using some statistical techniques such as : rations, mean, standard deviation, and range, Pearson product moment ( $r$ ), and step-wise multiple regression.

The step-wise multiple regression analysis revealed that:

There were fife variables affected effectiveness of rural community development association from point of view of the beneficiaries, those were: exposure to information sources, people satisfaction with the organization activities, geographical cosmopolites, membership in rural organizations and age, these varieties explained about $45.8 \%$ of the variance of effectiveness of rural community development associations. There were nine variables affected effectiveness of rural community development association from the point of view of the board of directors, those were: management capabilities, organizational behavior, people satisfaction with the organization activities, , motivation to achieve of the board of directors ' members , educational level, monthly income, age of associations and interaction relationship. These variables explained about $62.3 . \%$ of the variance in effectiveness of rural community development associations and from point of view of the board of directors ' members of (R.C.D.A).

Opinions the great majority of the beneficiaries and the board of directors, about the effectiveness of the (R.C.D.A) were medium.
\end{abstract}

Key Words: Effectiveness- NGOs- Rural Community Development Association 